ENGINEERING CHANGE NOTICE

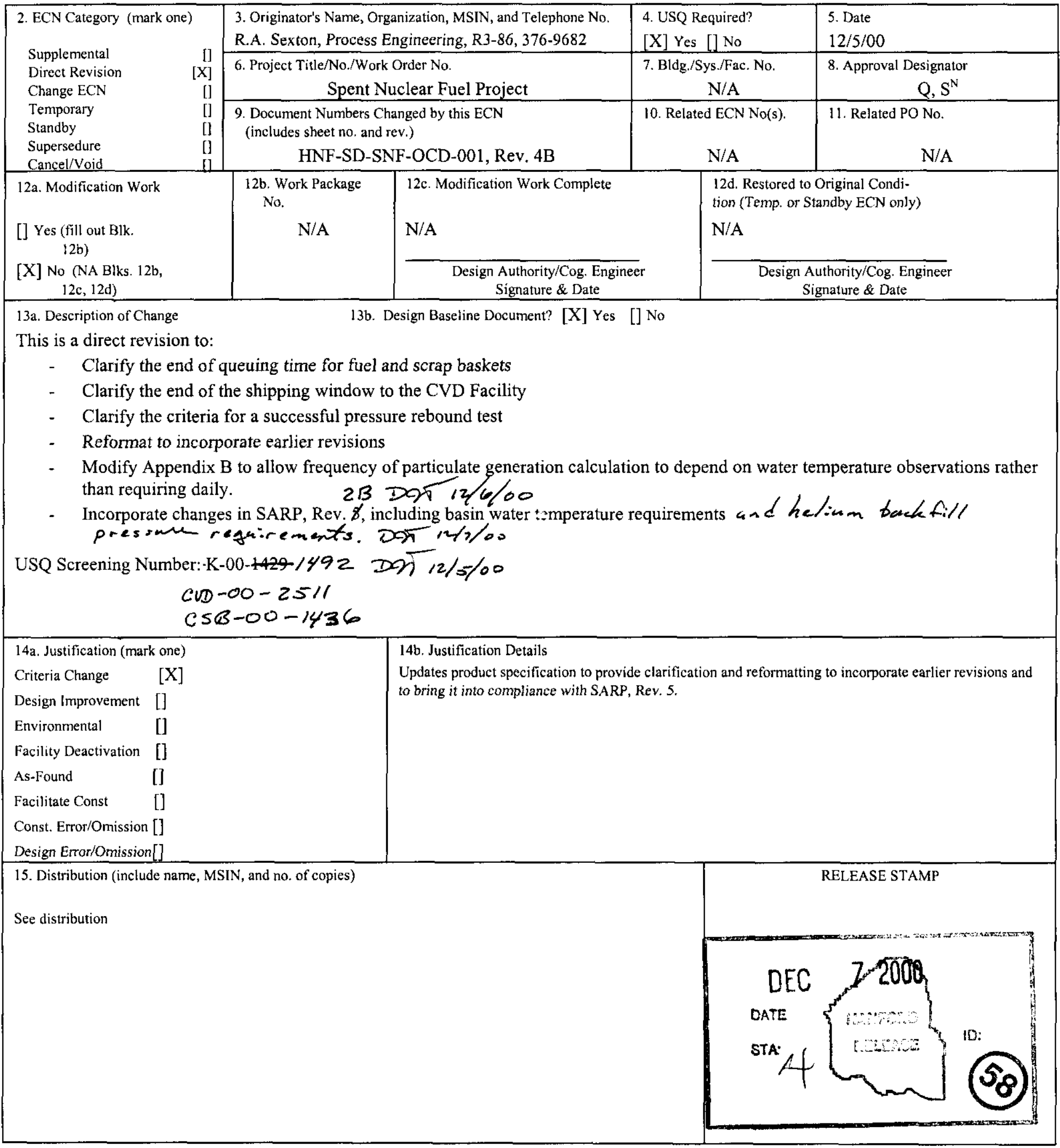




\begin{tabular}{|c|c|c|c|c|c|c|c|}
\hline \multicolumn{5}{|c|}{ ENGINEERING CHANGE NOTICE } & Page 2 of 2 & \multirow{2}{*}{\multicolumn{2}{|c|}{$\begin{array}{l}\text { 1. ECN (use no. from pg. 1) } \\
662257 \\
\text { 18. Schedule Impact (days) }\end{array}$}} \\
\hline $\begin{array}{l}\text { 16. Design } \\
\text { Verification }\end{array}$ & \multicolumn{3}{|c|}{ ENGINEERING } & \multicolumn{2}{|c|}{ CONSTRUCTION } & & \\
\hline $\begin{array}{l}\text { Required } \\
\text { [] Yes }\end{array}$ & Additional & & & Additional & A] $\$$ & $\begin{array}{l}\text { Improve } \\
\text { ment }\end{array}$ & {$[\mathrm{N} / \mathrm{A}]$} \\
\hline$[\mathrm{X}]$ No & Savings & {$[\mathrm{N} / \mathrm{A}]$} & $\$$ & Savings & A] $\$$ & Delay & {$[\mathrm{N} / \mathrm{A}]$} \\
\hline
\end{tabular}

19. Change Impact Review: Indicate the related documents (other than the engineering documents identified on Side 1) that will be affected by the change described in Block 13. Enter the affected document number in Block 20.

SDD/DD

Functional Design Criteria

Operating Specification

Criticality Specification

Conceptual Design Report

Equipment Spec.

Const. Spec.

Procurement Spec.

Vendor Information

OM Manual

FSAR/SAR

Safety Equipment List

Radiation Work Permit

Environmental Impact Statement

Environmental Report

Environmental Permit

Seismic/Stress Analysis
Stress/Design Report
Interface Control Drawing
Calibration Procedure
Installation Procedure
Maintenance Procedure
Engineering Procedure
Operating instruction
Operating Procedure
Operational Safety Requirement
IEFD Drawing
Cell Arrangement Drawing
Essential Material Specification
Fac. Proc. Samp. Schedule
Inspection Plan
Inventory Adjustment Request

[]

[]

[1] Process Control Manual/Plan

[1] Process Flow Chart

[] Purchase Requisition

[] Tickler File

[] N/A

[]

\begin{tabular}{ll} 
Tank Calibration Manual & {[]} \\
Health Physics Procedure & {[]} \\
Spares Multiple Unit Listing & {[]} \\
Test Procedures/Specification & {[]} \\
Component Index & {[]} \\
ASME Coded ltem & {[]} \\
Human Factor Consideration & {[]} \\
Computer Software & {[]} \\
Electric Circuit Schedule & {[]} \\
ICRS Procedure & {[]} \\
Process Control Manual/Plan & {[]} \\
Process Flow Chart & {[]} \\
Purchase Requisition & {[]} \\
Tickler File & {[]} \\
N/A & {$[\mathrm{X}]$} \\
& {[]} \\
\hline
\end{tabular}

20. Other Affected Documents: (NOTE: Documents listed below will not be revised by this ECN.) Signatures below indicate that the signing organization has been notified of other affected documents listed below.

Document Number/Revision

Document Number/Revision

Document Number Revision

N/A

21, Approvals

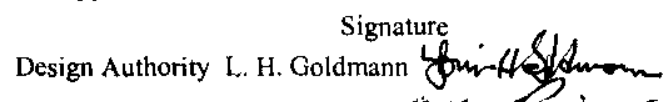

Cog. Eng. A. L. Pajunen

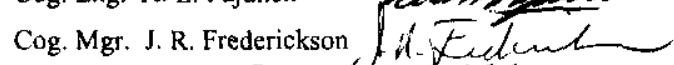

QA D.W. Smith Dw zuith

Safety C.T. Miller Candell

Environ

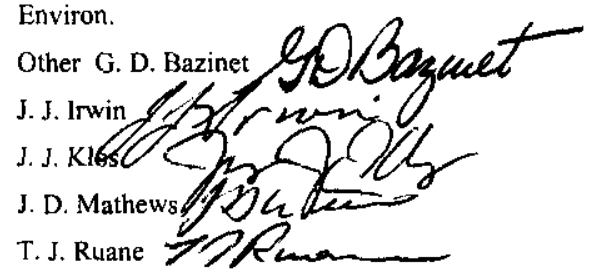

O. M. Serrano Cícura

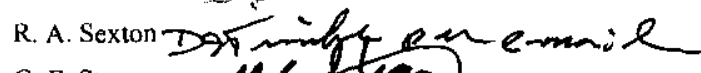

G. E. Stegen $y / 16$

DE Moody Dormal per telecon

\begin{tabular}{ll} 
Date & Signature \\
$\frac{12 / 5 / 2000}{12 / 5 / 2000}$ & Design Agent \\
$\frac{12 / 5 / 00}{12 / 5 / 00}$ & QA \\
$\frac{12 / 5 / 00}{12 / 6 / 00}$ & Safety \\
$\frac{12 / 7 / 2000}{12-6-00}$ & Design \\
$\frac{12 / 4 / 00}{10 / 4}$ & DEPARTh \\
\hline
\end{tabular}

Signature or a Control Number that tracks the Approval Signature

ADDULONAL

Date

cor205

$12 / 2100$

$12 / 5100$

$12 / 7 / 00$ 
DISTRIBUTION SHEET

\begin{tabular}{l|l|l|l|l}
\hline $\begin{array}{l}\text { To } \\
\text { Distribution }\end{array}$ & \multicolumn{2}{l|}{$\begin{array}{l}\text { From } \\
\text { Process Engineering }\end{array}$} & Page 1 of 1 \\
\cline { 4 - 5 } $\begin{array}{l}\text { Project Title/Work Order } \\
\text { Spent Nuclear Fuel Project Product Specification }\end{array}$ & MSIN & $\begin{array}{c}\text { Text } \\
\text { With All } \\
\text { Name }\end{array}$ & Text Only & EDT No. N/A \\
\cline { 5 - 6 } & & $\begin{array}{c}\text { Attach./ } \\
\text { Appendix } \\
\text { Only }\end{array}$ & $\begin{array}{c}\text { EDT/ECN } \\
\text { Only }\end{array}$ \\
\hline
\end{tabular}

Spent Nuclear Euel Project

W. C. Alaconis

G. D. Bazinet

X3-79 X

D. R. Duncan

S8.06

R3-86

J. R. Frederickson

R3-86

L. J. Garvin

K. D. Gibson

S8-07

L. H. Goldmann

J. R. Gregory

D. R. Henry

R. M. Hiegel

J. J. Irwin

X3-79

R3-86

$\mathrm{X} 3-78$

$\mathrm{X} 3-61$

R3-81

X3-78

M. J. Klem

R3-86

C. B. Loftis

L6-58

P. G. Loscoe

R. L. McCormack

R3-81

J. D. Mathews

M. A. Medsker

C. R. Miska

D. A. Moody

L. J. Olguin

A. L. Pajunen

S. H. Peck

D. R. Precechtel

R3-1:

$\mathrm{X} 3-65$

X3-79

$\mathrm{X} 3-78$

S8-06

$\mathrm{X} 4-01$

R3-86

R3-86

$\mathrm{X} 3-85$

T. J. Ruane

$\mathrm{X} 3-61$

K. M. Schierman

A6-39

O. M. Serrano

S2-44

R. A. Sexton

D. L. Sherrell

D. W. Smith

G. E. Stegen

J. A. Swenson

J. E. Turnbaugh

P. A. Young

R3-86

R3-86

S2-48

X4-01

$\mathrm{X} 3-78$

$\times 3-79$

$\mathrm{X} 3-88$

SNF Project Files

SNF Project Training

R3-11

S2-45

$X$
$X$
$X$
$X$
$X$
$X$
$X$
$X$
$X$
$X$
$X$
$X$
$X$
$X$
$X$
$X$
$X$
$X$
$X$
$X$
$X$
$X$
$X$
$X$
$X$
$X$
$X$
$X$
$X$
$X$
$X$
$X$
$X$
$X$
$X$


HNF-SD-SNF-OCD-001

Revision 5

\section{Spent Nuclear Fuel Project Product Specification}

Prepared for the U.S. Department of Energy Assistant Secretary for Environmental Management

Project Hanford Management Contractor for the

U.S. Department of Energy under Contract DE-AC06-96RL13200

Fluor Hanford

P.O. Box 1000

Richland, Washington 


\section{Spent Nuclear Fuel Project Product Specification}

Division: SNF

A. L. Pajunen
Fluor Hanford

Date Published

December 2000

Prepared for the U.S. Department of Energy

Assistant Secretary for Environmental Management

Project Hanford Management Contractor for the

U.S. Department of Energy under Contract DE-AC06-96RL13200

Fluor Hanford

P.O. Box 1000

Richland, Washington
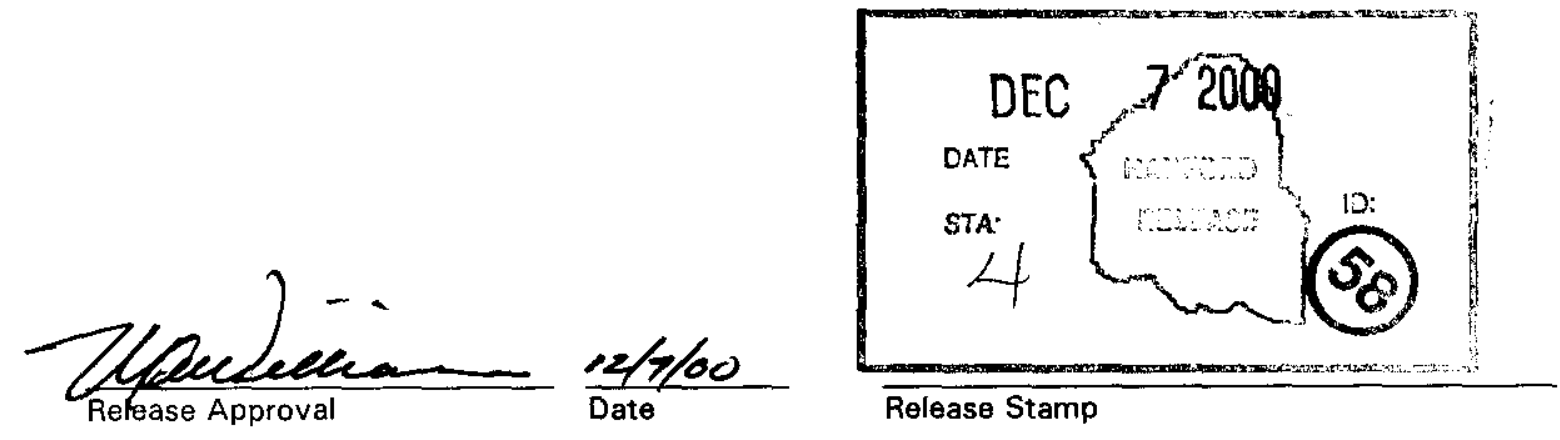

Release Stamp 
TRADEMARK DISCLAIMER

Reference herein to any specific commercial product, process, or service by trade name, trademark, manufacturer, or otherwise, does not necessarily constitute or imply its endorsement, recommendation, or favoring by the United States Government or any agency thereof or its contractors or subcontractors.

This report has been reproduced from the best available copy. Available in paper copy and microfiche.

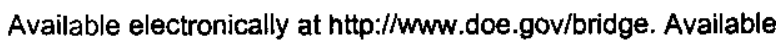
for a processing fee to the U.S. Department of Energy and its contractors, in paper, from:

U.S. Department of Energy

Office of Scientific and Technical Information

P.O. Box 62

Oak Ridge, TN 37831-0062

phone: 865-576-8401

fax: $865-576-5728$

email: reports@adonis.osti.gov(423) 576-8401

Available for sale to the public, in paper, from:

U.S. Department of Commerce

National Technical Information Service

5285 Port Royal Road

Springfield, VA 22161

phone: $800-553-6847$

fax: 703-605-6900

email: orders@ntis.fedworld.gov

online ordering: http://www.ntis.gov/orderil:y.htm

Printed in the United States of America

Total Pages:

78 


\section{RECORD OF REVISION}

(2) Title

Spent Nuclear Fuel Project Product Specification

CHANGE CONTROL RECORD

\begin{tabular}{|c|c|c|c|}
\hline \multirow[t]{2}{*}{ (3) Revision } & \multirow[t]{2}{*}{ (4) Description of Change - Replace, Add, and Delete Pages } & \multicolumn{2}{|c|}{ Authorized for Release } \\
\hline & & (5) Cog. Engr. & (6) Cog. Mgr. \\
\hline 0 & (7) Initial release - EDT 612998 & C.R. Miska & J.R. Frederickson \\
\hline 1 & Complete rewrite and name change on ECN 645045 & A.L. Pajunen & J.R. Frederickson \\
\hline 2 & $\begin{array}{l}\text { Update of new requirements on cleaning, pressure limis, a nd } \\
\text { associated parameters - ECN } 645062\end{array}$ & A.L. Pajunen & J.R. Frederickson \\
\hline 3 & $\begin{array}{l}\text { Update expanding descriptions and revising based on updated to } \\
\text { references - ECN } 648621\end{array}$ & A.L. Pajunen & J.R. Frederickson \\
\hline 4 & $\begin{array}{l}\text { General update to reflect revised references, clarify previous } \\
\text { specifications, include additional specifications identified during } \\
\text { subsequent design, and incorporate editorial changes - ECN } \\
657877\end{array}$ & A.L. Pajunen & J.R. Frederickson \\
\hline $4 \mathrm{~A}$ & $\begin{array}{l}\text { Update and reflect revisions, primarily from SARP revision - } \\
\text { ECN } 659418\end{array}$ & A.L. Pajunen & J.R. Frederickson \\
\hline 4B & $\begin{array}{l}\text { Update to explain the defense in depth measures to assure } \\
\text { knockout pot thermal stability and address breakage of fuel after } \\
\text { loading - ECN } 662251\end{array}$ & A.L. Pajunen & J.R. Frederickson \\
\hline $\mathrm{RS}^{5}$ & $\begin{array}{l}\text { Update to } \\
\text { - Clarify the end of queuing time for fuel and scrap baskets } \\
\text { - Clarify the end of the shipping window to the CVD Facility } \\
\text { - Clarify the criteria for a successful pressure rebound test } \\
\text { - Reformat to incorporate earlier revisions } \\
\text { - Revise basin water temperature specifications } \\
\text { ECN } 662257\end{array}$ & A.L. Pajunen & J.R. Frederickson \\
\hline & & & \\
\hline & & & \\
\hline & & & \\
\hline & & & \\
\hline & & & \\
\hline & & & \\
\hline & & & \\
\hline & & & \\
\hline & & & \\
\hline & & & \\
\hline & & & \\
\hline & & & \\
\hline
\end{tabular}




\section{SPENT NUCLEAR FUEL PROJECT PRODUCT SPECIFICATION}

\section{TABLE OF CONTENTS}

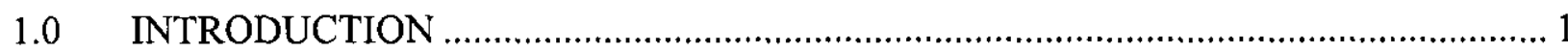

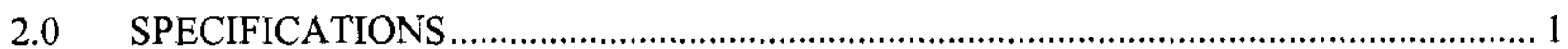

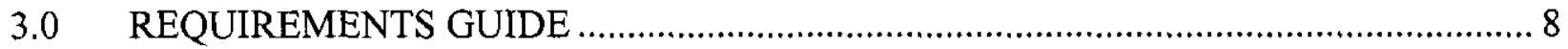

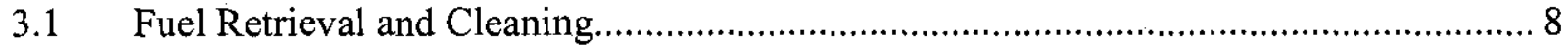

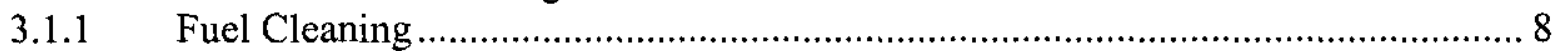

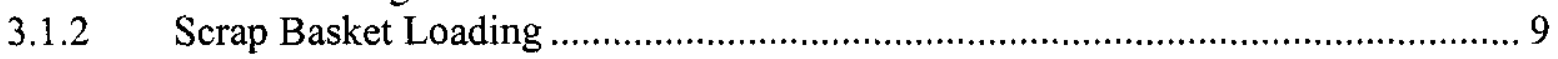

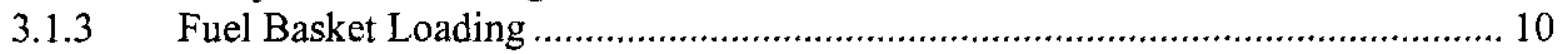

3.1.4 Organic Material Loading ............................................................................ 10

3.1.5 Fuel and Scrap Basket Queuing .................................................................... 11

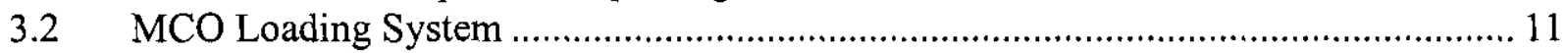

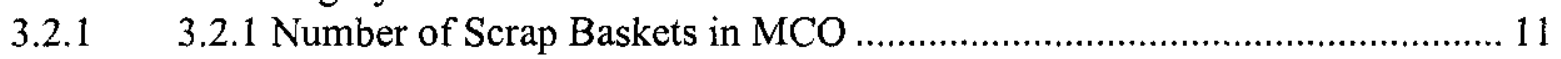

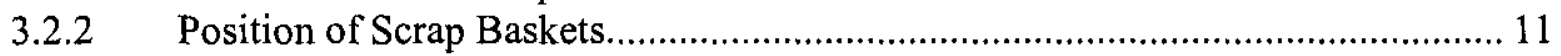

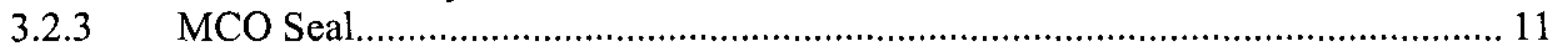

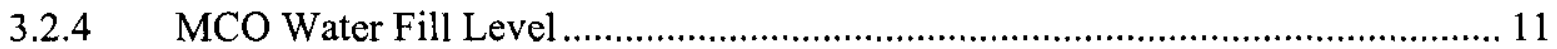

3.3 Cask Loading and Transport System .................................................................. 12

3.3.1 MCO/Cask Package Backfill ......................................................................... 12

3.3.2 MCO Cask Package Pressure.................................................................... 12

3.3.3 Cask Water Fill Level .............................................................................. 12

3.3.4 Cask Temperature ..................................................................................... 12

3.3.5 Time Limit for K Basins to CVD Facility Transfer............................................ 13

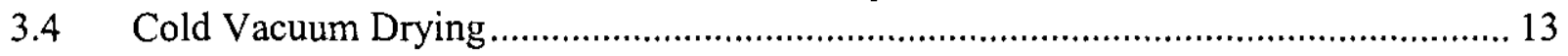

3.4.1 MCO Free Water Inventory ........................................................................ 13

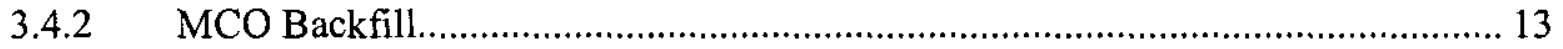

3.4.3 MCO Integrated Leakage Rate ……….......................................................... 14

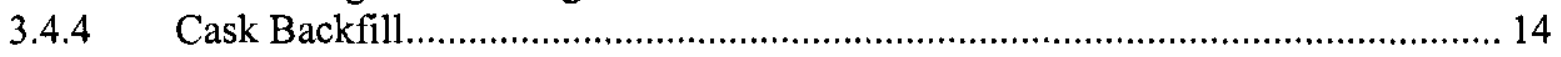

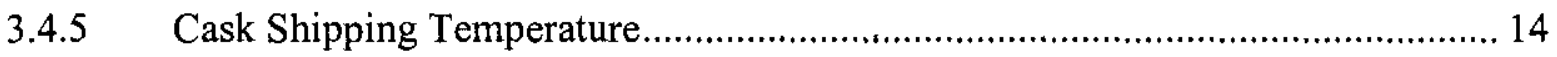

3.4.6 Halogenated and/or Organic Compounds ....................................................... 15

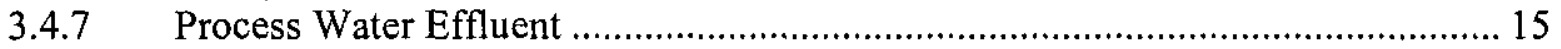

3.5 Cask Transport from the CVD Facility to the CSB ……............................................ 15

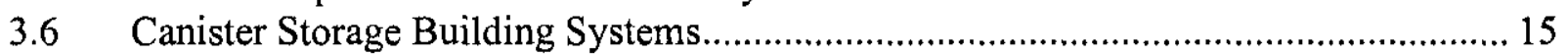

3.6.1 Mechanically Sealed MCO Storage at CSB ..................................................... 15

3.6.2 MCO Leakage Rate After Welded Cover Cap Installation .................................... 15

3.6.3 MCO Interim Storage Condition ................................................................... 15

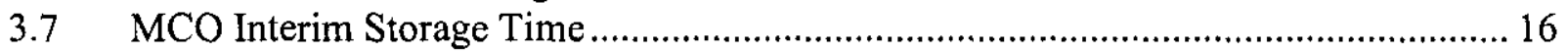

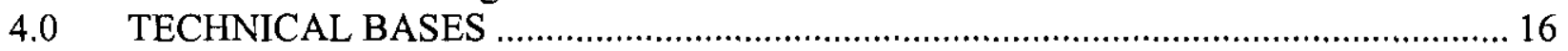

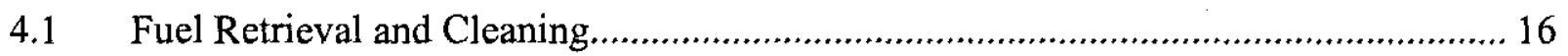

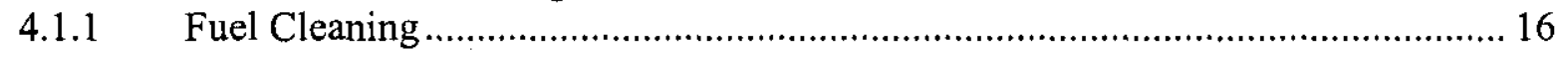

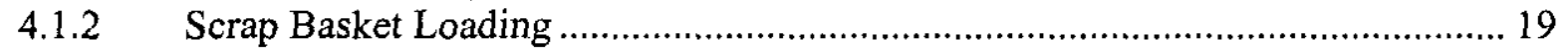

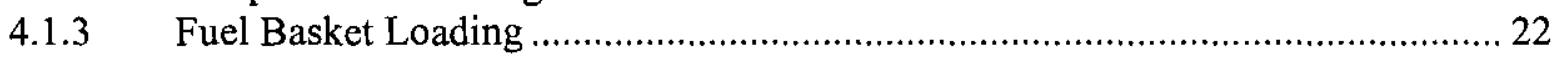

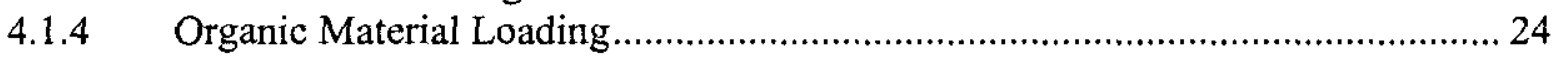

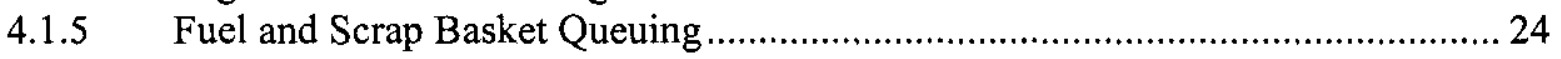

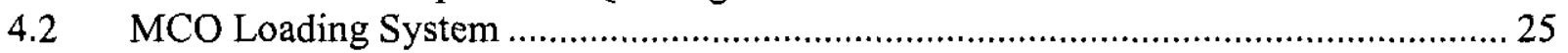




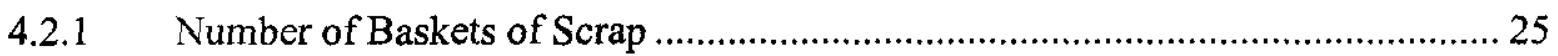

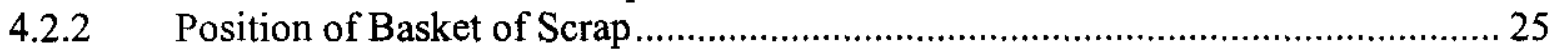

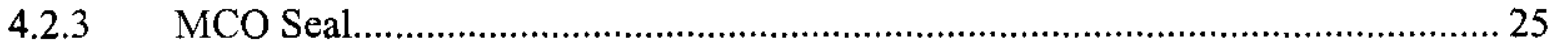

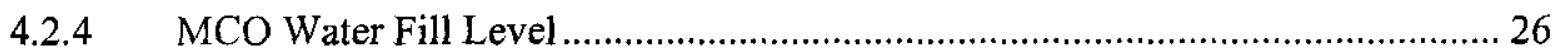

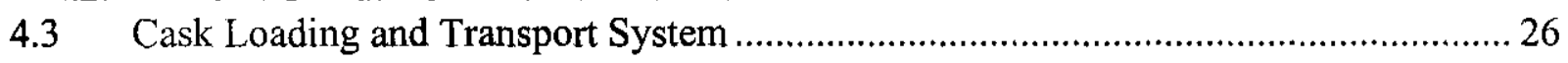

4.3.1 MCO/Cask Package Backfill ............................................................................ 26

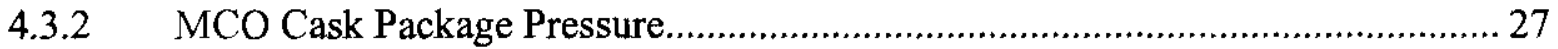

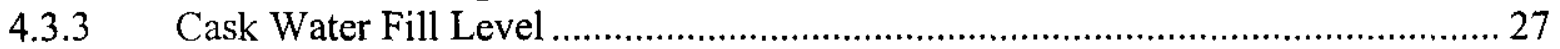

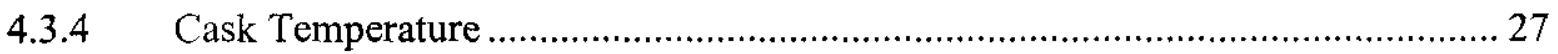

4.3.5 Time Limit for K Basins to CVD Facility Transfer............................................ 28

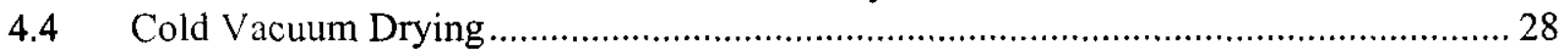

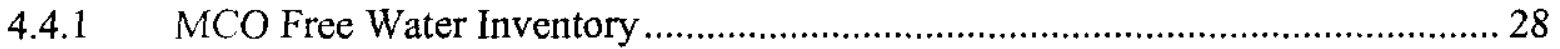

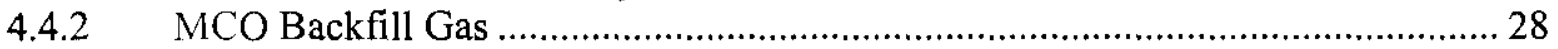

4.4.3 MCO Integrated Leakage Rate ……….......................................................... 30

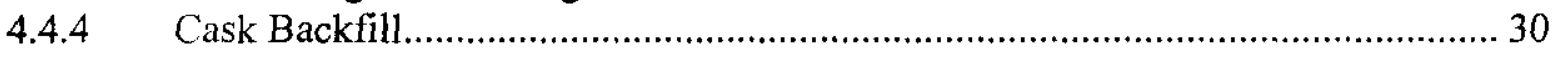

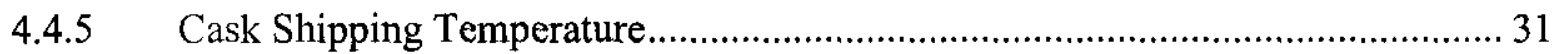

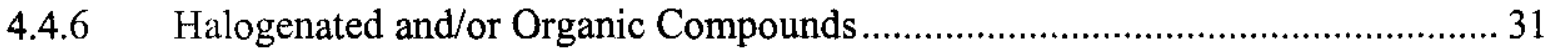

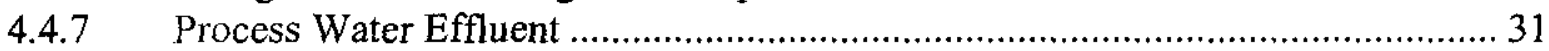

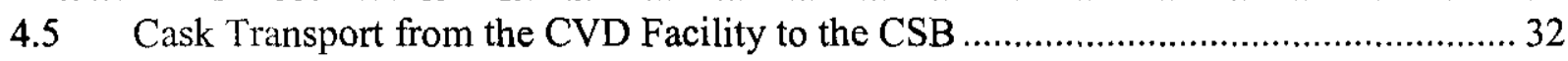

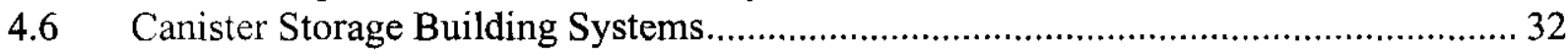

4.6.1 Mechanically Sealed MCO Storage at the CSB ............................................. 32

4.6.2 MCO Leakage Rate After Welded Cover Cap Installation ................................. 33

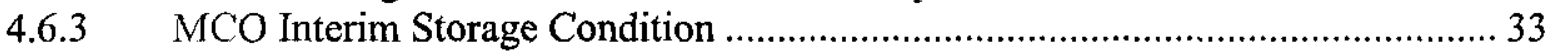

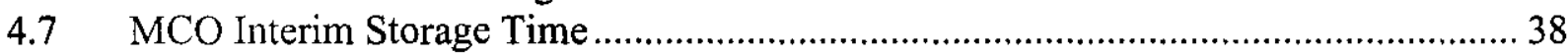

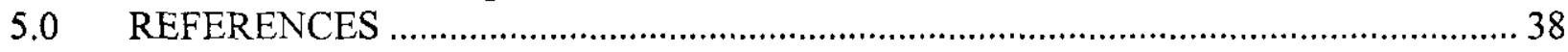

APPENDIX A. Assessment of the Effects of Organics on MCO Storage ............................... A-1

A.1 Epoxy Resin Gamma Irradiation Stability ....................................................... A-1

A.2 Gas Production from Organic Radiolysis ……….............................................. A-2

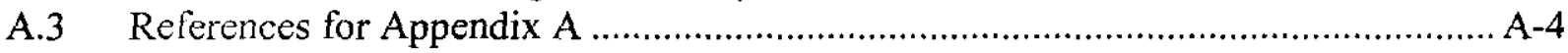

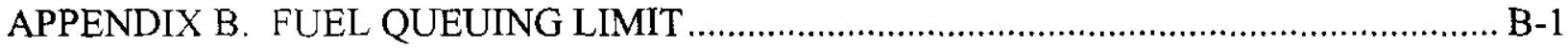

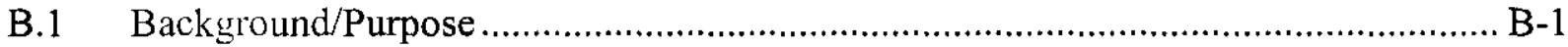

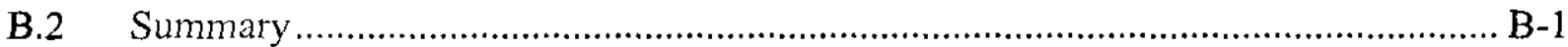

B.3 Particulate Generation Basis .......................................................................... B-1

B.4 Queuing Time Guidelines ............................................................................. B-2

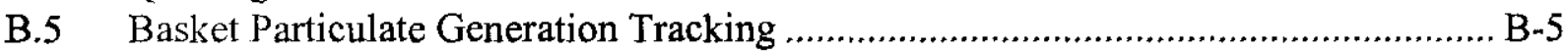

B.6 References for Appendix B........................................................................ B-13

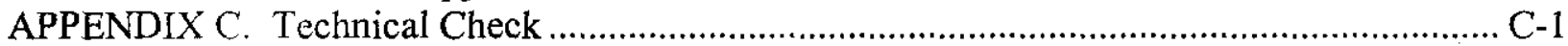

APPENDIX D. MINIMUM CASK RESIDENCE TIME IN BASIN WATER ………........... D- 1

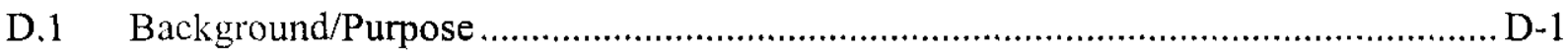

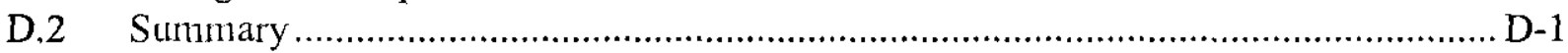

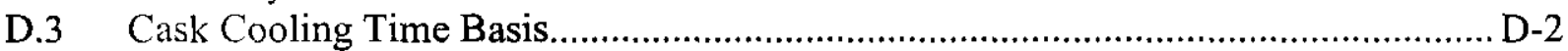

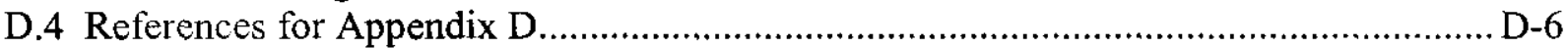

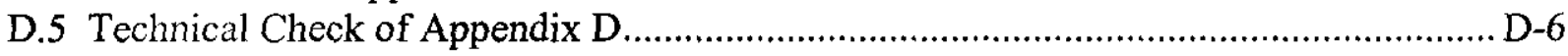


HNF-SD-SNF-OCD-001, Rev. 5

\section{LIST OF TABLES}

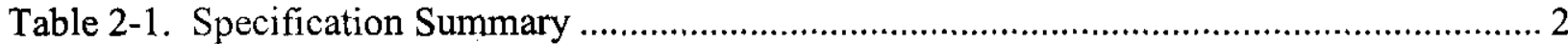

Table 4-1. Bounding Scrap Description................................................................................. 20

Table 4-2. Allowable Amounts of Gas in the Sealed Multi-Canister Overpack. ........................ 35

Table B-1. Basket Queuing Time Guidelines ....................................................................... B-3

Table B-2. Corrosion Rate Constants for Calculating Queuing Particulate Generation............ B-6

Table B-3. Tracking Example - Fuel and Scrap Basket Queuing Times ................................ B-7

Table B-4. Tracking Example - Particulate Generated During Scrap Basket Queuing ............. B-8

Table B-5. Tracking Example - Particulate Generated During Fuel Basket 1 Queuing............ B-9

Table B-6. Tracking Example - Particulate Generated During Fuel Basket 2 Queuing.......... B-10

Table B-7. Tracking Example - Particulate Generated During Fuel Basket 3 Queuing.......... B-11

Table B-8. Tracking Example - Particulate Generated During Fuel Basket 4 Queuing.......... B-12

Table B-9: Tracking Example - Queuing Generated Particulate Loaded in MCO ………..... B-12

Table D-1. Cask Cooling Time Estimates ........................................................................... D-5

\section{LIST OF FIGURES}

Figure B-1. Cumulative Particulate in an MCO based on Bounding Surface Areas B-2

Figure B-2. Cumulative Particulate Generated in MCOs with Common Queuing Generation at $10^{\circ} \mathrm{C}$ B-4

Figure B-3. Basket Queuing Time Guideline Temperature Adjustment Factor ........................ B-4

Figure B-4. Tracking Example -Basin Temperature During Queuing ………………........... B-7

Figure D-1. Variation of Cask Cooling Time with Basin Water Temperature.......................... D-2

Figure D-2. Assumed Cask Cooling Configuration........................................................... D-3

\section{List of Acronyms}

$\begin{array}{ll}\text { ANSI } & \text { American National Standards Institute } \\ \text { CSB } & \text { Canister Storage Building } \\ \text { CVD } & \text { Cold Vacuum Drying } \\ \text { FRS } & \text { Fuel Retrieval System } \\ \text { HEPA } & \text { High Efficiency Particulate Air } \\ \text { MCO } & \text { Multi-Canister Overpack } \\ \text { OCRWM } & \text { Office of Civilian Radioactive Waste Managment } \\ \text { PCM } & \text { Primary Cleaning Machine } \\ \text { PWC } & \text { Process Water Conditioning } \\ \text { SAR } & \text { Safety Analysis Report } \\ \text { SARP } & \text { Sarety Analysis Report For Packaging } \\ \text { SNF } & \text { Spcnt Nuclear Fuel } \\ \text { TRU } & \text { Transuranic }\end{array}$




\subsection{INTRODUCTION}

The process for removal of Spent Nuclear Fuel (SNF) from the K Basins has been divided into major sub-systems. The Fuel Retrieval System (FRS) removes fuel from the existing storage canisters, cleans it, and places it into baskets. The multi-canister overpack (MCO) loading system places the baskets into an MCO that has been pre-loaded in a cask. The cask, containing a loaded MCO, is then transferred to the Cold Vacuum Drying (CVD) Facility. After drying at the CVD Facility, the cask, and MCO, are transferred to the Canister Storage Building (CSB), where the MCO is removed from the cask, staged, inspected, sealed (by welding), and stored until a suitable permanent disposal option is implemented.

The purpose of this document is to specify the process related characteristics of an $\mathrm{MCO}$ at the interface between major process systems. The characteristics are derived from the primary technical documents that form the basis for safety analysis and design calculations. This document translates the calculation assumptions into implementation requirements and describes the method of verifying that the requirement is achieved. These requirements are used to define validation test requirements and describe requirements that influence multiple sub-project safety analysis reports.

This product specification establishes limits and controls for each significant process parameter at interfaces between major sub-systems that potentially affect the overall safety and/or quality of the SNF packaged for processing, transport, and interim dry storage. The product specifications in this document cover the SNF packaged in MCOs to be transported throughout the SNF Project.

The description of the product specifications are organized in the document as follows:

- Section 2.0 - Summary listing of product specifications at each major sub-system interface.

- Section 3.0 - Summary description providing guidance as to how specifications are complied with by equipment design or processing within a major sub-system.

- Section 4.0 - Specific technical basis description for each product specification.

The scope of this product specification does not include data collection requirements to support accountability or environmental compliance activities.

\subsection{SPECIFICATIONS}

Product specifications for the SNF, MCO, and cask are provided to ensure that packages leaving a sub-system satisfy the requirements of all subsequent process sub-systems such that the final $\mathrm{MCO}$ can be produced efficiently and stored for a 40 year time period. The specifications in this document are intended to provide requirements for individual sub-project performance specifications. Table 2-1 provides a summary of the process requirements and method of achieving the specified product. 
HNF-SD-SNF-OCD-001, Rev. 5

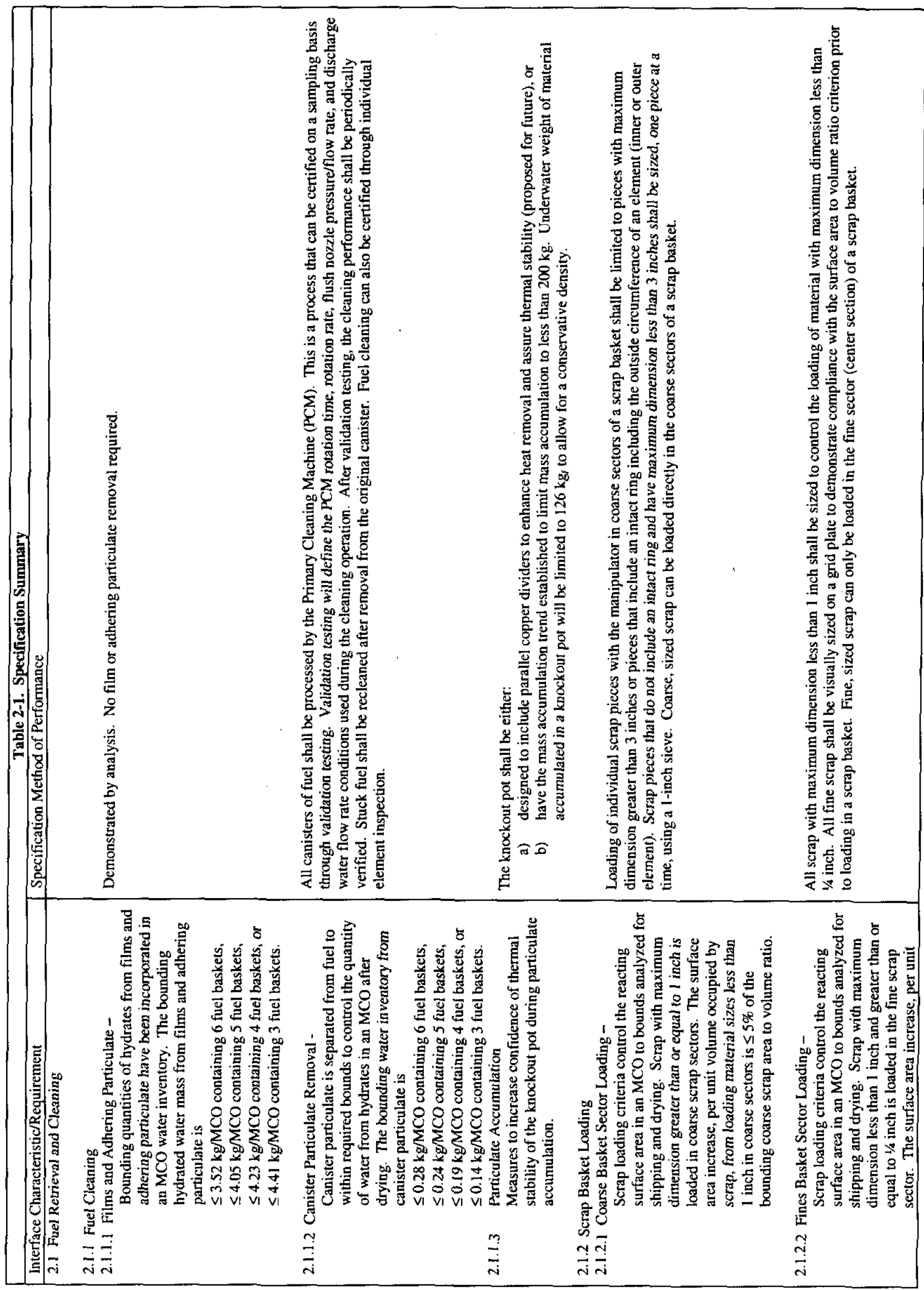


HNF-SD-SNF-OCD-001, Rev. 5

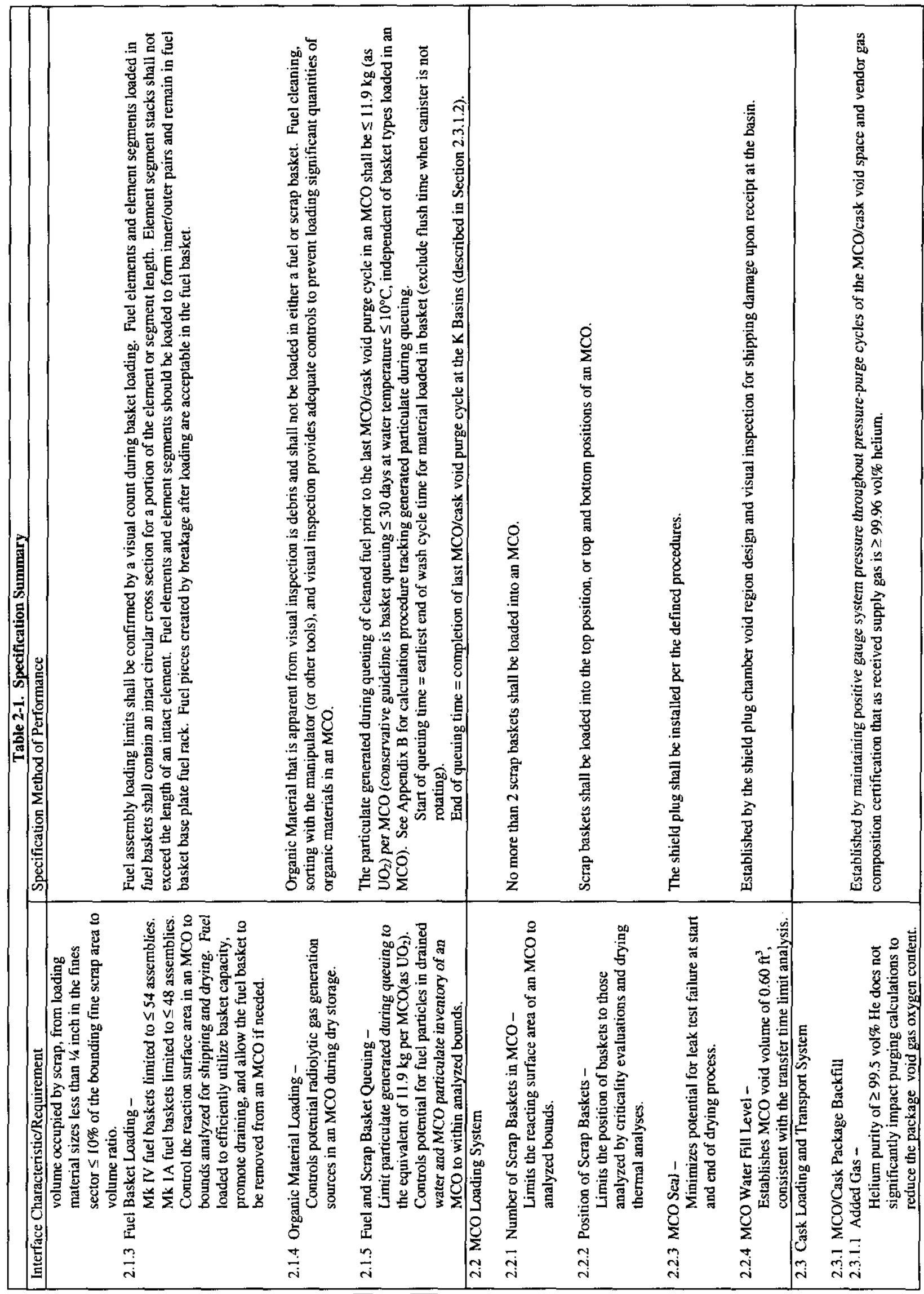


HNF-SD-SNF-OCD-001, Rev. 5

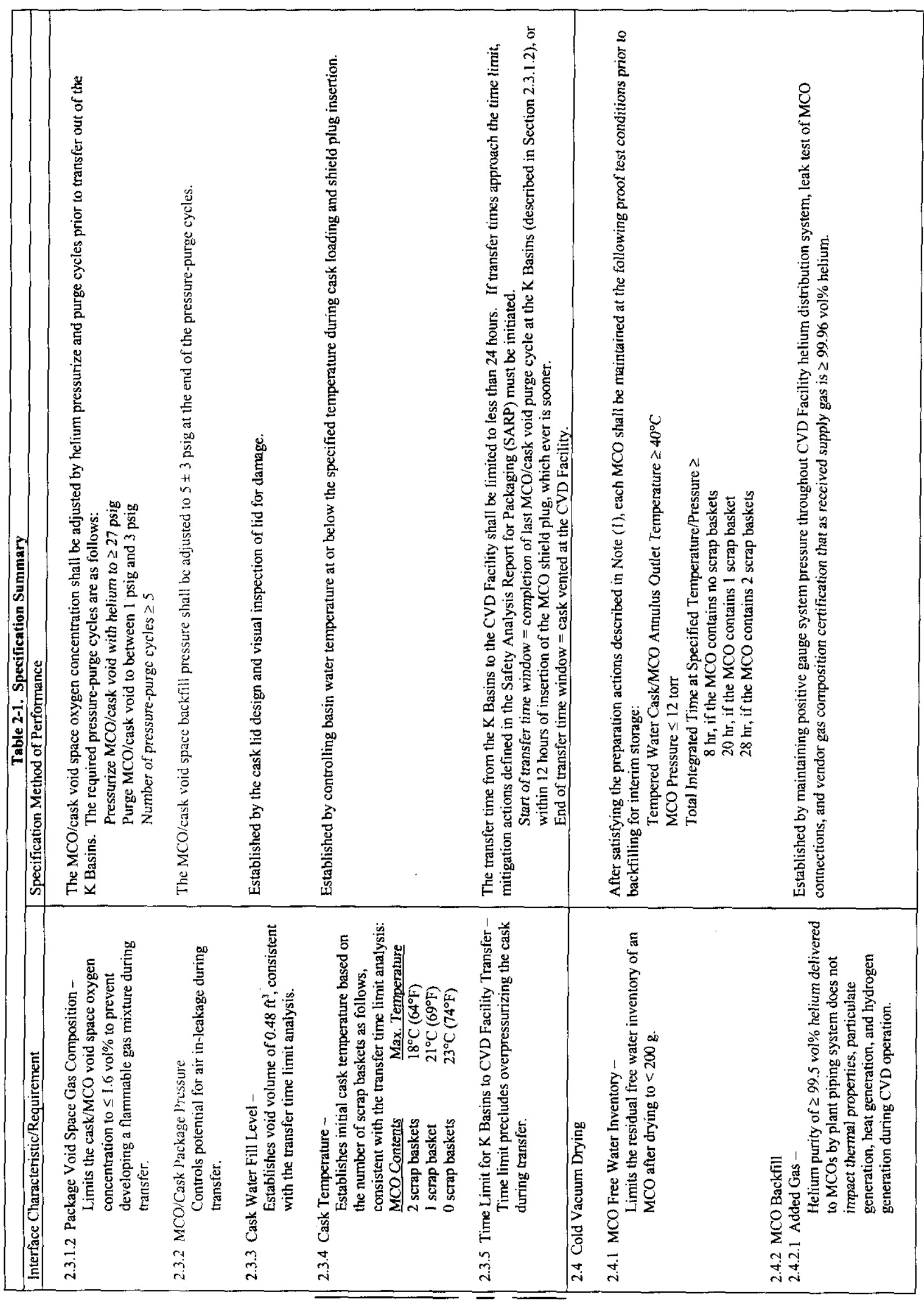


HNF-SD-SNF-OCD-001, Rev. 5

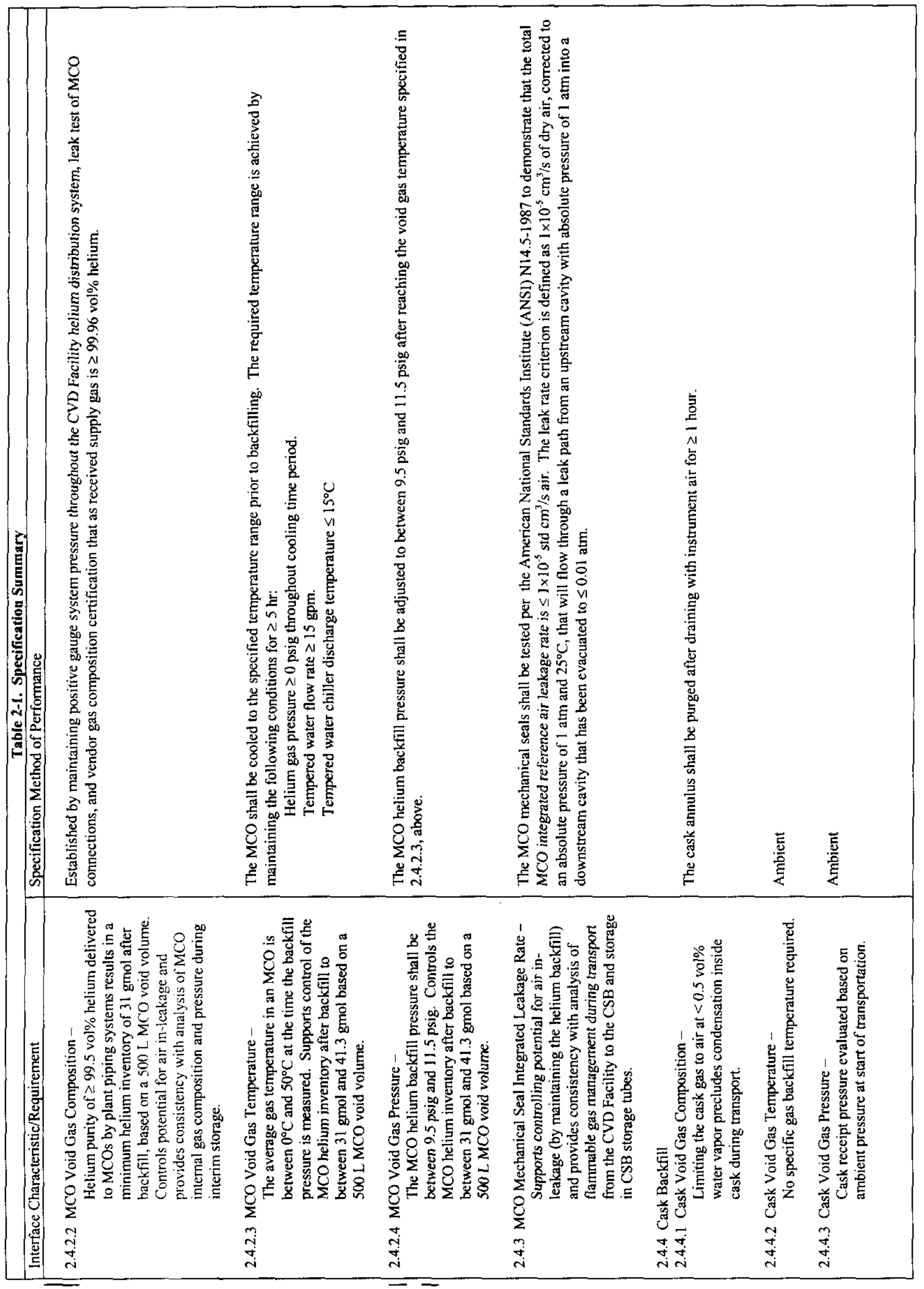


HNF-SD-SNF-OCD-001, Rev. 5

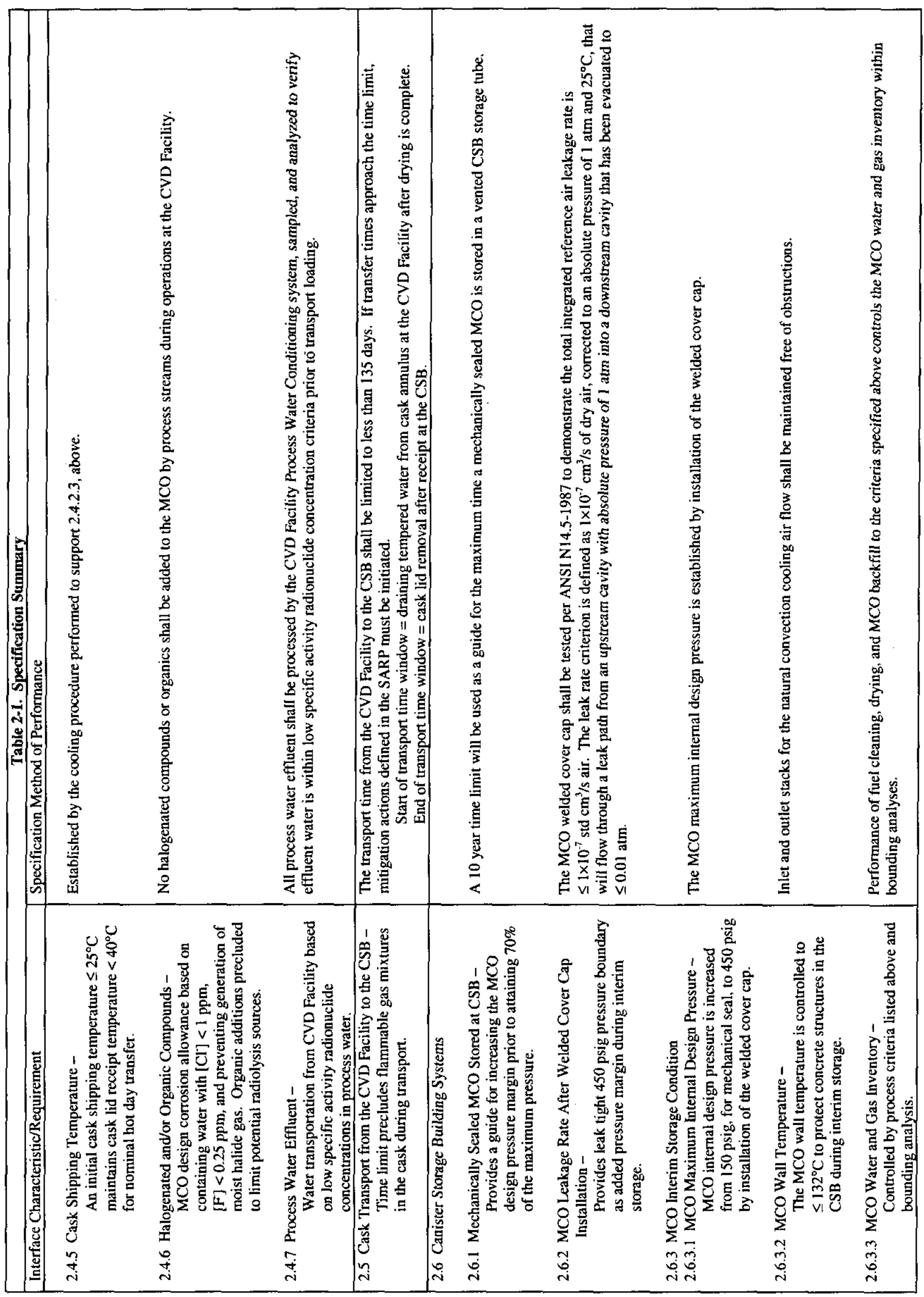




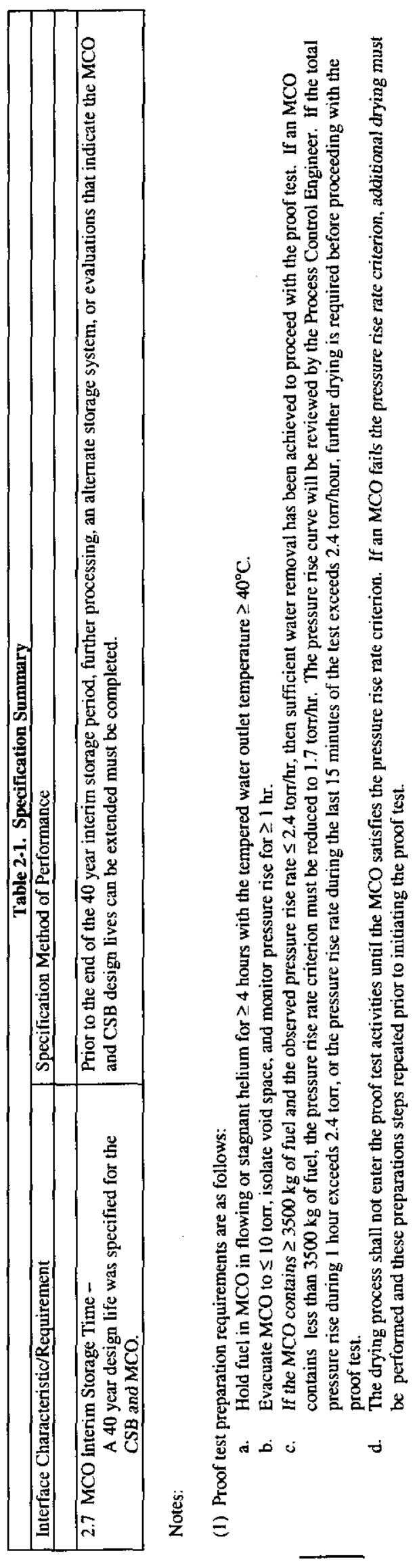




\subsection{REQUIREMENTS GUIDE}

The following discussion provides an overview of activities performed within a process step implementing the specifications of Section 2.0 to assist with specification interpretation.

\subsection{Fuel Retrieval and Cleaning}

\subsubsection{Fuel Cleaning}

Fuel cleaning is performed by retrieving a canister of fuel from the basin storage racks and processing it in the Primary Cleaning Machine (PCM). This operation provides the primary separation of fuel from corrosion products, reducing the quantity of material containing hydrated water loaded in an MCO. Performance of this cleaning step is based on identifying a set of operating conditions (e.g., time, rotation speed, water flowrates) that produce fuel that satisfy the canister cleaning criteria. Once a set of conditions is established, a process validation procedure is performed to demonstrate that the cleaning criteria are satisfied at a confidence level consistent with bounding particulate inventory analyses in Sloughter (1999). The actual set of PCM operating conditions and process validation activity will be performed during startup activities. Therefore, the operating conditions cannot be specified at this time. However, the criteria used to relate performance to the bounding particulate analysis are described in Section 4.1.1. Ultimately, cleaning is defined by processing all fuel through a properly operating PCM after validation has been established in accordance with Sloughter (1999).

\subsubsection{Films and Adhering Particulate}

The PCM is expected to remove some of the films or adhering particulate during processing. However, the development of a conservative MCO particulate inventory, and resultant hydrate water inventory after drying, assumes no credit for removal of these materials from fuel elements in the bounding analysis by Sloughter (1999) due to the difficulty in quantifying the residual film and adhering particulate on a production basis (see Section 4.1.1.1).

\subsubsection{Canister Particulate Removal}

The fuel cleaning criteria are based on separation of canister particulate (loose particulate collected between elements in the bottom of the canister) from fuel elements and scrap prior to loading these materials in baskets (see Section 4.1.1.2 for the criteria description). All fuel bearing materials loaded in either type of basket must be processed by the PCM in order for the analysis determining the $\mathrm{MCO}$ bounding particulate inventory to be valid.

\subsubsection{Particulate Accumulation}

During canister cleaning operations, some of the particulate will be accumulated in the knockout pot. The knockout pot has been shown to be thermally stable for all realistic combinations of particle size and metal mass fraction (Sloughter, 1999b). However, to increase confidence in thermal stability, addition of three parallel copper dividers has been proposed for future knockout 
pots. For knockout pots without these dividers, the mass accumulation trend will be established and the mass accumulation limited to $200 \mathrm{~kg}$. The underwater weight of the accumulated mass will be limited to $126 \mathrm{~kg}_{\mathrm{f}}$ to allow for a conservative density.

\subsubsection{Scrap Basket Loading}

Scrap consists of all fuel bearing material that is not allowed to be loaded in a fuel basket. Therefore, scrap can consist of material with a maximum dimension as small as $1 / 4$ inch, but can also consist of pieces as large as entire fuel elements which do not fit in bottom plate sockets of the fuel basket.

\subsubsection{Coarse Scrap Basket Sector Loading}

Scrap with maximum dimension greater than 1 inch will be placed primarily in the coarse scrap sectors of a scrap basket. Scrap pieces larger than 1 inch can also be placed in the scrap basket fines sector (center compartment) if needed during operations. However, use of the fines sector for coarse scrap should be limited until operational experience indicates the quantity of fine scrap generated as compared to coarse scrap quantities.

Loading of material that has a maximum dimension less than 1 inch in coarse sector of the scrap basket is controlled by the loading procedure. Scrap pieces with dimensions greater than 3 inches can be placed directly into the scrap basket coarse sectors using the manipulator. The manipulator end-effector jaws ( 3 inch width) can be used as the visual guide for determining that a scrap piece is suitable for direct loading in the coarse scrap basket sector. Significant uncertainty is acceptable in the visual comparison of scrap size with the manipulator end-effector jaw since the visual guide is three times larger than the actual coarse scrap size criterion. It should be noted that all scrap pieces that include a complete outside circumference ring (inner or outer element) will also have maximum dimension greater than 1 inch.

All material smaller than 3 inches, with incomplete outside circumferences, will be sized in a sizing device, operated at conditions determined during validation tests. Equipment designs and the validation tests will demonstrate that the specified operating conditions produce material suitable for loading in the scrap basket coarse sector (i.e., the surface area per unit volume occupied by scrap is no more than $5 \%$ greater than that calculated for the coarse sectors of a bounding scrap basket in Ball and Duncan [1998]).

The potential for fuel surface area increase from breakage of scrap pieces when dropped in a coarse sector of the scrap basket after sizing is accommodated by the bounding surface area calculation. 


\subsubsection{Fine Scrap Basket Sector Loading}

Scrap material with maximum dimension between $1 / 4 \mathrm{inch}$ and 1 inch must be loaded in the fines sector of a scrap basket. Loading material with maximum dimension greater than $1 \mathrm{inch}$ is allowed, limited only by the fines sector physical dimensions. However, operational considerations may determine that placing larger scrap pieces in the fines sector should be minimized in order to reserve space in the scrap baskets for fine scrap.

Loading of material that has a maximum dimension of less than $1 / 4$ inch in an MCO is controlled by specifying that no scrap is loaded in the fines sector of scrap baskets without being sized in a device designed to size fine scrap, operated at the proper conditions determined during validation tests. Equipment designs to support this size classification of materials and validation tests will demonstrate that the specified operating conditions produce material suitable for loading in the scrap basket fines sector (i.e., the surface area per unit volume occupied by scrap is no more than $10 \%$ greater than that calculated for the fines sector of a bounding scrap basket).

\subsubsection{Fuel Basket Loading}

Material that is generally described as pairs of fuel elements are loaded in a fuel basket. No more than 54 fuel assemblies shall be loaded in an Mk IV fuel basket and no more than 48 fuel assemblies shall be loaded in an Mk $1 \mathrm{~A}$ fuel basket.

Fuel bearing material is suitable for loading in a fuel basket if it can be loaded to form fuel element pairs, at least one end of the outer element fits within the hole machined in the plate of the fuel basket, and the inner element fits within the outer element. Both elements must seat within the fuel basket holes such that the top of either element does not exceed the fuel basket height. Fuel element segments may be stacked (outer segments on intact inner or inner segments in intact outer) to form element pairs in a fuel basket position. The height of stacked segments cannot exceed the length of intact element supporting the segment stack.

Inspection of fuel baskets prior to transport to the loading queue will indicate that fuel elements are properly positioned in the fuel basket. Inspection is to ensure that no material is wedged between the fuel assemblies, splaying out the upper ends of assemblies. Fuel pieces created by breakage after loading are acceptable in the fuel basket.

\subsubsection{Organic Material Loading}

The quantity of organic material loaded in fuel and scrap baskets will be minimized to minimize potential sources of radiolytic gas sources in the MCO. Painted identification numbers on MCO baskets do not provide a significant radiolytic gas source. Organic material, which can be removed from the fuel by the manipulator, may not be loaded in the MCO baskets. Removing this organic material will maintain the potential MCO organic inventory within allowable estimates indicated in Section 4.1.4. 
HNF-SD-SNF-OCD-001, Rev. 5

\subsubsection{Fuel and Scrap Basket Queuing}

Fuel and scrap basket durations in the basket queue (i.e. time that baskets are in the queue) must be administratively tracked to show that the particulate inventory generated during basket queuing is less than or equal to $11.9 \mathrm{~kg}$ (as $\mathrm{UO}_{2}$ ). The basket queuing time starts at the time material finishes the wash cycle in the cleaning machine. The earliest time of all the material loaded in a basket is used to characterize the start of queuing time for all material in a basket. The basket queuing time ends when the void space of a loaded $\mathrm{MCO} /$ cask has been purged with helium (start of wet transfer shipping window). Appendix B describes the generated particulate tracking procedure. A conservative guideline, based on two scrap baskets in an $\mathrm{MCO}$, is that the particulate generation criterion will be met if all baskets have been stored less than 30 days at water temperatures less than or equal to $10^{\circ} \mathrm{C}$. Alternative guidelines for other MCO loadings are provided in Appendix B.

\subsection{MCO LOADING SYSTEM}

\subsection{Number of Scrap Baskets in MCO}

Administratively controlled to no more than two scrap baskets per MCO through procedures.

\subsubsection{Position of Scrap Baskets}

Administratively controlled to the top, or top and bottom position, through procedures.

\subsubsection{MCO Seal}

The MCO seal ring cleanliness is controlled by design of a basket loading guide. Cleanliness is administratively controlled by specifying that the basket guide must be in place during basket loading activities and cleaning the seal area prior to shield plug installation. After the basket guides are removed, the seal ledge is to be cleaned with a tool or other suitable device to remove any particles that may interfere with proper sealing. Inspection of the sealing face will be performed by camera prior to seating the shield plug.

\subsubsection{MCO Water Fill Level}

The MCO fill level is controlled by equipment design to a height approximately 4 inches below the MCO shield plug main body. The cavity formed inside the shield plug assembly provides the appropriate water fill level. 
HNF-SD-SNF-OCD-001, Rev. 5

\subsection{Cask Loading and Transport System}

\subsubsection{MCO/Cask Package Backfill}

The MCO is vented to the cask during the transfer between the basin and CVD Facility. An inerting procedure is performed after installing the cask lid to preclude development of a

| flammable gas mixture in the $\mathrm{MCO} /$ cask void space as hydrogen is generated within the $\mathrm{MCO}$.

\subsubsection{Added Gas}

Helium is used as the inert gas added to the $\mathrm{MCO} /$ cask void space. Maintaining a positive gauge pressure in the piping supply system and $\mathrm{MCO} /$ cask void space throughout the inerting procedure eliminates the potential for adding significant quantities of impurities (air), which are not incorporated in the inerting procedure basis.

\subsubsection{Package Void Space Gas Composition}

After cask lid installation at the $\mathrm{K}$ Basins for shipment to the CVD Facility, the package void space gas composition is equivalent to air. A series of pressure-bleed cycles, introducing helium into the closed cask, is used to reduce the oxygen concentration of the $\mathrm{MCO} /$ cask void space. The number of cycles to achieve $1.6 \%$ oxygen depends on the operating pressure selected (e.g., 5 cycles to 27 psig achieves $1.6 \%$ oxygen in the package void space, Pajunen [2000]).

\subsubsection{MCO Cask Package Pressure}

I During the transfer from K Basins to the CVD Facility, the MCO Cask Package pressure will be administratively controlled to $5 \pm 3$ psig, as measured after backfill.

\subsubsection{Cask Water Fill Level}

The MCO cask annulus space is filled with water to a height equal to the water level within the MCO. The cask water level is dictated by the equipment design. Water level adjustments, using specifically designed tools, are allowed to accommodate thermal expansion of water during transfers.

\subsubsection{Cask Temperature}

| The cask temperature is controlled according to the MCO contents (see table below) at the completion of the helium purge to the MCO void space by equilibrating the cask to basin water temperatures.

\begin{tabular}{cc} 
MCO Contents & Max Temperature \\
\hline 2 scrap baskets & $18^{\circ} \mathrm{C}\left(64^{\circ} \mathrm{F}\right)$ \\
1 scrap basket & $21^{\circ} \mathrm{C}\left(69^{\circ} \mathrm{F}\right)$ \\
0 scrap baskets & $23^{\circ} \mathrm{C}\left(74^{\circ} \mathrm{F}\right)$
\end{tabular}


The cask temperature essentially equilibrates with the basin water temperature 8 hours after immersion in the cask loadout pit. Cask temperature begins to increase above the pool temperature with insertion of the MCO shield plug. Shorter water immersion times are required to control the initial cask temperature for lower basin water temperatures (see Figure D-1).

\subsubsection{Time Limit for K Basins to CVD Facility Transfer}

The transport time between the K Basins and the CVD Facility will be administratively controlled to less than 24 hours. If transport times approach the time limit, mitigation actions defined in Smith (2000) must be initiated. The transport time window starts when the procedure for adjusting the cask backfill gas composition in the K Basins is completed, or 12 hours from insertion of the MCO shield plug, which ever starts the transport window sooner. The transport time window ends when the cask has been vented in the CVD Facility.

\subsection{COLd VACUUm DRYing}

This section provides guidance to interpreting the CVD product specifications based on an MCO that has completed the drying process.

\subsubsection{MCO Free Water Inventory}

A bound for the residual free water inventory after CVD processing will be established based on the procedure described in Pajunen (1998a). This procedure consists of holding the $\mathrm{MCO}$ at a temperature greater than $40^{\circ} \mathrm{C}$ and a pressure less than 12 torr for a pre-determined time period (holding time calculations are dependent on the number of scrap baskets in the MCO, ranging from 8 hours for no scrap baskets, to 20 hours for one scrap basket, to 28 hours for two scrap baskets). The preparation actions for this test are also contained in Pajunen (1998a) and are interpreted and clarified by Frederickson (2000).

\subsubsection{MCO Backfill}

\subsubsection{Added Gas}

Helium is used as the inert gas added to the MCO void space during the drying process and as a backfill gas after drying is complete. The purity of gas added to the MCO is controlled to $\geq 99.5 \%$ helium by maintaining the supply distribution system at a positive gauge pressure, leak testing $\mathrm{MCO}$ process connections, and vendor gas composition certification.

\subsubsection{MCO Void Gas Composition}

MCO backfill gas is the same as the added gas composition. The MCO undergoes a series of process steps that evacuate and flow helium through the MCO. Therefore, the resulting void gas composition is not significantly different from the added gas and the controls to maintain backfill gas purity are the same as identified in Section 3.4.2.1. 


\subsubsection{MCO Void Gas Temperature}

Since temperature affects the mass of backfill helium added to an MCO, the backfill gas pressure must be measured after the cask/MCO assembly temperature has been adjusted to the backfill gas temperature criterion. Piepho (2000) determined that the MCO backfill gas temperature is within the required temperature range of $0^{\circ} \mathrm{C}$ to $50^{\circ} \mathrm{C}$ after drying if the $\mathrm{MCO}$ is cooled for at least 4 hours with tempered water flowrate of at least $15 \mathrm{gpm}$ and tempered water temperature of $17^{\circ} \mathrm{C}$. Allowing for a $2^{\circ} \mathrm{C}$ temperature rise in piping, a tempered water chiller discharge temperature of $\leq 15^{\circ} \mathrm{C}$ produces conditions consistent with the cooling analysis.

\subsubsection{MCO Void Gas Pressure}

The MCO void gas backfill pressure is adjusted to within the pressure range of $9.5 \mathrm{psig}$ to $11.5 \mathrm{psig}$ after performing the backfill gas temperature adjustment described in Section 3.4.2.3.

\subsubsection{MCO Integrated Leakage Rate}

Leakage testing of MCOs shall be performed to demonstrate that the total integrated reference air leakage rate is less than or equal to $1 \times 10^{-5} \mathrm{std} \mathrm{cm}^{3} / \mathrm{sec}$ air, per the American National Standards Institute (ANSI) N14.5-1987, prior to shipment from the CVD Facility to the CSB.

\subsubsection{Cask Backfill}

\subsubsection{Cask Void Gas Composition}

An instrument air purge will be used to dry the cask annulus after draining the water. Upon completion of water drainage and air purge, no more than $0.5 \mathrm{vol} \%$ water vapor is permitted in the cask.

\subsubsection{Cask Void Gas Temperature}

No gas temperature measurements are required (ambient temperature).

\subsubsection{Cask Voici Gas Pressure}

No backfill pressure measurements are required (ambient pressure).

\subsubsection{Cask Shipping Temperature}

The initial cask shipping temperature, the temperature of the cask at the CVD Facility when the MCO port plugs are closed, will be assured by the same cooling procedure used to adjust the backfill gas temperature in Section 3.4.2.3. 
HNF-SD-SNF-OCD-001, Rev. 5

\subsubsection{Halogenated and/or Organic Compounds}

CVD equipment and system designs preclude process addition of oils, other organics, and/or halogen containing materials that will not be removed at CVD operating conditions.

\subsubsection{Process Water Effluent}

The process water conditioning (PWC) system will be used during the transfer of all process water from an MCO to a transport. All process water effluent will be processed in the CVD Facility PWC system prior to transport loading.

\subsection{Cask TRANSPORT From the CVD FaciLity to the CSB}

The transport time from the CVD Facility to the CSB will be controlled administratively to comply with a maximum shipping time limit of 135 days. If shipping times approach the time limit, mitigation actions defined in Smith (2000) must be initiated. The transport time start is defined as when water is drained from the cask annulus at the CVD Facility. The end of the transport time is defined as when the cask lid is removed after receipt in the CSB.

\subsection{CANiSTer Storage BuILDing Systems}

\subsubsection{Mechanically Sealed MCO Storage at CSB}

The time a mechanically sealed MCO is stored in the CSB will be controlled administratively.

\subsubsection{MCO Leakage Rate After Welded Cover Cap Installation}

Leakage testing of MCOs shall be performed with CSB systems to meet the requirements of Goldmann (2000) and ANSI N14.5-1987 prior to placement in long-term storage at the CSB.

\subsubsection{MCO Interim Storage Condition}

\subsubsection{MCO Maximum Internal Design Pressure}

The maximum internal pressure of an $\mathrm{MCO}$, with welded cover cap installed, that has been loaded with cleaned fuel which was dried and backfilled in compliance with the criteria described in Section 3.1 through 3.6.2, will not exceed the MCO design pressure of $450 \mathrm{psig}$ during interim storage.

\subsubsection{MCO Wall Temperature}

The maximum MCO wall temperature is limited to less than $132^{\circ} \mathrm{C}$ by proper function of the CSB vault cooling system and conformance to the processing criteria described in Sections 3.1 through 3.4 . 
HNF-SD-SNF-OCD-001, Rev. 5

\subsubsection{MCO Water and Gas Inventory}

The MCO water and gas inventory is limited to the allocations shown in Table 4-2 by conformance to the processing criteria described in Sections 3.1 through 3.4.

\subsection{MCO INTERIM STORAgE TIME}

Some type of action to remove fuel from interim storage, or extend the storage system design life, must be defined and completed prior to the end of the CSB and MCO design life of 40 years.

\subsection{TECHNICAL BASES}

This section describes the technical bases for each process specification listed in Section 2.0.

\subsection{Fuel Retrieval and Cleaning}

The FRS is responsible for retrieving fuel from storage locations, cleaning it and placing it in fuel and scrap baskets. The fuel cleaning and basket loading activities performed by the FRS establish process parameters for all subsequent process systems. Fuel cleaning separates corrosion products from the fuel bearing materials loaded in fuel and scrap baskets. The criteria for this separation is consistent with the analysis of a bounding particulate inventory in an MCO which supports quantifying the inventory of material at risk for dispersion during accidents and the inventory of material containing hydration water. Basket loading specifications are consistent with analyses bounding the reacting surface area in an $\mathrm{MCO}$, while basket queuing specifications are consistent with analyses of particulate generation on fuel in baskets after cleaning.

\subsubsection{Fuel Cleaning}

Fuel cleaning performance is based on the bounding particulate analysis in Sloughter (1999). The analysis quantifies the bounding particulate inventory in an MCO by considering potential locations for residual particulate based on fuel characterization observations. These observations resulted in characterizing the components of residual particulate associated with fuel assemblies and scrap as: cladding films (composed of either uranium or aluminum compounds), an oxide film on exposed uranium surfaces, adhering particulate trapped in cracks within elements, and canister particulate (corrosion products accumulating in canisters that may collect in element flow channels). 
HNF-SD-SNF-OCD-001, Rev. 5

\subsubsection{Films and Adhering Particulate}

The bounding particulate inventory analysis in Sloughter (1999) and Wyman (1999) is based on bounding quantities of films and adhering particulate as found in the basin with no intentional cleaning. The bounding particulate inventory forms the basis for the hydrate water inventory in an MCO after drying described in Duncan and Plys (1998). The bounding particulate inventory, and resultant hydrate water inventory, is dependent on the number of fuel and scrap baskets loaded in a particular MCO. Since bounding estimates of hydrates were used to evaluate MCO interim storage, the FRS PCM is not required to remove films or adhering particulate.

Duncan and Plys (1998) develops the basis for water mass fraction in the different films and adhering particulate to determine that the hydrated water mass in an $\mathrm{MCO}$ is bounded by

- $4.05 \mathrm{~kg}$ water per MCO containing five fuel baskets,

- $4.25 \mathrm{~kg}$ water per MCO containing four fuel baskets, and

- $4.41 \mathrm{~kg}$ water per MCO containing three fuel baskets.

Duncan and Plys (1998) does not address a six fuel basket MCO. However, applying the film and particulate water content from Duncan and Plys (1998) to the bounding particulate inventory in Wyman (1999) yields a bounding hydrate water mass of $3.52 \mathrm{~kg}$ water per MCO containing six fuel baskets.

\subsubsection{Canister Particulate Removal}

The bounding particulate inventory analysis in Sloughter (1999) is based on satisfying cleaning criteria for separating canister particulate from fuel elements in the PCM. The overall approach is based on process validation, where the process performance is demonstrated for a set of PCM operating parameters during startup testing. Sloughter (1999) includes an allocation for the residual canister particulate in an MCO that defines the process validation cleaning criteria.

The assembly cleaning criterion is based on defining the quantity of canister particulate observed in flow channels that cause an assembly to be considered inadequately cleaned. The definition of an assembly that fails the cleaning criteria is as follows:

An assembly fails the cleaning criterion if, when removing the inner element from the outer element, a quantity of corrosion product is observed to fall out of the assembly exceeds $1.3 \mathrm{~cm}^{3}$.

This criterion is actually applied only to elements that are being separated during the process validation test. A trained review panel, familiar with the cleaned fuel description in Sloughter (1999) will provide the final determination that assembly cleaning conforms to the bounding analysis. A qualified process approach to operation of the PCM for loading fuel and scrap baskets cannot begin until the process validation test is successfully completed. However, basket loading could continue based on inspection of each assembly prior to loading. 


\section{HNF-SD-SNF-OCD-001, Rev. 5}

The allocation for residual canister particulate in the bounding particulate inventory in Sloughter (1999) is based on providing a $99 \%$ confidence that:

- Mk IV fuel baskets in an MCO contain no more than $0.96 \mathrm{~kg}$ canister particulate,

- Mk IV fuel baskets in an MCO contain no more than $1.28 \mathrm{~kg}$ canister particulate, and

- Mk IV fuel baskets in an MCO contain no more than $1.6 \mathrm{~kg}$ canister particulate.

Wyman (1999) duplicated the calculations in Sloughter (1999) for Mk 1A MCOs and indicates that total fuel particulate inventories of Mk IV MCO loadings bound the six basket configurations of an Mk $1 \mathrm{~A}$ MCO. However, the canister particulate component of the total particulate inventory is bounded by $1.86 \mathrm{~kg}$ in an MCO containing $6 \mathrm{Mk} 1 \mathrm{~A}$ fuel baskets.

Applying the water content of canister particulate ( $15 \mathrm{wt} \%$ hydration water) from Duncan and Plys (1998) to the bounding particulate inventories yields bounds for the hydration water from canister particulate of:

- $0.28 \mathrm{~kg}$ water in an MCO containing six Mk $1 \mathrm{~A}$ fuel baskets,

- $0.24 \mathrm{~kg}$ water in an MCO containing five fuel baskets,

- $0.19 \mathrm{~kg}$ water in an MCO containing four fuel baskets, and

- $0.14 \mathrm{~kg}$ water in an MCO containing three fuel baskets.

A process validation test lot consists of 29 canisters containing 406 assemblies. If more than one of the 406 assemblies in the validation test lot fails the assembly cleaning criterion, the cleaning process fails to meet the validation criteria for canister particulate removal (Sloughter 1999). If the validation test fails, the PCM operating parameters are adjusted and the validation test is repeated, or the process validation approach to cleaning control reconsidered.

After initiating routine operations, the canister cleaning is periodically verified to confirm that the cleaning criterion is being satisfied. The verification period will be selected by dividing the fuel into process lots. The validation test will be performed on a canister at the beginning and end of each lot. The size of a fuel lot is selected based on operational considerations (e.g., past experience, and implications of responding to an observed cleaning failure). If an individual assembly from the canister in this periodic confirmation test is determined to fail the cleaning requirements, cleaning performance confirmation actions must be initiated.

\subsubsection{Particulate Accumulation}

Sloughter (1999b) describes the basis for assuring thermal stability of the knockout pot during particulate accumulation from fuel cleaning operations. (The determination of mass accumulation in knockout pots will not be required for future knockout pots after the proposed addition of copper dividers for enhanced heat removal.) Sloughter (1999b) identifies $350 \mathrm{~kg}$ as an acceptable mass limit that assures thermal stability for metal mass fractions up to $95 \%$. However, since the Safety Analysis Report (SAR) identifies $200 \mathrm{~kg}$ as a bounding value for particulate mass in a knockout pot, this more conservative value will be used. Further, a limit of underwater weight of accumulated mass of $126 \mathrm{~kg}_{\mathrm{f}}$ will be used to allow for a conservative density of $2.7 \mathrm{~g} / \mathrm{cc}$ in the particulate (Sloughter 1999). 
Underwater weight $=200 \mathrm{~kg}(1-1 / 2.7) \mathrm{kg}_{f} / \mathrm{kg}_{\mathrm{m}}=126 \mathrm{~kg}_{\mathrm{f}}$ or $277 \mathrm{lb}_{\mathrm{f}}$

\subsubsection{Scrap Basket Loading}

A $10 \%$ total uncertainty in achieving the bounding scrap basket surface area was allowed in the loading criteria for scrap piece size classification activities. The surface area estimate developed in Ball and Duncan (1998) is based on a probability analysis that predicts $99.9 \%$ of the bounding scrap basket reactive area distribution lies between $40,000 \mathrm{~cm}^{2}$ and $49,000 \mathrm{~cm}^{2}$ with a mean of $45,300 \mathrm{~cm}^{2}$. Therefore, a $10 \%$ uncertainty in achieving the mean bounding surface area is within the range predicted by the probability analysis.

\subsubsection{Coarse Scrap Basket Sector Loading}

Scrap loading by the FRS must minimize the loading of scrap with maximum dimension smaller than 1 inch in coarse scrap basket sectors to produce loadings consistent with analysis of the bounding reacting surface area developed in Ball and Duncan (1998). The only limitation imposed on loading scrap pieces larger than 1 inch is that the scrap is physically placed within spaces formed by the scrap basket walls and the total scrap mass does not exceed criticality limits. This produces coarse scrap sector loadings consistent with the bounding reacting surface area developed in Ball and Duncan (1998). The procedure described in Section 3.1.2.1, with manipulator loading of pieces larger than 3 inches and sizing of pieces less than 3 inches, provides a conservative method of ensuring that the quantity of scrap smaller than $1 \mathrm{inch}$ in coarse sectors does not significantly impact the bounding surface area.

A total uncertainty of $10 \%$ is allowed in achieving the bounding surface area within coarse sectors of a scrap basket to accommodate potential events that could result in loading some scrap pieces smaller than 1 inch in coarse sectors. The uncertainty allowance for coarse scrap was partitioned to address two factors that may result in loading fuel pieces smaller than 1 inch in a coarse scrap sector:

- scrap sizing device inefficiency, and

- breakage of large scrap pieces when dropped into the coarse sector.

To achieve a total coarse sector fuel surface area that is within $10 \%$ of the bounding surface area, each of these factors is required to result in fuel loadings that are within $5 \%$ of the bounding surface area. Therefore, the coarse scrap sizing device is required to produce material such that the surface area of fuel pieces with maximum dimension less than 1 inch do not add more than $5 \%$ of the bounding surface area to the coarse sectors of the scrap basket. 
Heat transfer analyses of MCO drying utilize the scrap surface area per unit volume occupied by scrap as a basic input parameter. The bounding surface area of a scrap basket is achieved when the scrap basket is full. However, heat loss primarily occurs radially from the MCO. The radial heat loss path results in similar scrap basket thermal gradients when the basket sector is partially, or entirely filled with scrap. Since partial scrap basket loadings may be encountered during processing, the coarse scrap sizing requirement must be applied using a basis of scrap surface area per unit volume occupied by the scrap.

The implications of coarse scrap breakage is considered based on the description of a bounding scrap inventory shown in Table 4-1 for an Mk IV scrap basket (Ball and Duncan 1998). The Mk IV scrap basket capacity bounds the Mk 1A scrap basket capacity.

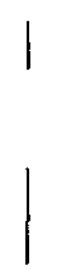

\section{Table 4-1. Bounding Scrap Description}

\begin{tabular}{|l|c|}
\hline & Bounding Scrap Basket \\
\hline Uranium Geometric Area, $\mathrm{cm}^{2}$ & \\
& \\
Coarse Scrap & 25,400 \\
Fine Scrap & 19,900 \\
Total Scrap & 45,300 \\
\hline Piece Count Characterization & \\
& \\
Total Equivalent Assemblies & 36.6 \\
Number of Intact Inners & 28.2 \\
Number of Coarse Scrap Pieces & 834 \\
Number of Fine Scrap Pieces & 1683 \\
\hline Total Fuel Mass, kg & 980 \\
\hline
\end{tabular}

The implication of coarse scrap breakage during handling is evaluated assuming minor breakage results in splitting off a small fuel piece when each scrap piece is dropped in a scrap basket. If this is characterized as a $1 / 4$ inch $(0.635 \mathrm{~cm})$ diameter sphere, the additional fuel area added to a scrap basket coarse sector is approximately $1.27 \mathrm{~cm}^{2} /$ scrap piece $\left(A=\pi 0.635^{2}\right)$. Based on the bounding scrap basket coarse scrap description in Table 4-1, this type of breakage would increase the coarse scrap surface area by approximately $1,060 \mathrm{~cm}^{2}(834 \times 1.27)$, which is an increase of approximately $4 \%$. The same surface area impact would be observed for more pieces of smaller diameter broken off (e.g., the same surface area increase would be observed if four 1/8 inch diameter pieces per scrap piece break off a coarse scrap piece during loading). This surface area increasc estimate is within the $5 \%$ requirement allowed for coarse scrap breakage. It should also be noted that, since the estimate is evaluated on a per scrap piece basis, it is equivalent to the area increase per unit volume occupied by scrap.

Physically breaking each piece in half when picking up coarse scrap with the manipulator cannot be shown to be bounded by the current surface area calculation. This could be characterized as creating a $1 / 2$ inch diameter scrap piece when handling each coarse scrap piece, which would be estimated to increase the coarse scrap surface area by $4,200 \mathrm{~cm}^{2}$, or $17 \%$. Therefore, if the manipulator physically breaks the coarse scrap when it is picked up, the pieces must be dropped and each piece re-evaluated as coarse scrap. 


\subsubsection{Fine Scrap Basket Sector Loading}

Scrap sized from $1 / 4$ inch to 1 inch is to be loaded only in the fine scrap region of the basket to produce loadings consistent with the bounding reacting surface area developed in Ball and Duncan (1998). Limiting the total scrap basket surface area ensures that the safety margin estimated in thermal calculations for subsequent process steps are maintained during operations. The fines sector fuel surface area is limited by the volume of the basket which can be loaded with small scrap pieces and size segregation of fuel pieces. The total scrap basket volume used for small scrap loading has been limited by creation of a separate basket sector for fine scrap that limits the maximum distance between small scrap pieces and a highly conductive fin in the scrap basket.

A total uncertainty of $10 \%$ is allowed in achieving the bounding surface area within the scrap basket fines sector to accommodate the potential for loading some fuel pieces smaller than $1 / 4$ inch within the fines sector. This represents the required efficiency of the fine scrap sizing device. The heat transfer path discussion described above for coarse sectors also applies to the fine sector. Therefore, the fines sizing devices is required to produce material such that the surface area of fuel pieces with maximum dimension less than $1 / 4$ inch do not add more than $10 \%$ of the bounding surface area to the fines sector of a scrap basket using a basis of surface area per unit volume occupied by scrap.

Loading material larger than 1 inch in a fines sector does not increase fuel surface area (shown below). Therefore, loading of fuel pieces with maximum dimension larger than 1 inch in a fines sector is constrained only by the physical dimensions of the scrap basket.

The impact of loading larger scrap pieces in a fines sector on surface area can be estimated by assuming scrap pieces are represented by spheres. The fines sector area is evaluated in Ball and Duncan (1998) by modeling the fines sector as a porous bed of solids with fixed total volume. The number of fuel pieces in a fines sector that fill the fixed volume is estimated as follows:

$$
\mathrm{V}=\frac{\mathrm{N} \mathrm{v}}{(1-\phi)}
$$

where: $\mathrm{V}=$ basket fines sector volume, $\mathrm{cm}^{3}$

$\mathrm{N}=$ number of fuel fine pieces loaded in the fines sector

$\mathrm{v}=$ volume of an individual fuel piece, $\mathrm{cm}^{3}$

$\phi=$ void fraction of porous bed formed by the fuel pieces

Assuming spherical particles, the number of fuel pieces in the fines sector becomes,

$$
\mathrm{N}=\frac{\mathrm{V}(1-\phi)}{\mathrm{V}}=\frac{\mathrm{V}(1-\phi)}{\frac{\pi}{6} \mathrm{D}^{3}}
$$

where: $\mathrm{D}=$ the equivalent fuel piece diameter, $\mathrm{cm}$ 
For a bed of fixed total volume, with the bed void fraction approximately constant, the number of fuel pieces changes with the equivalent diameter.

$$
\frac{N_{2}}{N_{1}}=\left(\frac{D_{1}}{D_{2}}\right)^{3}
$$

The total area of fuel pieces is also based on the number of fuel pieces and estimated assuming spherical particles.

$$
A=N \pi D^{2}
$$

where: $\mathrm{A}=$ total area of fuel pieces in the basket fines sector, $\mathrm{cm}^{2}$

Therefore, the change in total area with a change in fuel size is,

$$
\frac{A_{2}}{A_{1}}=\frac{N_{2} D_{2}^{2}}{N_{1} D_{1}^{2}}=\left(\frac{D_{1}}{D_{2}}\right)^{3}\left(\frac{D_{2}}{D_{1}}\right)^{2}=\frac{D_{1}}{D_{2}}
$$

or

$$
A_{2}=\frac{D_{1}}{D_{2}} A_{1}
$$

This indicates that the fuel area in a fines sector decreases as the particle equivalent diameter is increased and results from a decrease in the number of fuel pieces that fit in the fixed volume of basket fines sector. Therefore, there is no limit on the number of fuel pieces with maximum dimension larger than 1 inch loaded in the scrap basket fines sector. Limiting the loading of fuel pieces larger than 1 inch becomes an operational consideration that is practically limited by the size of fuel that can physically fit in the scrap basket fines sector and the need to reserve space in the scrap basket for material unsuitable for loading in coarse sectors. While dependent on the actual geometry of the fuel pieces, physical dimensions limit the maximum size of material placed in the fines sector to cross section dimensions of approximately 1.125 inch to 1.378 inch for the Mk 1A scrap basket and 2.08 inch to 2.18 inch for the Mk IV scrap basket.

\subsubsection{Fuel Basket Loading}

Fuel baskets are designed to produce an array of fuel assemblies standing on end when loaded in the MCO. All safety analyses and designs have been completed based on fuel basket arrays containing a maximum of 54 intact Mk IV fuel assemblies in the Mk IV fuel basket and 48 intact Mk $1 \mathrm{~A}$ fuel assemblies in the Mk $1 \mathrm{~A}$ fuel basket. These values represent bounds on the number of assemblies that can be loaded in a particular basket type. Criticality analyses have been performed to show that partial basket loadings (including empty positions and/or loading lone outer or inner elements in assembly positions) can be accepted in both Mk IV and Mk $1 \mathrm{~A}$ fuel baskets (Lorenz, et al. 1999). Therefore, only the maximum assembly count represents a constraint on fuel basket loading. 
Bounding surface area calculations for a fuel basket are based on loading material with the geometry of intact fuel assemblies, or stacked fuel pieces to form a stack of similar dimension to an assembly. The bounding surface area allocation in a fuel basket of $7,900 \mathrm{~cm}^{2}$, based on the equivalent of 20 assemblies composed of 3 inch long outer element segments stacked over an intact inner elements and 20 assemblies composed of 3 inch long inner element segments stacked inside intact outer elements. The bounding surface area assumption allows the fuel basket to be composed essentially of stacked fuel pieces. However, the fuel element piece geometry must be of a cylindrical shape to conform with the surface area calculation. Therefore, elements and element segments loaded in the fuel basket must contain an intact circular cross-section for a portion of the element length.

Due to the conservatism of the bounding fuel basket surface area assumptions (40 of 54 assemblies contain stacked 3 inch pieces), no constraint is placed on the number of elements that can be loaded in the fuel basket as stacked segments. However, the length of stacked segments cannot exceed the length of intact elements associated with the segment stack. The 3 -inch element segment is used as a guide for fuel basket loading that is consistent with fuel basket surface area calculations.

Some breakage of fuel pieces could occur after loading. This can only occur if fractures already exist in a loaded fuel element. Fracture surfaces are already available to react with water. Therefore, fuel breakage after loading would not change the effective reacting surface area of a fuel basket and would still be within the conservative assumption for bounding surface area.

The MCO fuel basket design is based on positioning fuel assemblies on end in sockets formed in the basket bottom plate. This orientation facilitates efficient packing of assemblies in baskets and promotes water drainage from the center and annular void region of each assembly. In addition, fuel drying during helium flow conditions is promoted by the alignment of assembly void regions with openings in the positioning socket. The positioning sockets also provide a guide for limiting the number of assemblies loaded in a fuel basket and ensure that seated fuel assemblies are properly loaded within the basket cavity (ends do not extend above the basket supports).

Loading fuel material between assemblies is to be precluded based on operational considerations. Fuel pieces wedged between elements can potentially splay out the top ends of assemblies. This configuration could make it difficult to remove a fuel basket from a storage queue position or MCO (basket removal from an MCO may be required during basket loading if a basket does not seat properly). The FRS will load fuel such as not to preclude normal loading of baskets into the MCO. 


\subsubsection{Organic Material Loading}

Appendix A provides an assessment of the potential effects of organic materials on MCO interim storage. Epoxy resin is used as a model of organics potentially loaded in an MCO. While epoxy resin was generally found to be stable at total integrated doses for materials in an MCO stored for 40 years, the assessment assumes complete decomposition of the organic material. The assessment concludes that organic material loadings of less than $450 \mathrm{~g}$ would not significantly impact the pressure and gas composition characteristics of an $\mathrm{MCO}$ during interim storage.

An identification number will be indicated on each $\mathrm{MCO}$ basket using an enamel paint. The markings are projected to cover approximately $3 \mathrm{in}^{2}, 5$ mils thick. Assuming a maximum MCO loading of six baskets and organic density of $1.5 \mathrm{~g} / \mathrm{cm}^{3}$, marking will add the following quantity of organics to an MCO.

$$
(6 \text { baskets } / \mathrm{MCO})\left(3 \mathrm{in}^{2} \times 0.005 \mathrm{in} / \mathrm{basket}\right)(2.54 \mathrm{~cm} / \mathrm{in})^{3}\left(1.5 \mathrm{~g} / \mathrm{cm}^{3}\right)=2.2 \mathrm{~g} / \mathrm{MCO}
$$

Therefore, identification markings will not significantly impact the organic inventory of an MCO.

An MCO containing $450 \mathrm{~g}$ of organic material at an assumed density of $1.5 \mathrm{~g} / \mathrm{cm}^{3}$ would contain $300 \mathrm{~cm}^{3}$ of organic pieces. Small pieces of organic material will be the most difficult material to visually separate from fuel. This material would be loaded in the fines sector of a scrap basket. Assuming two scrap baskets are allowed per MCO and a loading void fraction of $40 \%$, an MCO could approach the $450 \mathrm{~g}$ limit for organics if scrap baskets contained $250 \mathrm{~cm}^{3}$ interspersed with fuel fragments.

$$
\frac{150 \mathrm{~cm}^{3}}{(1-0.4)}=250 \mathrm{~cm}^{3}
$$

The scrap basket fines sector total capacity is approximately $17,000 \mathrm{~cm}^{3}$. Organic material must represent approximately $1.5 \%$ of the total volume of material added to each scrap basket fines sector for an MCO, containing two scrap baskets, to approach an organic loading of $450 \mathrm{~g}$. Visual segregation of organic material with the manipulator is considered sufficient to assure the organic loading limit is achieved.

\subsubsection{Fuel and Scrap Basket Queuing}

Cleaned fuel in baskets queued underwater for loading in an MCO will continue to react with basin water and generate additional particulate. The bounding particulate inventory in an MCO allows for $11.9 \mathrm{~kg}$ of corrosion products $\left(\mathrm{as}^{\mathrm{U}} \mathrm{O}_{2}\right.$ ) to be generated during basket queuing in the basin (Sherrell 1999). Conservative guidelines for the queuing time limit, varying with MCO basket loading and basin water temperature, are shown in Appendix B. 
The start of basket queuing time is defined as the earliest time that material loaded in a basket has completed rotating in the cleaning machine. This provides a conservative estimate of the start time for all material placed in a particular basket. The end of queuing is defined as the time when the void space of a loaded MCO/cask is purged with helium, establishing the initial conditions of the shipping window. The analysis in Sherrell (1999) addresses particulate generated after the basket is loaded in an MCO as part of other processing activities.

Particulate generation during basket queue storage is a small contributor to the MCO hydration water inventory due to the slow rate of hydrating uranium corrosion products at basin storage temperatures. Experimental data presented by Duncan and Plys (1998) indicate approximately 10 mole $\%$ of a $\mathrm{UO}_{2}$ corrosion product would be converted to a hydrate if stored for 30 days at $60^{\circ} \mathrm{C}$ in $80 \%$ humidity air. Storage underwater at basin temperatures is not projected to significantly impact the bounding particulate or water inventory of an MCO.

\subsection{MCO LOAding SYSTEM}

The MCO Loading System will take the loaded fuel and scrap baskets from the basket queue and load them into MCOs.

\subsubsection{Number of Baskets of Scrap}

The bounding surface area analysis in Ball and Duncan (1998) and thermal analyses of subsequent process steps limits the MCO loading to two scrap baskets.

\subsubsection{Position of Basket of Scrap}

Criticality analyses (Kessler 1999) are based on loading configurations where scrap baskets are located in either the top, the bottom, or in both positions of an MCO. Thermal analyses of process steps are documented in Plys and Duncan (1998a) based on configurations where scrap baskets are located in either the top, or top and bottom positions of an MCO. Undocumented thermal analyses have been performed for an MCO containing only a scrap basket in the bottom position. However, until these thermal analyses are formally released, the allowed scrap basket configurations are limited to either the top, or top and bottom positions of an MCO.

\subsubsection{MCO Seal}

A seal leak will prevent completion of the CVD process or MCO leak check at CVD and could lead to returning the MCO to K Basins to establish the seal. Basket loading procedures include the use of a guide to minimize the potential for particulate accumulations on MCO sealing surfaces. Prior to shield plug installation, a cleaning step is performed on the collar sealing surface to further reduce the potential for observing an inadequate seal. 


\subsubsection{MCO Water Fill Level}

The MCO minimum void space volumes are established by the equipment design. The MCO is filled with water during loading activities and remains filled with water during transport from the $\mathrm{K}$ Basins to the CVD Facility in the $100 \mathrm{~K}$ Area. The water in the MCO is slightly contaminated water from the K Basins. The water level inside the $\mathrm{MCO}$ is to be approximately $8.3 \mathrm{~cm}$ ( 3.25 inches) below the bottom of the shield plug main body to provide a void volume of approximately $0.60 \mathrm{ft}^{3}$, consistent with transport window calculations in Smith $(2000)$. The shield plug design (chamber protecting the high efficiency particulate air [HEPA] filters) produces the required MCO water fill level. The MCO is vented through a HEPA filter to the cask cavity during this transfer to provide a larger volume for the gas generated from corrosion (Smith 2000).

\subsection{Cask LoAding ANd Transport System}

The package loaded on a semi-trailer for transport to the CVD Facility consists of the loaded and vented MCO inside of a sealed cask. During the package preparation, air in the void space at the top of the $\mathrm{MCO}$ and cask must be replaced by inert gas to preclude developing of a flammable gas mixture. Furthermore, the shipping window is based on the generation rate of gases such as hydrogen to preclude over pressurization of the cask.

\subsubsection{MCO/Cask Package Backfill}

\subsubsection{Added Gas}

Helium was selected as the MCO/cask inerting gas consistent with the gas used throughout the CVD process. The helium introduced into the $\mathrm{MCO}$ is expected to be maintained at least $99.5 \%$ pure, which takes into account impurities added to the system during supply change-over, $\mathrm{MCO}$ connection operations, or maintenance activities. Sherrell and Pajunen (1999) identifies the types and quantities of impurities that may be present within helium that is introduced into the MCO by the CVD process and assesses their impacts on the entire SNF process.

\subsubsection{Package Void Space Gas Composition}

The uranium fuel will react with water in the $\mathrm{MCO}$ to generate hydrogen during transport to the CVD Facility. The MCO cover gas needs to be inert to prevent the accumulation of flammable mixtures of hydrogen and oxygen from forming while the MCO is in transport between the K Basins and the CVD Facility. Flammable gas mixtures of helium, hydrogen, and oxygen are precluded by reducing the void space oxygen concentration to less than 4 vol\%. A maximum oxygen of $1.6 \mathrm{vol} \%$ is established in Cooley and Hagmann (1999) to comply with National Fire Protection Association standards in shipping and receiving areas. This provides an oxygen concentration consistent with the gas composition requirements specified by the Safety Analysis Report for Packaging (SARP) (Smith 2000). As hydrogen accumulates in the cask void space, the initial oxygen concentration decreases and the gas mixture remains in a non-flammable regime. 
HNF-SD-SNF-OCD-001, Rev. 5

The SNF is to be transferred from the K Basins to the CVD Facility in a flooded condition. This means that water will be present in the MCO and cask to within $8.3 \mathrm{~cm}$ (3.25 inches) of the bottom of the MCO shield plug main body. Furthermore, the MCO is vented to the void space at the top of the cask during transfer. This combined MCO and cask void space will be filled with helium to ensure that accumulation of flammable gas concentrations will be precluded during shipment and receiving (Smith 2000, Cooley and Hagmann 1999).

Pajunen (2000) provide calculations determining the gas composition of the two void spaces during pressurization and purge cycles. While many combinations can be used to achieve 1.6 vol\% oxygen in the void volume, the calculation indicates that both the $\mathrm{MCO}$ and cask void volumes will be less than 1.6 vol\% after pressurizing to $\geq 27 \mathrm{psig}$ and purging to $\leq 3 \mathrm{psig}, 5$ times. A minimum pressure of 1 psig is specified for the purge cycle to prevent air in-leakage during the pressure/purge cycles.

\subsubsection{MCO Cask Package Pressure}

During the flooded transfer conditions from the K Basins to the CVD Facility, the MCO and cask cavities are backfilled with helium gas that is relatively oxygen free to a pressure sufficient to ensure that any leakage would be from the package to the environment while keeping the initial pressure low to allow for additional pressurization due to hydrogen gas generation (Smith 2000). A pressure of $5 \pm 3$ psig is specified in Smith (2000).

\subsubsection{Cask Water Fill Level}

The SARP analysis of pressurization rates during transportation activities are based on a void space volume of $0.48 \mathrm{ft}^{3}$, which is established by the equipment design (Smith, 2000). The cavity between the $\mathrm{MCO}$ and the $\mathrm{MCO}$ cask is filled with water during transportation from the $\mathrm{K}$ Basins to the CVD Facility in the $100 \mathrm{~K}$ Area. The water in the cask cavity is fresh demineralized water. The water level in the cask cavity is approximately the same as the water level in the MCO. The MCO is vented through a HEPA filter to the cask cavity during this transfer to provide a larger volume for the gas generated from corrosion (Smith 2000).

\subsubsection{Cask Temperature}

A temperature limit is imposed on the cask temperature to provide consistency with heat transfer calculations that form the basis for the transport time limit between the basin and the CVD Facility. The SARP (Smith 2000) general requirements limit the average basin water temperature prior to transport to less than or equal to $18^{\circ} \mathrm{C}$ for an $\mathrm{MCO}$ with 2 scrap baskets, or $21^{\circ} \mathrm{C}$ for 1 scrap basket, or $23^{\circ} \mathrm{C}$ for zero scrap baskets prior to insertion of the shield plug. This initial temperature allows a 24 hour shipping window, as indicated in Section 4.3.5, while maintaining an 8 hour margin between the shipping window time limit and the time that the cask 1 pressure is predicted to reach 150 psig. 
Appendix D indicates that immersion of a hot cask in the basin water for eight hours would produce an initial cask temperature within $1^{\circ} \mathrm{F}$ of the basin water. Operating experience to date indicates the operating steps to immerse cask and load baskets exceeds eight hours. Therefore, the operating time cycles result in initial cask temperatures essentially equivalent to basin water temperature.

\subsubsection{Time Limit for K Basins to CVD Facility Transfer}

The SARP (Smith 2000) limits the transfer time between the K Basins and the CVD Facility to 24 hours. Thermal analyses indicate that the temperature of $\mathrm{MCO}$ contents begin to increase upon insertion of the shield plug. Therefore, the transfer shipping window must be initiated within 12 hours of MCO shield plug insertion for consistency with the SARP thermal analysis. Alternatively, the shipping window is initiated upon establishing the void space pressure at the completion of the MCO cask helium purge. To satisfy these alternative analysis assumption, the shipping window starts upon completion of the helium purge or 12 hours after shield plug insertion, which ever is sooner. Mitigation actions specified in Smith (2000) must be implemented if transfer times exceed this limit.

\subsection{Cold Vacuem Drying}

The CVD Facility removes free water from the MCO, allowing transport to the CSB and storage there for up to 40 years. The CVD criteria bases, applicable to the MCO, represent the characteristics of the facility product after drying is complete.

\subsubsection{MCO Free Water Inventory}

The inventory of free water in an MCO after drying $(200 \mathrm{~g})$ has been allocated based on the feasibility of identifying tests or procedures that confirm compliance with the specified limit (Pajunen 1998a). This allocation has been used as the basis for evaluating MCO pressurization and gas compositions during storage. Therefore, any future modification of this limit requires reanalysis of the stored MCO pressure and gas composition (see Plys and Duncan 1998b). Section 4.6.3.3.7 describes the overall basis for allocating water to different constituents that may exist in an MCO during storage.

\subsubsection{MCO Backfill Gas}

\subsubsection{Added Gas}

Helium is to be used as the MCO backfill gas based on thermal property performance. Heard (1996) compared MCO fuel temperatures during final storage in the CSB assuming helium, nitrogen, and argon as the backfill gas. Helium significantly reduced the peak fuel temperature. Subsequent thermal analyses (Plys and Duncan 1998a), which assume a helium backfill gas, have been used as the basis for gas temperature defining the molar gas inventory during storage (see Section 4.6.3.2). Therefore, helium must be used as a backfill gas for this analysis to be applicable. 
Helium will be the only inert gas utilized at the CVD Facility and will be controlled to Office of Civilian Radioactive Waste Management (OCRWM) requirements per Irwin (1999). Sherrell and Pajunen (1999) evaluates the impact of helium impurities on gas thermal properties, particulate generation, heat generation, and hydrogen generation during CVD operation. This analysis concludes that a gas composition of $99.5 \%$ helium added to the MCO will support process safety and design assumptions.

\subsubsection{MCO Void Gas Composition}

The MCO void space gas composition oxygen content must be less than $1.6 \%$ to satisfy transportation criteria specified in Smith (2000).

Hydrogen can be generated in a stored MCO after drying by residual water radiolysis or corrosion of uranium metal. Therefore, control of the MCO void space oxygen concentration was selected to preclude development of a flammable gas mixture in an MCO. Analyses of the MCO internal gas composition, investigating the transient oxygen composition of gas in an MCO over a range of characteristics are performed Plys and Duncan (1998b). This analysis, demonstrating that formation of a flammable gas mixture is precluded over the 40 year storage period in the CSB, is based on an initial backfill gas that is essentially pure helium. Sherrell and Pajunen (1999) determined that an initial backfill gas composition of $99.5 \%$ helium would not impact the results and conclusions of Plys and Duncan (1998b). Therefore, the MCO void space gas composition is specified as greater than or equal to $99.5 \%$ helium.

\subsubsection{MCO Void Gas Temperature}

The MCO temperature during backfill operation impacts the molar quantity of added gas. The basis for maximum pressure during storage assumes backfill gas quantities are specified at $0^{\circ} \mathrm{C}$. Backfilling the $\mathrm{MCO}$ at a lower temperature, to the same backfill pressure range, would result in adding a molar quantity of gas that exceeds the contribution allocated in Table 4-2. Therefore, the backfill gas temperature must be greater than or equal to $0^{\circ} \mathrm{C}$ when measuring the backfill pressure.

The maximum backfill gas temperature impacts the minimum molar quantity of helium added to an MCO. The $\mathrm{MCO}$ gas temperature of $50^{\circ} \mathrm{C}$ at the minimum backfill pressure specified in Section 4.4.2.4 results in a minimum helium inventory consistent with that used to evaluate leak I rate criteria in Sherrell (2000). 
HNF-SD-SNF-OCD-001, Rev. 5

\subsubsection{MCO Void Gas Pressure}

The MCO void gas backfill pressure after drying is based on establishing a positive internal gas pressure within the MCO with respect to atmospheric conditions to preclude air in leakage during transport and storage. A minimum backfill pressure of 9.5 psig supports maintaining a positive internal gauge gas pressure at MCO temperatures as low as $-31^{\circ} \mathrm{C}$ (Sherrell 2000 ). The calculations in Sherrell (2000) also demonstrate that the minimum backfill pressure, combined with satisfying the leak rate criterion in Section 4.4.2.4, will maintain a positive gauge pressure in the MCO for over 40 years. The maximum backfill pressure of $11.5 \mathrm{psig}$ is based on the total pressure allocation to backfill gas specified in Section 4.6.3.3.3 of Smith (2000).

\subsubsection{MCO Integrated Leakage Rate}

Goldmann (2000) specifies a total integrated helium leak test criterion of $1 \times 10^{-5} \mathrm{std} \mathrm{cm}^{3} / \mathrm{sec}$ for mechanically sealed MCOs. This gaseous leakage rate is based on a clean seal and a clean sealing surface at the final mechanical closure boundary. The mechanical seal leakage rate is evaluated in Sherrell (2000) based on a total reference air integrated leak rate of $1 \times 10^{-5} \mathrm{std} \mathrm{cm} / \mathrm{sec}$ air as measured per ANSI N14.5-1987. The leak rate criterion is defined as $1 \times 10^{-5} \mathrm{~cm}^{3} / \mathrm{sec}$ of dry air, corrected to an absolute pressure of $1 \mathrm{~atm}$ and $25^{\circ} \mathrm{C}$, that will flow through a leak path from an upstream cavity with absolute pressure of 1 atm into a downstream cavity that has been evacuated to less than or equal to 0.01 atm. The specified leak rate precludes development of flammable gas mixtures during transport and CSB storage prior to seal welding, as indicated in Section 4.5 and Section 4.6.2.

Flammable gas mixtures are controlled during CVD processing by CVD systems. Therefore, this leakage rate criterion does not apply during processing in the CVD Facility. During transport, the cask provides the containment for the MCO.

\subsubsection{Cask Backfill}

\subsubsection{Cask Void Gas Composition}

Based on a sealed $\mathrm{MCO}$, air provides a suitable environment for the $\mathrm{MCO}$ during transport and storage. The annulus region (between cask and $\mathrm{MCO}$ ) is used for controlled heating and cooling with tempered water during processing at the CVD Facility. The annular region is dried prior to transporting an MCO to the CSB. The dew point of a 0.5 vol\% water vapor-gas mixture is approximately $-2^{\circ} \mathrm{C}$. Smith $(2000)$ evaluates minimum component temperatures for a normal 14 hour transfer assuming no solar, radiolytic or chemical heat during worst case low environment temperatures of $-33^{\circ} \mathrm{C}\left(-27^{\circ} \mathrm{F}\right)$. Under these conditions, the MCO exterior and cask interior surface temperatures range from $-2^{\circ} \mathrm{C}$ to $44^{\circ} \mathrm{C}$. Therefore, limiting the water vapor content of the annular space to less than 0.5 vol\% precludes the presence of liquid water on the $\mathrm{MCO}$ exterior and cask internal surfaces if the cask temperature does not decrease below $-2^{\circ} \mathrm{C}$ $\left(28^{\circ} \mathrm{F}\right)$ during transport. 


\subsubsection{Cask Void Gas Temperature}

No special considerations are associated with the molar quantity of air in a cask prior to shipping. Therefore, ambient temperature is specified for the cask backfill temperature.

\subsubsection{Cask Void Gas Pressure}

No special considerations are associated with the molar quantity of air in a cask prior to shipping. Therefore, ambient pressure is specified for the cask backfill pressure.

\subsubsection{Cask Shipping Temperature}

Thermal analyses indicate that the cask lid temperature on receipt at the CSB, after a normal transfer time period under hot day conditions, will be bounded at $40^{\circ} \mathrm{C}\left(104^{\circ} \mathrm{F}\right)$ for an initial shipping temperature of $25^{\circ} \mathrm{C}\left(77^{\circ} \mathrm{F}\right)$ [refer to Figure B8-16 of Smith (2000)]. This temperature is considered low enough for operator handling activities in the CSB receiving area and represents the basis for specifying a cask temperature of less than $25^{\circ} \mathrm{C}$ prior to shipping. Actual cask lid temperatures are dependent on the transport time period and may exceed $40^{\circ} \mathrm{C}$ if the transport were delayed on the road for an extended time period.

\subsubsection{Halogenated and/or Organic Compounds}

Goldmann (2000) describes the corrosion conditions used as a basis for design of the MCO. When flooded with water, the MCO design corrosion considerations are based on water with chloride ion concentrations less than $1 \mathrm{ppm}$ and fluoride ion concentrations less than $0.25 \mathrm{ppm}$. Once drained, the MCO design corrosion considerations are based on preventing the generation of a moist halide gas within the MCO. Halogenated compounds have the potential to produce a halide gas by radiolysis. Therefore, introduction of halogenated compounds into the MCO must be prevented to comply with design assumptions.

Oils and other organic compounds have the potential to produce complex radiolysis products that are not addressed in the analysis of MCO pressurization and gas composition during storage.

Therefore, the introduction of halogenated or organic compounds into an MCO shall be precluded throughout the life cycle of the MCO as states the OCRWM requirement for the CVD Facility per Irwin (1999).

\subsubsection{Process Water Effluent}

Irwin (1999) describes a PWC system for conditioning water from the MCOs prior to transport out of the facility. Irwin (1999), Appendix D, lists the low specific activity radionuclide concentrations allowing conditioned water transport. The PWC will also be operated to ensure that no transuranic (TRU) waste materials are produce (Irwin 1999). 


\subsection{Cask Transport From the CVD Facility to the CSB}

Upon completion of CVD, the MCO and cask are prepared for transport to the CSB. Smith (2000) evaluates hydrogen leakage from an MCO, assuming the MCO mechanical seal leak rate

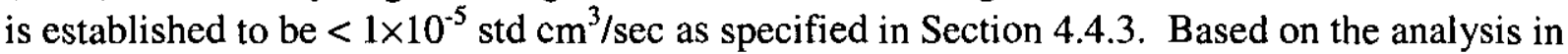
Smith (2000), the most restrictive time limit ( $<135$ days) results from the requirement to maintain the cask void gas hydrogen concentration around a bounding MCO below $1 \mathrm{vol} \%$. Mitigation actions must be implemented if transfer times exceed 135 days.

The transport time start is defined as when water is drained from the cask, since this creates a thermal configuration similar to the transport analysis initial conditions. The transport window end point is based on the point where hydrogen can no longer accumulate in the cask (lid removed).

\subsection{Canister Storage Building Systems}

After arrival at the CSB (and possibly some amount of lag storage time), the MCOs are to be welded for long term storage. Process requirements to be imposed on the final package closure are specified in this section.

\subsubsection{Mechanically Sealed MCO Storage at the CSB}

The mechanically sealed MCO storage time limit is based on:

- maintaining a positive pressure in the $\mathrm{MCO}$ while in a CSB storage tube that contains an air atmosphere, and

- precluding hydrogen concentrations above $1 \mathrm{vol} \%$ within any vented CSB storage tube containing up to two mechanically sealed MCOs.

| The positive pressure precludes oxygen leakage into the MCO. Sherrell (2000) evaluates helium leak rates from an MCO assuming the MCO mechanical seal has satisfied the $1 \times 10^{-5} \mathrm{std} \mathrm{cm}^{3} / \mathrm{sec}$ leak test acceptance criterion, as specified in Section 4.4.3. Based on the analysis in Sherrell

(2000) and the minimum helium backfill addition specified in Section 4.4.2.4, a positive pressure is maintained in mechanically sealed MCOs for over 40 years without replenishing the helium

I gas. Sherrell (2000) also indicates that two mechanically sealed MCOs may be stored indefinitely in a CSB storage tube, that is continuously vented to the atmosphere, without exceeding a steady state hydrogen concentration of $1 \mathrm{vol} \%$. Therefore, the time limit for storing mechanically sealed MCOs in a vented storage tube is greater than 40 years.

The analysis in Sherrell (2000) also evaluates a sealed CSB storage tube. Based on the sealed storage tube analysis, the storage tube hydrogen concentration would exceed 1 vol\% after 3.4 years if the tube contained one MCO. The time to reach 1 vol\% hydrogen in the sealed storage tube is reduced to 10 months if the tube contains two MCOs. 
The mechanically sealed MCO design pressure is $150 \mathrm{psig}$, while the design pressure after installation of a welded cover cap increases to $450 \mathrm{psig}$ (Goldmann 2000). Plys and Duncan (1998b) indicates that a maximum internal MCO pressure of $61.7 \mathrm{psig}$ is anticipated over a 40 year storage time period, based on a transient analysis of radiolytic gas generation, fuel corrosion, dehydration of fuel corrosion products, and oxygen gettering. Therefore, while the mechanically sealed MCO is suitable for containing the projected pressure buildup, the welded cover cap provides a significant increase in the safety margin between the anticipated internal pressure and the $\mathrm{MCO}$ design pressure.

The time limit for storage of a mechanically sealed MCO in the CSB becomes a judgment on when the increased safety margin is required. The transient calculations in Plys and Duncan (1998b) indicate that $70 \%$ of the maximum pressure for a worst case MCO occurs 10 years after the start of storage in the CSB. Therefore, a maximum time of 10 years was selected for mechanically sealed MCOs based on increasing the design pressure safety margin for the interim storage time when an $\mathrm{MCO}$ is projected to approach the maximum pressure.

\subsubsection{MCO Leakage Rate After Welded Cover Cap Installation}

The MCO, when sealed by welding at the CSB weld station, shall be capable of meeting a maximum total integrated leak test acceptance criterion of $1 \times 10^{-7} \mathrm{std} \mathrm{cm}^{3} / \mathrm{sec}$ (Goldmann 2000). | Flammable gas management evaluations in Sherrell (2000) indicate that multiple ("dozens") weld penetrations, each with a leakage rate of $1 \times 10^{-7} \mathrm{std} \mathrm{cm}^{3} / \mathrm{sec}$ as measured per ANSI N14.5-1987, can be accepted while maintaining control of the flammable gas concentrations in a storage tube. Individual $\mathrm{MCO}$ components are tested against the leakage rate specifications of $1 \times 10^{-7} \mathrm{std} \mathrm{cm} / \mathrm{sec}$. Therefore, a composite package leak rate of less than $4 \times 10^{-7} \mathrm{std} \mathrm{\textrm {cm } ^ { 3 }} / \mathrm{sec}$ is specified based on each of the following components satisfying the leak rate test: (1) MCO shell assembly, (2) MCO cover cap assembly, (3) test plug assembly, and (4) joining seal weld. The leak rate criterion basis is the same as that defined in Section 4.4.3.

\subsubsection{MCO Interim Storage Condition}

\subsubsection{MCO Maximum Internal Design Pressure}

The MCO maximum internal design pressure, with welded cover cap installed, is limited to $450 \mathrm{psig}$, or $465 \mathrm{psia}$ (3.2 Mpa), consistent with the design pressure in Goldmann (2000).

\subsubsection{MCO Wall Temperature}

The CSB design is based on limiting the MCO wall temperature, with bounding heat load, to $270^{\circ} \mathrm{F}\left(132^{\circ} \mathrm{C}\right)$ during storage (Swenson 1996). Plys and Duncan (1998a) found that the bounding $\mathrm{MCO}$ wall temperature $\left(132^{\circ} \mathrm{C}\right)$ is approached when an $\mathrm{MCO}$ remains in the $\mathrm{MCO}$ Handling Machine for 5 days without cooling or ventilation. Simulation of storage in the CSB storage tube predicts a bounding $\mathrm{MCO}$ wall temperature of approximately $108^{\circ} \mathrm{C}$. Therefore, the maximum gas temperature, consistent with CSB storage tube conditions, was estimated to be $125^{\circ} \mathrm{C}$ (Reilly 1998 ). 


\subsubsection{MCO Water and Gas Inventory in MCO}

The total water inventory after drying determines the worst case projected internal pressure within the MCO. The maximum water inventory during storage is derived from a combination of bounding analyses defining the hydration water inventory and the free water removal criteria described in Section 4.4.1. Other identified gas generation mechanisms in an MCO are evaluated, and the sum of gases compared to the total gas inventory defined by the maximum pressure and temperature. The difference between identified sources and total gas limit represents the MCO design conservatism. Table 4-2 summarizes the total gas and contributors identified by other mechanisms. The following sections describe the basis for gas quantities associated with each contributor shown in Table 4-2.

\subsection{Total Gas Limit in MCO}

The limiting molar quantity of gas in an $\mathrm{MCO}$ is based on the maximum allowable gas pressure in the minimum projected $\mathrm{MCO}$ void volume at the maximum projected storage temperature after sealing. The ideal gas law is used to convert these parameters into a limiting molar quantity of gas. Total gas pressure and temperature are based on Sections 4.6.3.1 and 4.6.3.2.

The limiting molar quantity of gas is based on a $500 \mathrm{~L}$ free-gas volume of an MCO loaded with $270 \mathrm{E}$ Length Mk IV fuel assemblies (6.34 MTU of Mk IV fuel). The free volume is based on an MCO internal volume of $953 \mathrm{~L}$ derived from internal dimensions shown on drawing H-2-828041, Rev. 3. Mk IV fuel basket displacement volumes are based on a basket mass of $228 \mathrm{lb}$, as indicated on drawing H-2-828070, Rev. 1, and the density of stainless steel $\left(8 \mathrm{~g} / \mathrm{cm}^{3}\right)$ yielding a displacement volume of $12.9 \mathrm{~L}$ per basket. Fuel assembly displacement volumes for $\mathrm{E}$ length fuel elements are derived from dimensions in Packer (1999) resulting in a displacement volume of $1.47 \mathrm{~L} /$ assembly. These factors result in a minimum free volume estimate of $500 \mathrm{~L}$ (953 - 5×12.9 - 270×1.47): Other fuel loadings, including a scrap basket or variety of MK IA fuel loadings, result in larger calculated void volumes.

Based on the limiting pressure, temperature, and minimum volume, the limiting molar quantity of gas is found as follows.

$$
\text { Gas quantity }=\frac{P V}{R ~ T ~}=\frac{\left(\frac{465 \mathrm{psia}}{14.7 \mathrm{psia} / \mathrm{atm}}\right)(500 \mathrm{~L})}{\left(0.082 \frac{\mathrm{atm}-\mathrm{L}}{\mathrm{gmol}-\mathrm{K}}\right)(273+125 \mathrm{~K})}=485 \mathrm{gmol}
$$


HNF-SD-SNF-OCD-001, Rev. 5

Table 4-2. Allowable Amounts of Gas in the Sealed Multi-Canister Overpack.

\begin{tabular}{|c|c|c|}
\hline Constituent & $\begin{array}{l}\text { Gas in multi-canister } \\
\text { overpack, gmol }\end{array}$ & Explanation \\
\hline Total gas & 485 & $\begin{array}{l}\text { Maximum pressure of } 465 \text { psia ( } 450 \mathrm{psig} \text { ) } \\
\text { at } 125^{\circ} \mathrm{C} \text { gas temperature with a } 500 \mathrm{~L} \\
\text { gas volume. }\end{array}$ \\
\hline Backfill gas & 39.8 & $\begin{array}{l}\text { The MCO will be initially filled with } \\
\text { helium to a positive gage pressure not to } \\
\text { exceed } 26.2 \text { psia }\left(11.5 \text { psig) at } 0^{\circ} \mathrm{C} \text {. }\right.\end{array}$ \\
\hline Noble gases $(\mathrm{Kr}, \mathrm{Xe})$ & $<0.2$ & $\begin{array}{l}\text { Fission product noble gases released as a } \\
\text { result of corrosion of the fuel, based on a } \\
\text { water inventory of } 5,000 \mathrm{~g} \text { in a sealed } \\
\text { MCO. }\end{array}$ \\
\hline $\mathrm{He}$ & $<0.1$ & $\begin{array}{l}\text { Helium is released from alpha decay of } \\
\text { transuranics combined with fuel } \\
\text { corrosion. }\end{array}$ \\
\hline Oxygen & 13.7 & $\begin{array}{l}\text { Oxygen concentration not to exceed } \\
4 \text { vol\% to preclude flammable gas } \\
\text { mixtures. }\end{array}$ \\
\hline $\begin{array}{l}\text { Total water and } \\
\text { hydrogen }\end{array}$ & 301 & See Section 4.6.3.3.7 \\
\hline Unallocated & 129 & $\begin{array}{l}\text { Difference between total allowable gas } \\
\text { and sum of identified constituents. } \\
\text { Currently identified constituents result in } \\
\text { MCO approaching within } 75 \% \text { of the } \\
465 \text { psia design pressure. }\end{array}$ \\
\hline
\end{tabular}

\subsection{Unallocated Gas Inventory}

| The unallocated gas inventory represents the margin available to accommodate uncertainties in the addition of trace materials not specifically considered as a contributor to MCO pressure. Trace quantities of materials, as small pieces of debris that cannot be distinguished from scrap, represent the primary loading uncertainty. Gaseous products produced by trace material radiolysis or dehydration can add to the internal pressure of the MCO.

Table 4-2 indicates the unallocated gas inventory in a MCO is approximately 129 gmol, assuming bounding values from other constituents. The unallocated gas inventory represents a $25 \%$ margin between the bounding estimates for identified constituents and the vessel design pressure. 
HNF-SD-SNF-OCD-001, Rev. 5

\subsection{MCO Backfill Gas}

The pressure inside the MCO upon sealing is established at a positive pressure with respect to atmospheric conditions to preclude air in leakage. The allocation of total gas inventory to the backfill gas is limited by a selected set of conditions in excess of the minimum backfill requirements. Increasing the quantity of backfill gas added decreases the margin between bounding and design pressures within an MCO. The maximum backfill conditions selected are based on backfilling to $11.5 \mathrm{psig}(26.2 \mathrm{psia})$ at $0^{\circ} \mathrm{C}$. The maximum backfill gas pressure was selected to provide a practical control range above the minimum backfill pressure of $9.5 \mathrm{psig}$ (24.2 psia) required in Section 4.4.2.4. The minimum backfill pressure results in an allocation of at least $31 \mathrm{gmol}$ of gas added to an $\mathrm{MCO}$ with minimum void volume and $50^{\circ} \mathrm{C}$ gas temperature. The actual molar quantity of backfill gas added will vary with the MCO void volume when the addition is based on temperature and pressure. However, since the other contributors are fixed molar quantities, the effect of other contributors on $\mathrm{MCO}$ pressure is reduced as the $\mathrm{MCO}$ void volume increases. Therefore, if the molar quantity of backfill gas exceeds the allocation in Table 4-2 due to a larger MCO void volume, the total margin available between bounding and design pressure is maintained.

\subsection{Noble Gas Release}

Noble gas release is estimated based on an assumed water inventory corroding uranium metal fuel to release xenon and krypton. A maximum estimate of noble gas release is based on the radionuclide content estimated for Mk IV fuel irradiated to produce $16 \%{ }^{240} \mathrm{Pu}$ that is cooled 10 years (a conservative amount of time) in Schwarz (1997) (see pg. V2.545). Based on these estimates, the fuel krypton content is $45.45 \mathrm{~g} / \mathrm{MTU}$ and xenon content is $628.6 \mathrm{~g} / \mathrm{MTU}$. The fuel corrosion is approximated for a total water content of $5,000 \mathrm{~g}(278 \mathrm{gmol})$. Note that the water content estimate is refined in Section 4.6.3.3.7. The following simplified corrosion stoichiometry results in 1 gmol of uranium corroded per 2 gmol of water reacted.

$$
\mathrm{U}+2 \mathrm{H}_{2} \mathrm{O} \rightarrow \mathrm{UO}_{2}+\mathrm{H}_{2}
$$

Therefore, the quantity of uranium corroded by $278 \mathrm{gmol}$ of water is approximately $139 \mathrm{gmol} \mathrm{U}$, or $33 \mathrm{~kg}$ uranium reacted. Based on molecular weights of $85 \mathrm{~g} / \mathrm{gmol}$ for krypton and $131 \mathrm{~g} / \mathrm{gmol}$ for xenon, the fuel noble gas content is $5 \times 10^{-4} \mathrm{gmol} \mathrm{Kr} / \mathrm{kg} \mathrm{U}$ and $5 \times 10^{-3} \mathrm{gmol} \mathrm{Xe} / \mathrm{kg} \mathrm{U}$. The noble gas release by metal corrosion is then estimated at $0.18 \mathrm{gmol} \mathrm{Kr}+\mathrm{Xe}$, or less than 0.2 gmol gas.

\subsection{Helium Decay Product}

Helium gas release is estimated based on an assumed water inventory corroding uranium metal fuel. A maximum estimate of helium gas release is based on the radionuclide content estimated for Mark IV fuel irradiated to produce $16 \%{ }^{240} \mathrm{Pu}$ that is cooled 60 years (conservative value) in Schwarz (1997) (see pg. V2.533). Based on these estimates, the fuel helium content is $0.29 \mathrm{~g} / \mathrm{MTU}$. 
The fuel corrosion is approximated as in Section 4.6.3.3.4 at $33 \mathrm{~kg}$ of uranium reacted. Based on a molecular weight of $4 \mathrm{~g} / \mathrm{gmol}$ for helium, the helium gas release by metal corrosion is then estimated at 0.002 gmol He, or less than the 0.1 gmol of He gas allowed for in Table 4-2.

\subsection{Oxygen}

Oxygen is generated as a decomposition product of water through radiolysis. The oxygen concentration in an $\mathrm{MCO}$ is limited to $4 \mathrm{vol} \%$ to prevent developing a flammable gas mixture during interim storage (Plys and Duncan 1998b). Oxygen gettering by uranium metal is projected to maintain oxygen concentrations at less than $4 \mathrm{vol} \%$ in an MCO for all potential combinations of MCO loadings and decay heat. An allocation of $4 \%$ of the backfill gas plus hydrogen is included as a contribution from oxygen to allow for the build up of a driving force for oxygen consumption reactions during the storage period. This results in allocating $(0.04 \times[301+41.3]) 13.7 \mathrm{gmol}$ of gas for oxygen.

\subsection{Water and Hydrogen}

As indicated above, water reacts with uranium metal to form uranium oxide and release hydrogen gas. In addition, radiolytic decomposition of water can also occur, producing hydrogen and oxygen gases. As the temperature in the MCO increases, volatilization of water also will increase. The MCO water inventory must be controlled to limit the total gas pressure observed during interim storage.

Duncan and Plys (1998) summarize maximum estimates for the bound water content of solids (fuel particulate and fuel coatings) in an MCO. While free water removal is expected to be complete, configurations can be hypothesized where water is trapped in fuel pockets or cracks. An allocation of $200 \mathrm{~g}$ free water has been included in the consideration of total water inventory based on satisfying the criterion in Section 4.4.1. Therefore, the MCO water inventory after drying is not directly measured, but derived from a combination of analyses and process procedures that allow one to conclude the water inventory is bounded. The following list summarizes maximum estimates for the MCO bound and free water inventory from Duncan and Plys (1998).

- Water in cladding film

- Water in oxide film, scrap

- Water in adhering particulate

- Water in canister particulate

- Water in generated particulate

Total water in particulate

- Residual free water after drying

Total water in $\mathrm{MCO}$
$3.315 \mathrm{~kg}$
$0.063 \mathrm{~kg}$
$1.036 \mathrm{~kg}$
$0.144 \mathrm{~kg}$
$0.083 \mathrm{~kg}$
$4.641 \mathrm{~kg}$
$0.200 \mathrm{~kg}$
$4.841 \mathrm{~kg}$

The water inventory above is based on a MCO containing two scrap baskets. This represents the maximum total water inventory estimated for a MCO. 
Water and hydrogen produce comparable MCO pressurization due to the equimolar stoichiometry of the uranium metal corrosion reaction. Therefore, one mole of hydrogen is produced per mole of water reacted with uranium metal. Radiolytic water decomposition also produces up to one mole of hydrogen per mole of water (oxygen generated from water radiolysis is addressed in Section 4.6.3.3.6). Water can potentially react with uranium hydride to produce hydrogen based on the following stoichiometry.

$$
\mathrm{UH}_{3}+2 \mathrm{H}_{2} \mathrm{O} \rightarrow \mathrm{UO}_{2}+3.5 \mathrm{H}_{2}
$$

This results in producing 1.75 moles of hydrogen per mole of water reacted.

Pajunen (1998b) provides a bounding estimate of $5.13 \mathrm{~kg} \mathrm{UH}_{3}$ after drying for an MCO containing two scrap baskets. This corresponds to an inventory of $21.3 \mathrm{gmol} \mathrm{UH}_{3}(5130 / 241)$, which can react with water by the above stoichiometry to form $74.5 \mathrm{gmol} \mathrm{H}_{2}$ while consuming $42.6 \mathrm{gmol}$ water. The total water inventory is bounded by $269 \mathrm{gmol}(4841 / 18)$ listed above. Therefore, the maximum hydrogen production, independent of rate considerations, can be found by assuming all uranium hydride reacts to form water and the remaining water reacts with uranium metal. This results in a hydrogen production estimate of 301 gmol $(269-42.6+74.5)$.

\subsection{MCO INTERIM STORAge Time}

The MCO structure and components, as well as CSB systems, are designed for a 40 year life (Goldmann 2000 and Swenson 1996) based on storing two sealed MCOs per vented storage tube. Prior to expiration of that time period, the SNF will require further processing, an alternate storage system, or evaluations that indicate the $\mathrm{MCO}$ and CSB design lives can be extended without jeopardizing safety.

\subsection{REFERENCES}

ANSI, 1987, American National Standard for Radioactive Materials - Leakage Tests on Packages for Shipment, ANSI N14.5-1987, American National Standards Institute, New York, New York.

Ball, D. E. and D. R. Duncan, 1998, Fuel Surface Area, HNF-SD-SNF-CN-017, Rev. 3, DE \& S Hanford, Inc., Richland, Washington.

Cooley, D. L., and D. B. Hagmann, 1999, Cask/MCO Helium Purge System Design Report, SNF-4889, Rev 0, Fluor Daniel Hanford, Richland, Washington.

Duncan, D. R., and M. G. Plys, 1998, K-Basins Sludge Water Content Behavior, and Impact, HNF-1523, Rev. 1, DE \& S Hanford, Inc., Richland, Washington.

Frederickson, J. R., 2000, Clarification of Pressure Rebound Criteria, Interoffice Correspondence 00-SNF/JRF-016, Fluor Hanford, Richland, Washington. 
Goldmann, L. H., 2000, Performance Specification for the Spent Nuclear Fuel Multi-Canister Overpack, HNF-S-0426, Rev. 6, DE\&S Hanford, Inc., Richland, Washington.

Heard, F. J., 1996, Thermal Hydraulic Feasibility Assessment for the Spent Nuclear Fuel Project, WHC-SD-WM-ER-525, Rev. 0, Westinghouse Hanford Company, Richland, Washington.

H-2-828041, Rev. 3, Multi-Canister Overpack Assembly.

H-2-828070, Rev. 1, MCO Mark IV SNF Storage Basket.

Irwin, J. J., et. al., 1999, Cold Vacuum Drying Facility Design Requirements, HNF-SD-SNF-DRD-002, Rev 4, Numatec Hanford Co., Richland, Washington.

Kessler, S. F., 1999, Criticality Safety Evaluation Report for the Multi-Canister Overpack, HNF-SD-SNF-CSER-005, Rev 4, Fluor Daniel Northwest, Richland, Washington.

Lorenz, B. D., et al., 1999, Multi-Canister Overpack Topical Report, HNF-SD-SNF-SARR-005, Rev 1, Fluor Hanford, Richland, Washington.

Packer, M. J., 1999, 105-K Basin Material Design Basis Feed Description for Spent Nuclear Fuel Project Activities, Volume 1, Fuel, HNF-SD-SNF-TI-009, Volume 1, Rev 3, DE\&S Hanford, Richland, Washington.

Pajunen, A. L., 1998a, Cold Vacuum Drying Residual Free Water Test Description, HNF-1851, Rev. 2, COGEMA Engineering Corporation, Richland, Washington.

Pajunen, A. L., 1998b, Uranium Hydride in Multi-Canister Overpacks, HNF-3372, Rev. 0, COGEMA Engineering Corporation, Richland, Washington.

Pajunen, A. L., 2000, Inert Gas Requirements for Cask Loading, HNF-2833, Rev. 1, Fluor Hanford, Richland, Washington.

Piepho, M. G., 2000, Thermal Analysis of Cold Vacuum Drying of Spent Nuclear Fuel, HNF-SD-SNF-CN-023, Rev 2, Fluor Federal Services, Richland, Washington.

Plys, M. G., and D. R. Duncan, 1998a, Simulation of Normal and Off-Normal Multi-Canister Overpack Behavior, HNF-2256, Rev 2, DE\&S Hanford, Richland, Washington.

Plys, M. G., and D. R. Duncan, 1998b, MCO Internal Gas Composition and Pressure During Interim Storage, HNF-SD-SNF-TI-040, Rev 3, DE\&S Hanford, Richland, Washington.

Reilly, M. A., 1998, Spent Nuclear Fuel Project Technical Databook, HNF-SD-SNF-TI-015, Rev. 6, DE\&S Hanford, Richland, Washington. 


\section{HNF-SD-SNF-OCD-001, Rev. 5}

Rohsenow, W. M., and J. P. Hartnett, 1973, Handbook of Heat Transfer, McGraw-Hill Book Company, New York, New York.

Schwarz, R. A., 1997, Modification to ORIGEN2 for Generating N Reactor Source Terms, PNNL-11555, Pacific Northwest National Laboratory, Richland, Washington.

Sherrell, D. L., 1998, Post Fuel-Cleaning Corrosion of Uranium Within MCO Payloads, HNF-3048, Rev. 0, DE\&S Hanford, Inc., Richland, Washington.

Sherrell, D. L., 1999, Radionuclide Inventory of Bulk MCO Water at the Cold Vacuum Drying Facility, HNF-SD-W441-CN-001, Rev. 3A, DE\&S Hanford, Inc., Richland, Washington.

Sherrell, D. L., 2000, Multi-Canister Overpack Combustible Gas Management Leak Test Acceptance Criteria, HNF-2155, Rev. 2, DE\&S Hanford, Inc., Richland, Washington.

Sherrell, D. L. and A. L. Pajunen, 1999, Evaluation of Helium Impurity Impacts on Spent Nuclear Fuel Project Processes (OCRWM), HNF-4702, Rev. 0, Numatec Hanford Company, Richland, Washington.

Sloughter, J. P., 1999, Estimates of Particulate Mass in Multi-Canister Overpacks, HNF-1527, Rev. 3, Numatec Hanford Corp., Richland, Washington.

Sloughter, J. P., 1999b, Uranium Metal Water Reactions in the Integrated Water Treatment System Issue Closure Package, SNF-4424, Rev. 0, Numatec Hanford Corporation, Richland, Washington

Smith, R. J., 2000, Safety Analysis Report for Packaging (On-Site) Multi-Canister Overpack Cask, HNF-SD-TP-SARP-017, Rev. 2B, Waste Management Federal Services, Inc., Richland, Washington.

Swenson, C. E., 1996, Performance Specification for the Spent Nuclear Fuel Canister Storage Building, WHC-S-0425, Rev. 2, Westinghouse Hanford Company, Richland, Washington.

Welty, J. R., C. E. Wicks, and R. E. Wilson, 1969, Fundamentals of Momentum, Heat and Mass Transfer, John Wiley \& Sons, New York, New York.

Wyman, H. A., 1999, Estimates of Particulate Mass for an MCO Containing Mark 1 A Fuel, HNF-4465, Rev 0, COGEMA Engineering Corporation, Richland, Washington. 
HNF-SD-SNF-OCD-001, Rev. 5

\section{APPENDIX A. ASSESSMENT OF THE EFFECTS OF ORGANICS ON MCO STORAGE}

Based on the following assessment, it was found that organic polymer materials, modeled as epoxy resins, are relatively stable under gamma irradiation. Only mechanical and optical property changes are reported to occur at total integrated doses comparable to that predicted for material in an $\mathrm{MCO}$ over a 40 year interim storage time period. It is difficult to attribute these changes to large changes in the molecular structure composition. If it were possible for an epoxy resin to undergo complete radiolytic decomposition during interim storage, then a limit of $450 \mathrm{~g}$ of organic would avoid increasing the MCO void space oxygen concentration to a flammable mixture. Total pressure increases from complete decomposition would not be significant as compared to the $\mathrm{MCO}$ design pressure.

Epoxy resin was used to model organics that may be inadvertently added to an MCO. Epoxy resin was selected because in-pool fuel handling equipment is coated with an epoxy phenolic with the trade name Amercoat-90HS ${ }^{1}$ and small quantities of the coating could end up in MCOs from scraping coatings during basket handling.

\section{A.1 EpOXY RESIn Gamma IrRadiation STABILITY}

Radiation fields are projected to produce gamma dose rates to materials within an MCO of less than $1000 \mathrm{rad} / \mathrm{hr}$ at temperatures on the order of $100^{\circ} \mathrm{C}$ for a time period of 40 years. This results in a total integrated dose to the contents of an MCO that is bounded by $10^{9} \mathrm{rad}$.

The effects of irradiation on polymer properties were extensively studied in the 1950s and 1960s. West and Watson (1965) evaluated irradiation of protective coatings. Epoxy resin materials were found to be highly resistant to damage from gamma irradiation. The testing involved gamma intensities of $10^{6} \mathrm{rad} / \mathrm{hr}$ at temperatures between $40^{\circ} \mathrm{C}$ and $80^{\circ} \mathrm{C}$. The coatings survived integrated doses in excess of $10^{8} \mathrm{rad}$.

West and Watson (1965) found that most protective coatings develop a discoloration of the surface during gamma irradiation. The depth of discoloration increases with exposure. The white-pigmented epoxies and modified phenolics start to turn yellow at $1 \times 10^{8}$ to $5 \times 10^{8} \mathrm{rad}$ and progressively darken to brown-toast color at $10^{9} \mathrm{rad}$. The color changes may be caused by nitrogen groups in the curing agents which cause a color shift during oxidation, radiationenhanced aging via chemical changes, and heating.

\footnotetext{
${ }^{1}$ Amercoat is a registered trademark of Ameron, Inc. Corporation.
} 
Coating failures at doses greater than $10^{9}$ rad resulted from film deterioration (embrittlement and chalking), loss of adhesion, and decrease in impact resistance. Some coatings were tested in deionized water. Extreme chalking, erosion, and softness was evident on most of the coatings. Some of these failures were attributed to lack of resistance to deionized water and chemical attack from the decomposition of water to hydrogen peroxide. Coating breakdown in both air and deionized water may originate from the ionizing effect of radiation and major chemical changes such as cross linking. Chemical effects associated with ozone production were also possible. Finally, while one material investigated by West and Watson (1965) liquefied after a dose of approximately $10^{8} \mathrm{rad}$, there were no reports of any polymer being vaporized.

\section{A.2 Gas Production from Organic Radiolysis}

The potential for radiolysis of organic materials, producing a source of gaseous constituents, is the primary reason for restricting the addition of organics to an $\mathrm{MCO}$. The gaseous radiolysis products potentially impact the evaluation of total pressure in an MCO during storage and the oxygen concentration of gases contained by the MCO during storage. The implications of gas production from organic material radiolysis were evaluated by assuming the organic material is represented by an epoxy resin that completely disassociates into constituent molecules (hydrogen and oxygen). The epoxy resin Bisphenol $\mathrm{A}\left(\mathrm{C}_{15} \mathrm{H}_{16} \mathrm{O}_{2}\right)$, with molecular weight of $228.28 \mathrm{~g} / \mathrm{gmol}$, is used as a specific description of the organic material for this evaluation. However, it is possible for a wide variety of trace organic materials, including organics of biological origin, to be loaded in an MCO.

The study of epoxy resins described above indicates that minimal decomposition of organic materials, as a fraction of its initial mass, will be expected during the storage time of an $\mathrm{MCO}$. However, the maximum pressure increase possible from the addition of organic materials to an MCO can be conservatively estimated by assuming complete decomposition. Complete decomposition of Bisphenol $\mathrm{A}$ is described by the following stoichiometry.

$$
\mathrm{C}_{15} \mathrm{H}_{16} \mathrm{O}_{2} \stackrel{\gamma}{\rightarrow} 15 \mathrm{C}+8 \mathrm{H}_{2}+\mathrm{O}_{2}
$$

Noting that the disassociation stoichiometry predicts a total of 9 moles of gas generated for every mole of resin decomposed, the total pressure increase from the organic material is estimated as follows.

$$
\frac{\Delta P}{m_{r}}=\frac{\left(9 \frac{\text { moles gas }}{\text { mole re } \sin }\right) R T}{\left(M W_{r}\right) V}=\frac{(9)(0.082)(273+60)}{(228.28)(500)}=2.1 \times 10^{-3} \mathrm{~atm} / \mathrm{g}=0.03 \mathrm{psi} / \mathrm{g} \text { resin decomposed }
$$

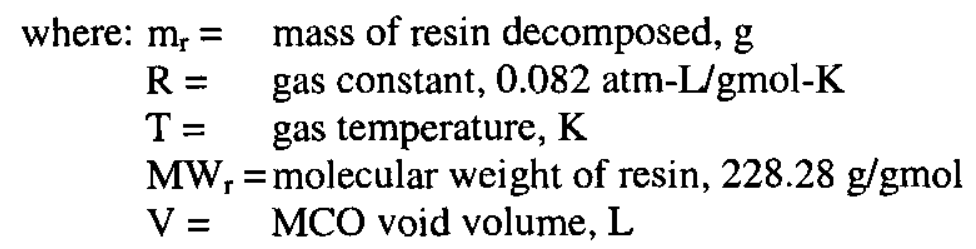


This implies that complete decomposition of $500 \mathrm{~g}$ resin over the storage life of an $\mathrm{MCO}$ would increase the total pressure in an $\mathrm{MCO}$ by $15 \mathrm{psi}$. The maximum internal pressure of an $\mathrm{MCO}$ is indicated in Reilly (1998) to be $76.4 \mathrm{psia}(61.7 \mathrm{psig})$, as compared to a mechanically sealed MCO design pressure of $150 \mathrm{psig}$ and a welded MCO design pressure of $450 \mathrm{psig}$. Therefore, the total pressure increase possible from organic additions on the order of $500 \mathrm{~g}$ will not result in overpressurizing an $\mathrm{MCO}$.

The impact of organics on flammable gas compositions was evaluated by limiting the quantity of resin that could completely decompose to produce an oxygen concentration of 4 vol\% in a MCO. This criterion was selected as a conservative basis for the following reasons:

- Plys and Duncan (1998) indicates that oxygen concentrations in an MCO approach 4 vol\% | only when a unique combination of characteristics exists, including high decay power, maximum aluminum hydroxide coating, and no exposed uranium to getter oxygen. The probability that an MCO would contain this unique combination of characteristics in addition to an inventory of organics was considered remote.

- The following calculations assume complete decomposition of the organic material. The observations of West and Watson (1965), as compared to the total integrated dose to materials in an MCO over a 40 year storage period, indicate that complete decomposition is unlikely.

- Oxygen is not generally observed as a product of organic material radiolysis.

The combined observations listed above led to evaluating the impact of trace quantities of organic material on flammable gas compositions that was independent from the evaluation of radiolytic gas generated by inorganic materials expected in an MCO.

The quantity of resin that could completely decompose to yield a 4 vol\% oxygen concentration in an $\mathrm{MCO}$ was found as follows:

$$
\begin{aligned}
& y_{\mathrm{O} 2}=\frac{\mathrm{n}_{\mathrm{O} 2}}{\mathrm{n}_{\mathrm{He}}+\mathrm{n}_{\mathrm{H} 2}+\mathrm{n}_{\mathrm{O} 2}} \\
& \mathrm{n}_{\mathrm{H} 2}=\left(8 \frac{\text { mole } \mathrm{H}_{2}}{\text { mole se sin }}\right) \mathrm{n}_{\mathrm{r}}=8 \mathrm{n}_{\mathrm{r}} \\
& \mathrm{n}_{\mathrm{O} 2}=\left(1 \frac{\text { mole } \mathrm{O}_{2}}{\text { mole re sin }}\right) \mathrm{n}_{\mathrm{r}}=\mathrm{n}_{\mathrm{r}}
\end{aligned}
$$

where: $\mathrm{y}_{\mathrm{O} 2}=$ mole fraction of oxygen in $\mathrm{MCO}$ void space

$\mathrm{n}_{\mathrm{He}}=$ moles helium in $\mathrm{MCO}$ void space, gmol

$\mathrm{n}_{\mathrm{H} 2}=$ moles hydrogen in $\mathrm{MCO}$ void space, gmol

$\mathrm{n}_{\mathrm{O} 2}=$ moles oxygen in $\mathrm{MCO}$ void space, gmol

$n_{\mathrm{r}}=$ moles of resin reacted, gmol 
This can be rearranged to the following.

$$
\begin{aligned}
& n_{r}=\frac{y_{O 2} n_{H e}}{\left(1-9 y_{O 2}\right)}=\frac{m_{r}}{M W_{r}} \\
& m_{r}=\frac{y_{O 2} n_{H e} M W_{r}}{\left(1-9 y_{O 2}\right)}
\end{aligned}
$$

The initial helium inventory is estimated based on a backfill pressure of $9.5 \mathrm{psig}$ and $42^{\circ} \mathrm{C}$ with 99.5\% helium at the CVD Facility. This results in the following helium inventory estimate.

$$
n_{H e}=\frac{P V}{R T}(0.995)=\frac{\left(\frac{14.7+9.5}{14.7} \mathrm{~atm}\right)(500 \mathrm{~L})}{\left(0.082 \frac{\mathrm{atm}-\mathrm{L}}{\mathrm{gmol}-K}\right)(273+42 \mathrm{~K})}(0.995)=31.9 \mathrm{gmol} \mathrm{He}
$$

The mass of resin reacted resulting in 4 vol\% oxygen in the $\mathrm{MCO}$ void space becomes:

$$
m_{r}=\frac{(0.04)(31.7)(228.28)}{(1-9[0.04])}=452 \mathrm{~g}, \text { or approximately } 450 \mathrm{~g}
$$

Based on the above calculations, it is concluded that trace organic material additions to an MCO on the order of $450 \mathrm{~g}$ will not significantly impact the total pressure or approach to a flammable gas composition during interim storage.

\section{A.3 REFERENCES FOR APPENDIX A}

Duncan, D. R., and M.G. Plys, 1998, MCO Internal Gas Composition and Pressure during Interim Storage, HNF-SD-SNF-TI-040, Rev 3, DE\&S Hanford, Richland, Washington.

Reilly, M. A., 1998, Spent Nuclear Fuel Project Technical Databook, HNF-SD-SNF-TI-015, Rev 6, DE\&S Hanford, Richland, Washington.

West, G. A., and C. D. Watson, 1965, Gamma Radiation Damage and Decontamination Evaluation of Protective Coatings and Other Materials for Hot Laboratory and Fuel Processing Facilities, ORNL-3589, Oak Ridge National Laboratory, Oak Ridge, Tennessee. 
HNF-SD-SNF-OCD-001, Rev. 5

\section{APPENDIX B. FUEL QUEUING LIMIT}

\section{B.1 BACKGROUND/PURPOSE}

A fuel and scrap basket queue, or lag storage capability, has been installed in the $\mathrm{K}$ Basins as part of the FRS. The basket queue provides a buffer between fuel retrieval and MCO loading/cask loading operations to minimize the potential for short term operating delays in one system impacting the other. The queue has capacity to store baskets to fill two MCOs. If operations perform at overall average design rates of about two MCOs per week from a basin, fuel for an MCO could reside in the queue on the order of $1 / 2$ to 1 week.

A queuing time limit in the basin was specified to support safety evaluations of the CVD Facility and CSB. After cleaning, uranium surfaces exposed to water or water vapor are assumed to continue to corrode. The particulate generated by uranium corrosion adds to the residual particulate remaining after cleaning. The generated particulate creates an inventory of dispersible material that is at risk for accident scenarios.

The MCO particulate inventory bound includes $11.9 \mathrm{~kg}$ (as $\mathrm{UO}_{2}$ ) generated by corrosion of fuel during basket queuing. This limit was originally derived by allowing all baskets in an MCO containing two scrap baskets to be queued up to 30 days in basin water at $10^{\circ} \mathrm{C}$. Actual implementation is based on tracking particulate generated in each basket during the queuing period, assuming bounding fuel surface areas exist in each basket, and ensuring the particulate generated during queuing is less than or equal to $11.9 \mathrm{~kg}$ (as $\mathrm{UO}_{2}$ ) per $\mathrm{MCO}$.

The purpose of this appendix is to describe the procedure for tracking basket particulate generation during queuing and conservative guidelines for queuing times that may be useful during operation.

\section{B.2 SUMMARY}

The attached appendix summarizes the basis for limiting basket queuing times in the basin water after queuing. The total particulate generated after cleaning is limited to $11.9 \mathrm{~kg}\left(\mathrm{as} \mathrm{UO}_{2}\right)$ for consistency with design assumptions. This generation rate is conservatively achieved by limiting basket storage to less than 30 days while holding the basin water temperature at $10^{\circ} \mathrm{C}\left(50^{\circ} \mathrm{F}\right)$. Queuing time guidelines have been developed to assist in operation planning that reflect the potential for varying basin water temperature and $\mathrm{MCO}$ loadings. A tracking procedure is described to formally monitor and define the generated particulate loaded in a particular MCO for comparison with the $11.9 \mathrm{~kg}$ particulate limit.

\section{B.3 Particulate Generation Basis}

Figure B-1 shows the cumulative generation of particulate in an $\mathrm{MCO}$ assuming bounding fuel and scrap basket characteristics (surface area and uranium hydride inventory after cleaning). Values for an MCO containing two scrap baskets come directly from estimates in Sherrell (1998) and Sherrell (1999). Estimates for MCOs containing no scrap baskets and one scrap basket were 
derived using the same method described in Sherrell (1998) and Sherrell (1999). Since the bounding surface area of an MCO is dominated by the scrap basket, MCOs with fewer than two scrap baskets will contain less generated particulate than the bound used in evaluating accident conditions.

\section{Figure B-1. Cumulative Particulate in an MCO based on Bounding Surface Areas} (Assumes Basket Queuing Limited to 30 days at $10^{\circ} \mathrm{C}$ )

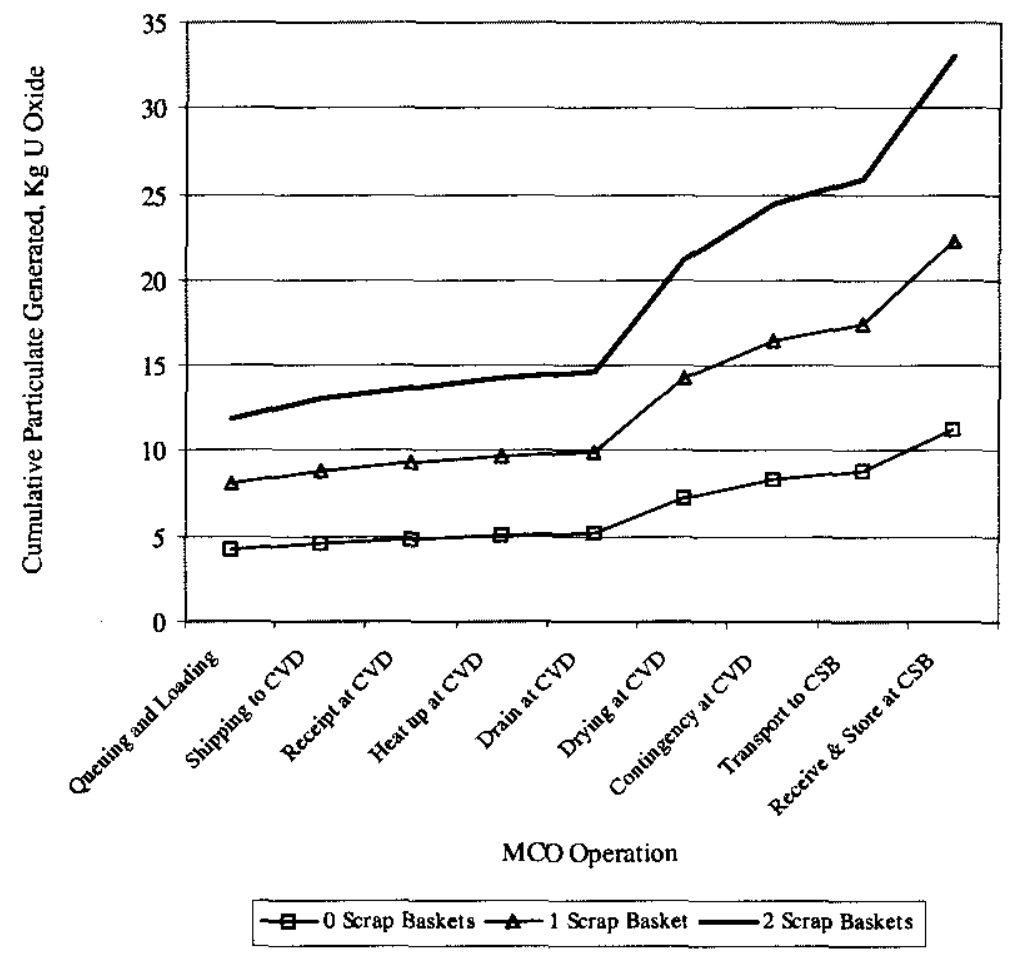

\section{B.4 QUEUING TIME GUIDELINES}

Conservative queuing guidelines have been developed to aid operational planning during processing. These guidelines are conservative in that it is assumed that all baskets are queued at a constant basin water temperature (e.g., $10^{\circ} \mathrm{C}$ ). If all baskets loaded in a particular $\mathrm{MCO}$ have been stored for a time period less than the indicated guideline queuing time, the MCO will contain less than $11.9 \mathrm{~kg}\left(\mathrm{as} \mathrm{UO}_{2}\right)$ generated during queuing. The queuing guidelines are provided as a simplified method of alerting operating personnel as to when queuing particulate generation is approaching the limit and are not intended to replace the rigorous generated particulate tracking described in Section B.5. 
The original particulate generation basis provides a basket queuing time guideline for an MCO containing two scrap baskets, with all baskets stored at a water temperature less than or equal to $10^{\circ} \mathrm{C}$ (i.e., 30 days). Table B-1 shows the equivalent queuing time limit for generating $11.9 \mathrm{~kg}$ (as $\mathrm{UO}_{2}$ ) particulate if an MCO were to be loaded with zero or one scrap basket. Figure B-2 shows the cumulative particulate generation in subsequent processing steps, indicating that the particulate bounds developed from a two scrap basket MCO continue to bound the particulate inventory of MCOs containing zero or one scrap baskets.

Table B-1. Basket Queuing Time Guidelines

(Based on water temperature $\leq 10^{\circ} \mathrm{C}$ throughout queuing time period)

\begin{tabular}{|c|c|}
\hline Number of Scrap Baskets in MCO & Queuing Time Guideline* \\
\hline 0 & 130 days \\
\hline 1 & 52 days \\
\hline 2 & 30 days \\
\hline
\end{tabular}

* - all baskets loaded in MCO queued for less than this time limit.

The queuing time guidelines are based on maintaining the basin water at $10^{\circ} \mathrm{C}$, or less, throughout the storage time. The queuing time is temperature dependent. Figure B-3 provides an adjustment factor for the queuing time guideline to adjust for basin water temperature. As indicated on Figure B-3, the time limit decreases as the basin water temperature increases. For example, if the basin water reaches a maximum temperature of $14^{\circ} \mathrm{C}\left(57^{\circ} \mathrm{F}\right)$ at some point during the basket queuing period for an $\mathrm{MCO}$, the queuing time adjustment factor from Figure B-3 is 0.7. The baskets for an MCO containing one scrap basket will approach the particulate generation limit after queuing for 36 days $(0.7 \times 52)$. Note that the actual tracking procedure adjusts particulate generation based on periodic basin water temperature readings such that additional time beyond the guideline time will be available. 
HNF-SD-SNF-OCD-001, Rev. 5

Figure B-2. Cumulative Particulate Generated in MCOs with Common Queuing Generation at $10^{\circ} \mathrm{C}$

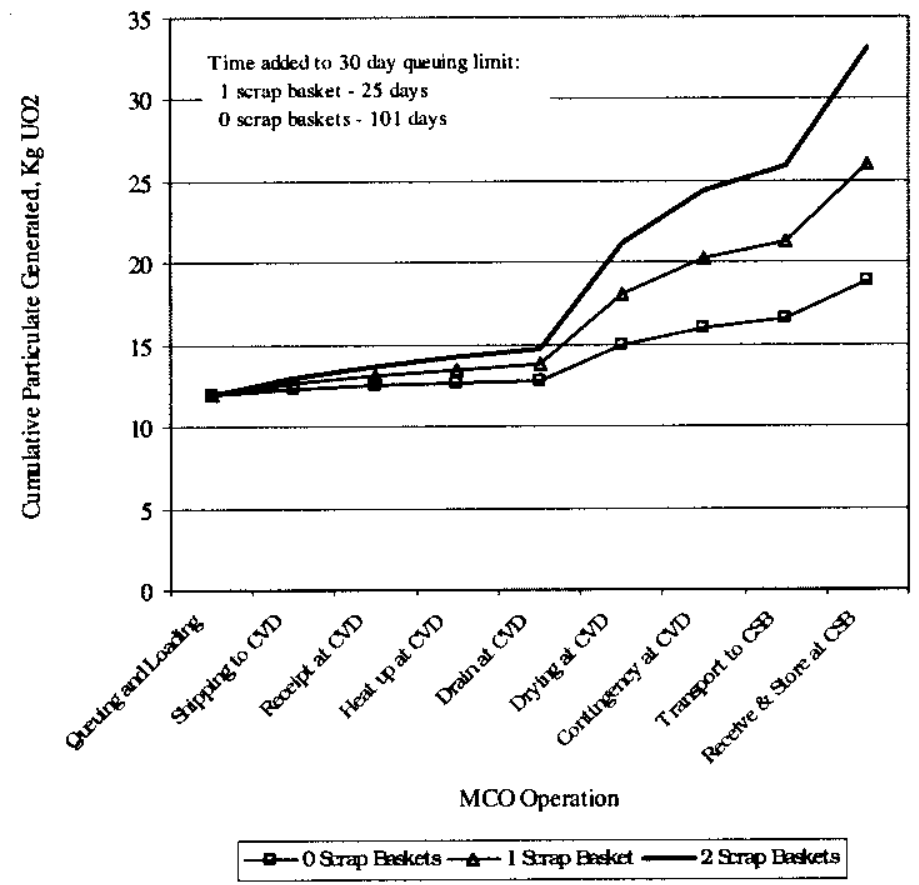

Figure B-3. Basket Queuing Time Guideline Temperature Adjustment Factor

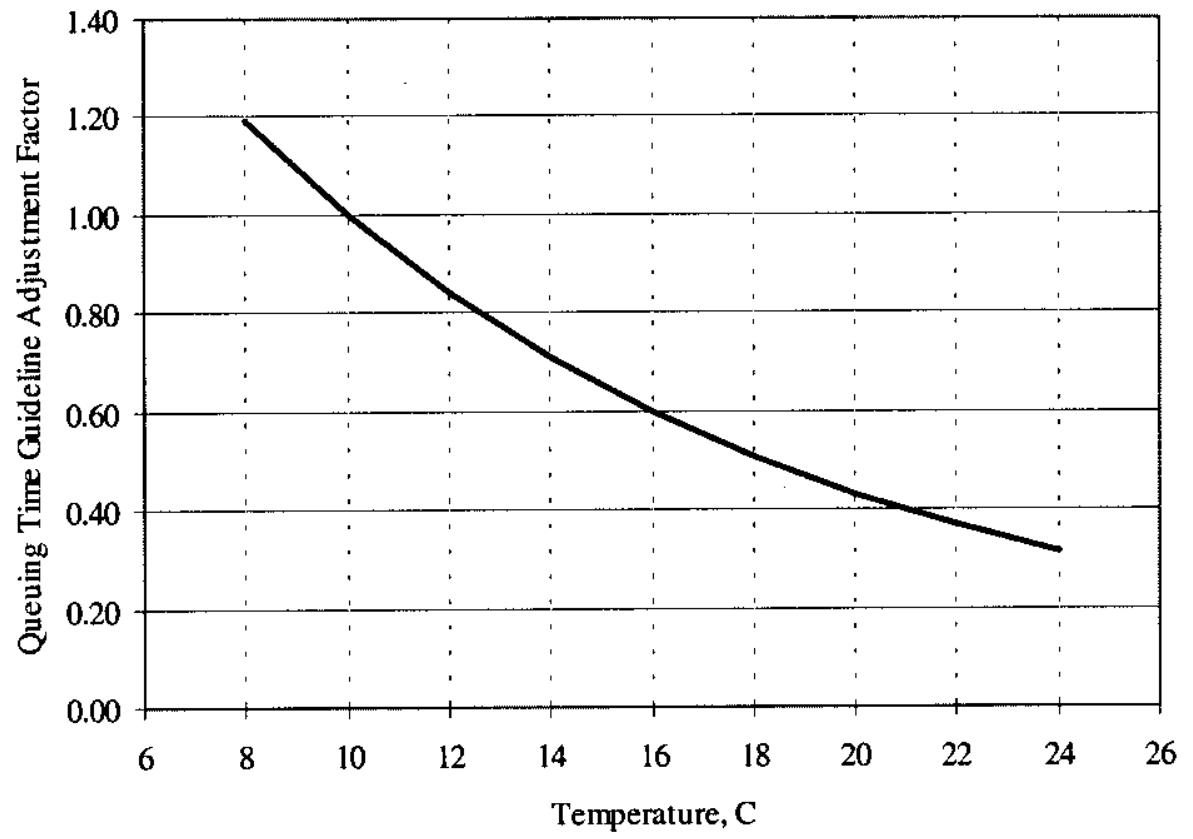




\section{B.5 Basket Particulate Generation Tracking}

The procedure for tracking particulate generation in a basket during queuing duplicates the bounding particulate generation calculation in each basket in Sherrell (1999) on a periodic basis and sums the generated particulate in an $\mathrm{MCO}$, depending on the baskets loaded. Basic bounding input data for the calculation and the data source is shown as follows.

\section{Basket Type}

Reacting Surface Area Uranium Hydride Inventory

\begin{tabular}{cc}
\multicolumn{1}{c}{ Scrap } & \multicolumn{1}{c}{ Fuel } \\
$45,000 \mathrm{~cm}^{2}$ & $7,900 \mathrm{~cm}^{2}$ \\
$1.56 \mathrm{~kg}$ & $0.324 \mathrm{~kg}$
\end{tabular}

Reaction Rate Constant, $\mathrm{k}$ (oxygen free water):

$$
\begin{aligned}
& \log _{10} k=7.634-\frac{3016}{T} \\
& \mathrm{k} \equiv \frac{m g(\text { wt gain })}{h r-c m^{2}} \\
& \mathrm{~T} \equiv \operatorname{Kelvin}(\mathrm{K})
\end{aligned}
$$

Reilly (1998), Table 4-4

Table B-2 lists values for the rate constant at various basin water temperatures in $0.5^{\circ} \mathrm{F}$ increments between $45^{\circ} \mathrm{F}$ and $61.5^{\circ} \mathrm{F}$.

Reaction Rate Enhancement Factor:

$$
\begin{aligned}
& \xi=\text { 22, when uranium hydride is present } \quad \text { Reilly (1998), Table 4-2 } \\
& 10, \text { otherwise }
\end{aligned}
$$

The reaction is assumed to consume $50 \%$ uranium hydride and $50 \%$ uranium metal while hydride is present, consistent with Sherrell (1999). Therefore, the reaction rate enhancement factor is 22 until the cumulative particulate generated is $3.495 \mathrm{~kg}\left(\mathrm{as} \mathrm{UO}_{2}\right)$ in a scrap basket or $0.726 \mathrm{~kg}\left(\mathrm{as} \mathrm{UO}_{2}\right)$ in a fuel basket. The reaction rate enhancement factor is then reduced to 10 . 
HNF-SD-SNF-OCD-001, Rev. 5

Table B-2. Corrosion Rate Constants for Calculating Queuing Particulate Generation

\begin{tabular}{|c|c|c|}
\hline \multicolumn{2}{|c|}{$\begin{array}{l}\text { Basin Water } \\
\text { Temperature }\end{array}$} & \multirow{2}{*}{$\begin{array}{c}\text { Rate } \\
\text { Constatut } \\
\left(1 \mathrm{ng} / \mathrm{hr}-\mathrm{cun}^{2}\right)\end{array}$} \\
\hline$\left({ }^{\prime} \mathrm{F}\right)$ & $(\mathrm{K})$ & \\
\hline 45.0 & 280.4 & 0.06075 \\
\hline 45.5 & 280.7 & 0.00077 \\
\hline 46.0 & 280.9 & 0.00079 \\
\hline 46.5 & 281.2 & 0.00081 \\
\hline 47.0 & 281.5 & 0.00083 \\
\hline 47.5 & 281.8 & (). .00085 \\
\hline+8.0 & 282.0 & 0.00087 \\
\hline 48.5 & 282.3 & 0.00089 \\
\hline 49.0 & 282.6 & 0.00092 \\
\hline 49.5 & 282.9 & 0.00094 \\
\hline 50.0 & 283.2 & 0.00096 \\
\hline 50.5 & 283.4 & 0.00098 \\
\hline 510 & 283.7 & 0.000101 \\
\hline 51.5 & 284.0 & 0.00103 \\
\hline 520 & $28+.3$ & 0.00100 \\
\hline 52.5 & 284.5 & 0.00108 \\
\hline 53.0 & $28+8$ & 0.00111 \\
\hline 53.5 & 285.1 & 0.00114 \\
\hline 54.0 & 285.4 & 0.00116 \\
\hline 51.5 & 285.7 & 0.00110 \\
\hline 55.0 & 285.9 & 0.00122 \\
\hline 55.5 & 286.2 & 0.00125 \\
\hline 56.0 & 286.5 & 8ב 0001 \\
\hline 56.5 & 286.8 & 0.00131 \\
\hline 57.0 & 287.0 & 0.01013 .34 \\
\hline 57.5 & 287.3 & 0.00137 \\
\hline 58.0 & 287.6 & 0.00140 \\
\hline 58.5 & 287.9 & $0.001+4$ \\
\hline 590 & 288.2 & $0 .(4) \sqcap 47$ \\
\hline 59.5 & 288.4 & 0.00150 \\
\hline 60.0 & 288.7 & 0.00154 \\
\hline 60.5 & 289.0 & $0.6(x) 1.58$ \\
\hline 61.0 & 289.3 & 0.00161 \\
\hline 61.5 & 289.5 & 0.00165 \\
\hline
\end{tabular}

The particulate generation rate is calculated as follows.

$$
R=\frac{\xi \cdot k\left(\frac{m g(\text { wtgain })}{h r-\mathrm{cm}^{2}}\right) \cdot A\left(\mathrm{~cm}^{2}\right)}{\left(10^{6}\left(\frac{\mathrm{mg}}{\mathrm{kg}}\right)\right)\left(\frac{32(\mathrm{kgwt} \text { gain })}{270\left(\mathrm{kgUO} \mathrm{O}_{2} \text { produced }\right)}\right)}
$$

This reduces to

$$
\begin{array}{llll}
\text { For Scrap Basket } & \mathrm{R}=0.380 \cdot \xi \cdot \mathrm{k} & (\mathrm{kg} \mathrm{UO} / \mathrm{hr}) & (\mathrm{B}-1) \\
\text { For Fuel Basket } & \mathrm{R}=0.067 \cdot \xi \cdot \mathrm{k} & \left(\mathrm{kg} \mathrm{UO}_{2} / \mathrm{hr}\right) & (\mathrm{B}-2)
\end{array}
$$

The tracking procedure is demonstrated by an example calculation. The following analysis examines a scenario to determine the amount of particulate loaded into an MCO containing Mark IV fuel. Figure B-4 indicates an example of daily basin water temperature readings over a 25 day period. The actual frequency used in calculations could be varied, depending on the observed water temperature data. Table B-3 summarizes assumed fuel cleaning finish times and the cask helium backfill time for this example. 
HNF-SD-SNF-OCD-001, Rev. 5

Figure B-4. Tracking Example -Basin Temperature During Queuing

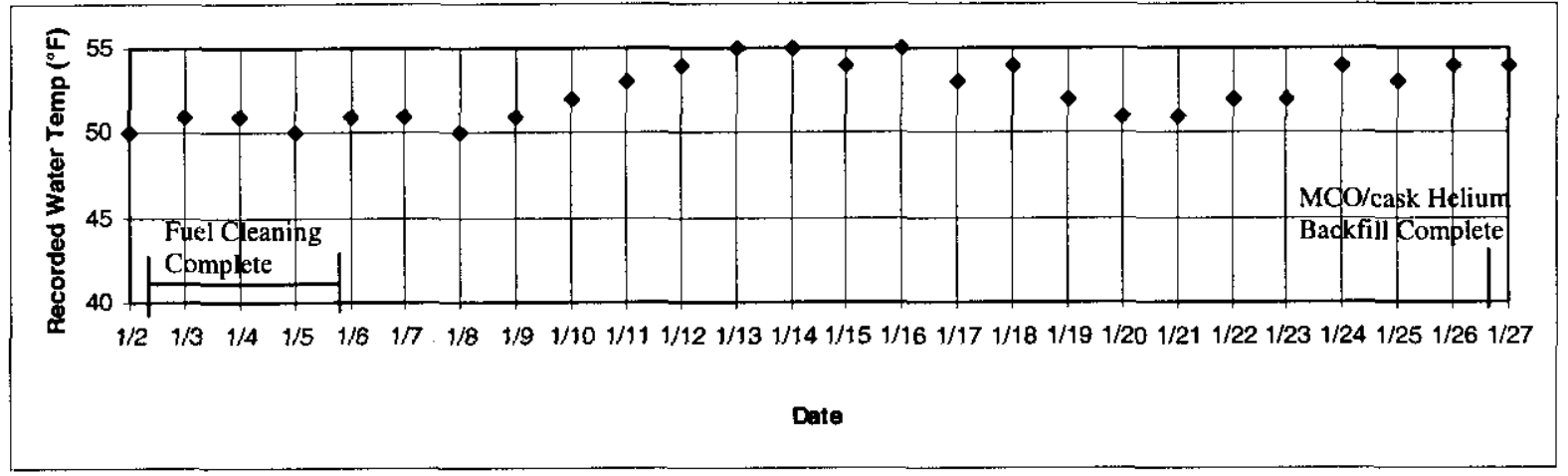

Table B-3. Tracking Example - Fuel and Scrap Basket Queuing Times

\begin{tabular}{|c|c|c|c|c|c|}
\hline MCO Number & AAAA & & & & \\
\hline Position Within $\mathrm{MCO}$ & 1 (Top) & 2 & 3 & 4 & 5 (Bottom) \\
\hline Basket Number & $\mathrm{XXXX}$ & XXYY & XXYX & $\mathrm{XXXZ}$ & XXXY \\
\hline Basket Type & Scrap & Fuel & Fuel & Fuel & Fuel \\
\hline Cleaning Complete & & & & & \\
\hline Queuing Start: & 0800 & 2000 & 1700 & 1300 & 0800 \\
\hline Date & $1 / 2 / \mathrm{XX}$ & $1 / 5 / \mathrm{XX}$ & $1 / 4 / \mathrm{XX}$ & $1 / 3 / \mathrm{XX}$ & $1 / 2 / \mathrm{XX}$ \\
\hline Cask Helium Backfill Complete & & & & & \\
\hline Queuing Finish: & 1500 & 1500 & 1500 & 1500 & 1500 \\
\hline Date & $1 / 26 / \mathrm{XX}$ & $1 / 26 / \mathrm{XX}$ & $1 / 26 / \mathrm{XX}$ & $1 / 26 / \mathrm{XX}$ & $1 / 26 / \mathrm{XX}$ \\
\hline
\end{tabular}

Table B-4 indicates an example tracking form for the scrap basket. The queuing start time is determined from the finish time of the first fuel cleaned.

The average water temperature for the first time increment of particulate generation is $50.5^{\circ} \mathrm{F}$ and the time increment is 1 hour between the start of queuing and the first water temperature measurement. From Table B-2, the reaction rate at $50.5^{\circ} \mathrm{F}$ is $0.00098 \mathrm{mg}(\mathrm{wt}$ gain $) / \mathrm{hr}-\mathrm{cm}^{2}$. The initial cumulative particulate generated is $0 \mathrm{~kg} \mathrm{UO}_{2}$, so the reaction rate enhancement factor is 22. The rate and enhancement factor are used in Equation (B-1) for a scrap basket to yield a reaction rate yielding $0.0082 \mathrm{~kg} \mathrm{UO}_{2} / \mathrm{hr}(0.380 \times 22 \times 0.00098)$. The particulate generated over the first time increment is $0.0082 \mathrm{~kg} \mathrm{UO} 2(0.0082 \mathrm{~kg} / \mathrm{hr} \times 1 \mathrm{hr})$. This calculation is continued on a daily basis until the loaded $\mathrm{MCO} /$ cask is purged with helium, or the hydride generation boundary of $3.495 \mathrm{~kg} \mathrm{UO}_{2}$ has been accumulated in the scrap basket. Once the cumulative particulate generated in a scrap basket reaches this boundary, the reaction rate enhancement factor used in the particulate generation calculation is reduced to 10 . This is shown on $1 / 21$ in the example calculation shown on Table B-4.

Similar tracking calculations are performed for fuel baskets using Equation (B-2) to calculate the particulate generation rate. Tables B-5, B-6, B-7, and B-8 show the basket tracking sheet calculations for fuel baskets in the example. 
Once a loaded MCO/cask has been backfilled with helium, a final summary particulate generation form can be completed as shown on Table B-9. This summarizes the particulate generated in each basket and compares the total to the particulate generation limit specified in Section 2.1.5. For this example, the total $\mathrm{MCO}$ generated particulate inventory is $7.45 \mathrm{~kg} \mathrm{\textrm {UO } _ { 2 }}$ after basket queuing times that range from 20 to 24 days. Note that the maximum water temperature is this example is $55^{\circ} \mathrm{F}\left(13^{\circ} \mathrm{C}\right)$. Table $\mathrm{B}-1$, combined with Figure B-3, provides a queuing time guideline of 39 days $(0.75 \times 52$ days $)$, which is an indication of the time when the basket queuing time approaches the particulate generation limit of $11.9 \mathrm{~kg} \mathrm{UO}_{2}$.

\section{Table B-4. Tracking Example - Particulate Generated During Scrap Basket Queuing}

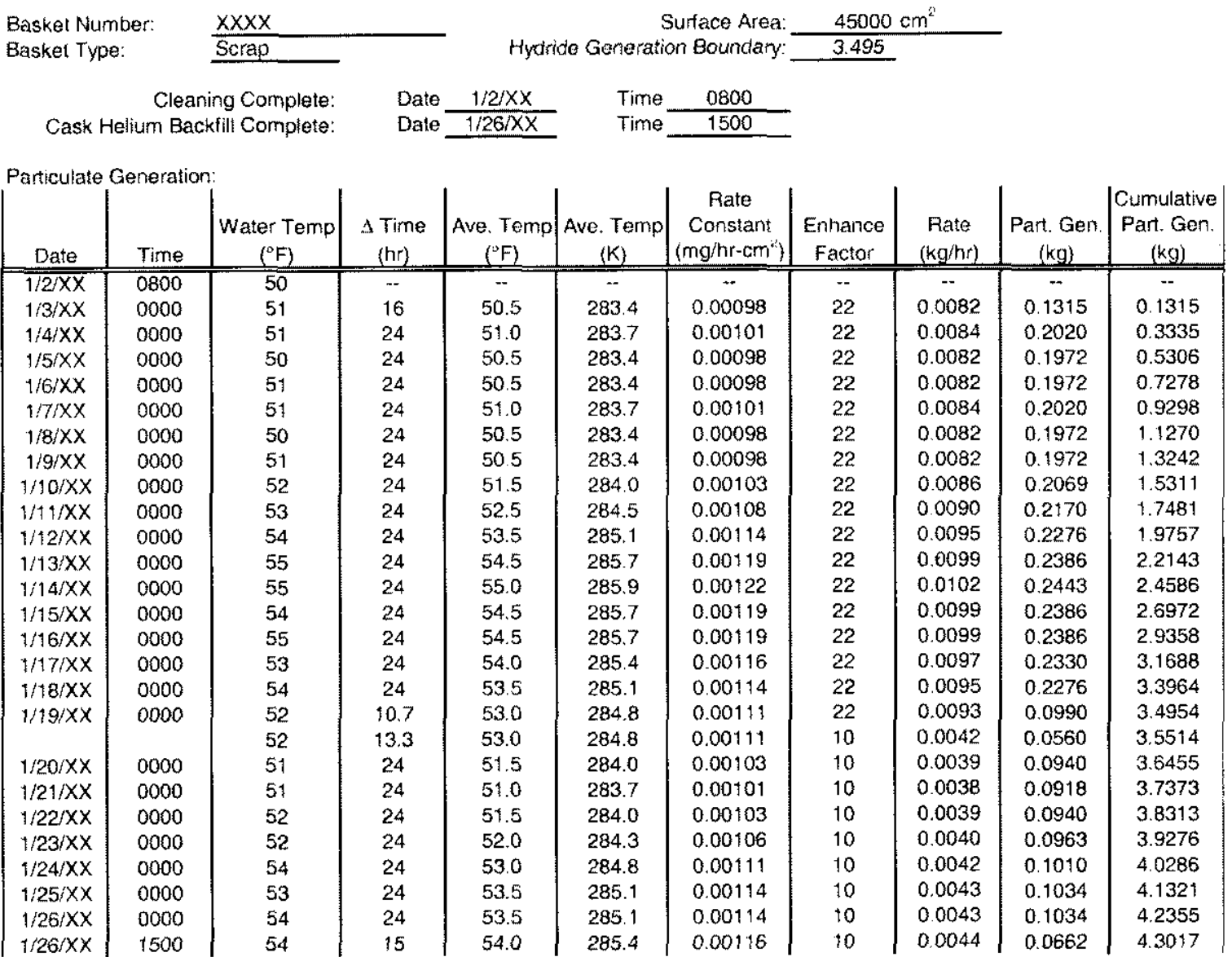


HNF-SD-SNF-OCD-001, Rev. 5

Table B-5. Tracking Example - Particulate Generated During Fuel Basket 1 Queuing

\begin{tabular}{|c|c|c|c|c|c|c|c|c|c|c|}
\hline Basket Nu & & $X X X Y$ & & & S & Surface Area: & $\frac{7900}{0726}$ & $m^{2}$ & & \\
\hline Basket Ty & & Fuel & & Hydri & ide Generati & & & & & \\
\hline & Clea & ing Complete: & Date & $1 / 2 / x \times$ & Time & 0800 & & & & \\
\hline Cask & lium $\mathrm{Ba}$ & xfill Complete: & Date & $1 / 26 / \times x$ & Time & 1500 & & & & \\
\hline Part & $\mathrm{ra}$ & & & & & & & & & \\
\hline Date & Time & $\begin{array}{c}\text { Water Temp } \\
\text { ('F) }\end{array}$ & $\begin{array}{l}\text { a Time } \\
\text { (hr) }\end{array}$ & $\begin{array}{c}\text { Ave. Temp } \\
\text { (F) }\end{array}$ & $\begin{array}{c}\text { Ave. Temp } \\
\text { (K) }\end{array}$ & $\begin{array}{c}\text { Rate } \\
\text { Constant } \\
\left(m g^{\prime} h r \cdot \mathrm{cm}^{2}\right)\end{array}$ & $\begin{array}{c}\text { Enhance } \\
\text { Factor }\end{array}$ & $\begin{array}{c}\text { Rate } \\
\text { (ko/hr) }\end{array}$ & $\begin{array}{c}\text { Part. Gen. } \\
(\mathrm{kg})\end{array}$ & $\begin{array}{c}\text { Cumulative } \\
\text { Part. Gen. } \\
\text { (kg) }\end{array}$ \\
\hline $1 / 2 / X X$ & 0800 & 50 & -- & $\cdots$ & - & $m$ & w. & - & -- & $\cdots$ \\
\hline $1 / 3 / \times x$ & 0000 & 51 & 16 & 50.5 & 283.4 & 0.00098 & 22 & 0.0014 & 0.0231 & 0.0231 \\
\hline $1 / 4 / X X$ & 0000 & 51 & 24 & 51.0 & 283.7 & 0.00101 & 22 & 0.0015 & 0.0355 & 0.0585 \\
\hline $1 / 5 / \times X$ & 0000 & 50 & 24 & 50.5 & 283.4 & 0.00098 & 22 & 0.0014 & 0.0346 & 0.0932 \\
\hline $1 / 6 / x \times$ & 0000 & 51 & 24 & 50.5 & 283.4 & 0.00098 & 22 & 0.0014 & 0.0346 & 0.1278 \\
\hline $1 \pi / \times x$ & 0000 & 51 & 24 & 51.0 & 283.7 & 0.00101 & 22 & 0.0015 & 0.0355 & 0.1632 \\
\hline $1 / 8 / x \times$ & 0000 & 50 & 24 & 50.5 & 283.4 & 0.00098 & 22 & 0.0014 & 0.0346 & 0.1979 \\
\hline $1 / 9 / \times X$ & 0000 & 51 & 24 & 50.5 & 283.4 & 0.00098 & 22 & 0.0014 & 0.0346 & 0.2325 \\
\hline $1 / 10 / x X$ & 0000 & 52 & 24 & 51.5 & 284.0 & $0.00 \pm 03$ & 22 & 0.0015 & 0.0363 & 0.2688 \\
\hline $1 / 11 / x x$ & 0000 & 53 & 24 & 52.5 & 284.5 & 0.00108 & 22 & 0.0016 & 0.0381 & 0.3069 \\
\hline $1 / 12 / X X$ & 0000 & 54 & 24 & 53.5 & 285.1 & 0.00114 & 22 & 0.0017 & 0.0400 & 0.3468 \\
\hline $1 / 13 / X X$ & 0000 & 55 & 24 & 54.5 & 285.7 & 0.00119 & 22 & 0.0017 & 0.0419 & 0.3887 \\
\hline $1 / 14 / X X$ & 0000 & 55 & 24 & 55.0 & 285.9 & 0.00122 & 22 & 0.0018 & 0.0429 & 0.4316 \\
\hline $1 / 15 / X \times$ & 0000 & 54 & 24 & 54,5 & 285.7 & 0.00119 & 22 & 0.0017 & 0.0419 & 0.4735 \\
\hline $1 / 46 / x \times$ & 0000 & 55 & 24 & 54.5 & 285.7 & 0.00119 & 22 & 0.0017 & 0.0419 & 0.5154 \\
\hline $1 / 17 / X \times$ & 0000 & 53 & 24 & 54.0 & 285.4 & 0.00116 & 22 & 0.0017 & 0.0409 & 0.5563 \\
\hline $1 / 18 / \times X$ & 0000 & 54 & 24 & 53.5 & 285.1 & 0.00114 & 22 & 0.0017 & 0.0400 & 0.5963 \\
\hline $1 / 19 / \mathrm{XX}$ & 0000 & 52 & 24 & 53.0 & 284.8 & 0.00111 & 22 & 0.0016 & 0.0390 & 0.6353 \\
\hline $1 / 20 / X \times$ & 0000 & 51 & 24 & 51.5 & 284.0 & 0.00103 & 22 & 0.0015 & 0.0363 & 0.6716 \\
\hline $1 / 21 / X X$ & 0000 & 51 & 24 & 51.0 & 283.7 & 0.00101 & 22 & 0.0015 & 0.0355 & 0.7070 \\
\hline $1 / 22 / X X$ & 0000 & 52 & 12.5 & 51.5 & 284.0 & 0.00103 & 22 & 0.0015 & 0.0189 & 0.7260 \\
\hline & & 52 & 11.5 & 51.5 & 284.0 & 0.00103 & 10 & 0.0007 & 0.0079 & 0.7339 \\
\hline $1 / 23 / X X$ & 0000 & 52 & 24 & 52.0 & 284.3 & 0.00106 & 10 & 0.0007 & 0.0169 & 0.7508 \\
\hline$t / 24 / x \times$ & 0000 & 54 & 24 & 53.0 & 284.8 & 0.00111 & 10 & 0.0007 & 0.0177 & 0.7685 \\
\hline $1 / 25 / X X$ & 0000 & 53 & 24 & 53.5 & 285.1 & 0.00114 & 10 & 0.0008 & 0.0182 & 0.7867 \\
\hline $1 / 26 / X X$ & 0000 & 54 & 24 & 53.5 & 285.1 & 0.00114 & 10 & 0.0008 & 0.0182 & 0.8048 \\
\hline $1 / 26 / X X$ & 1500 & 54 & 15 & 54.0 & 285.4 & 0.00116 & 10 & 0.0008 & 0.0116 & 0.8165 \\
\hline
\end{tabular}

Total Particulate from Fuel Basket \#1 Loaded into MCO

$0.816 \mathrm{~kg}$ 
HNF-SD-SNF-OCD-001, Rev. 5

Table B-6. Tracking Example - Particulate Generated During Fuel Basket 2 Queuing

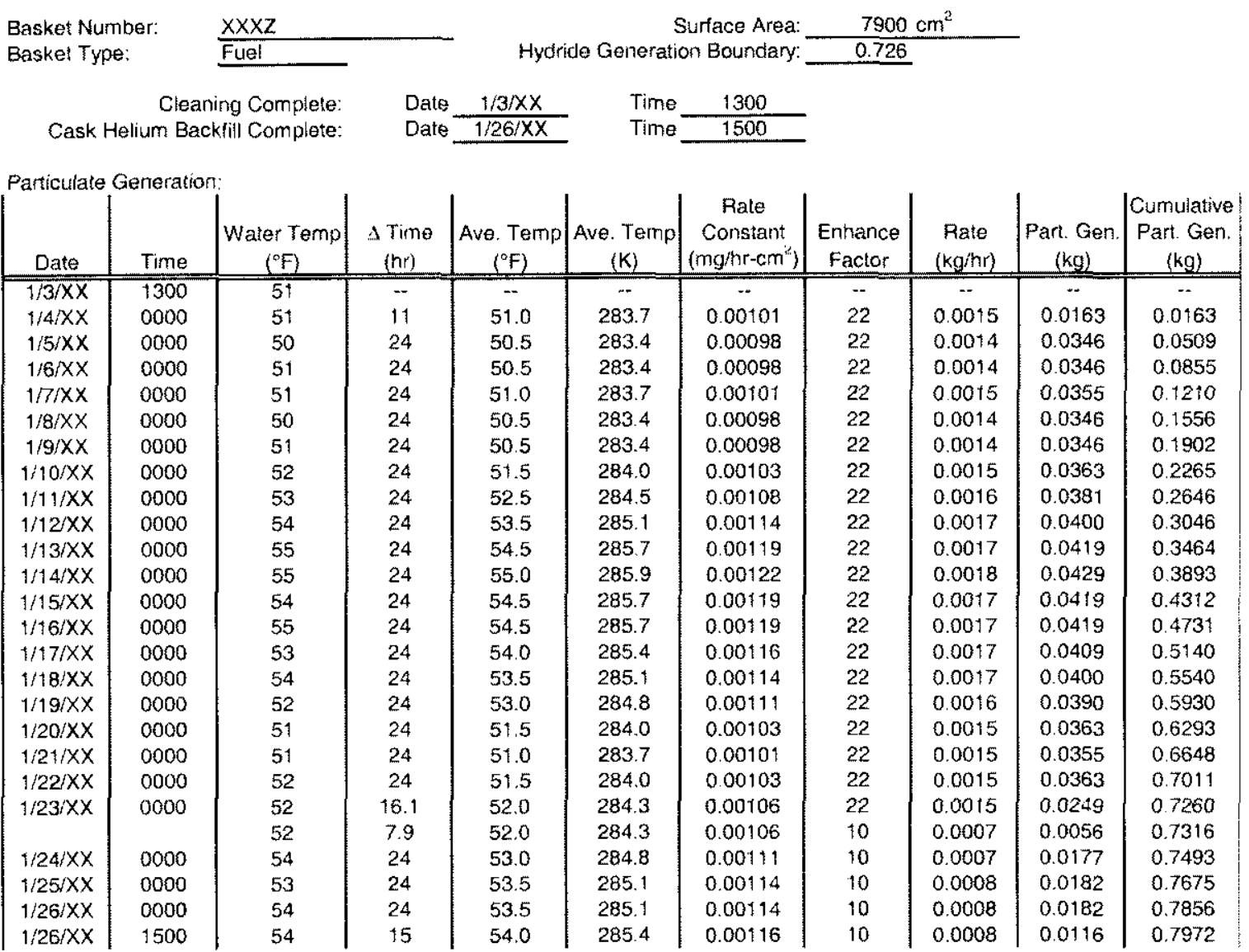

Total Particulate from Fuel Basket \#2 Loaded into MCO

$0.797 \mathrm{~kg}$ 
HNF-SD-SNF-OCD-001, Rev. 5

Table B-7. Tracking Example - Particulate Generated During Fuel Basket 3 Queuing

\begin{tabular}{|c|c|c|c|c|c|c|c|c|c|c|}
\hline \multirow{2}{*}{\multicolumn{2}{|c|}{$\begin{array}{l}\text { Basket Number: } \\
\text { Basket Type: }\end{array}$}} & \multirow{2}{*}{\multicolumn{2}{|c|}{$\frac{X X Y X}{\text { Fuel }}$}} & \multicolumn{3}{|r|}{ Surtace Area: } & \multicolumn{2}{|c|}{$7900 \mathrm{~cm}^{2}$} & & \\
\hline & & & \multirow{3}{*}{$\begin{array}{l}\text { Date } \\
\text { Date }\end{array}$} & \multicolumn{3}{|c|}{ Hydride Generation Boundary } & \multicolumn{2}{|l|}{0.726} & & \\
\hline & Cles & ing Complete: & & \multirow{2}{*}{$\frac{1 / 4 / X X}{1 / 26 / X X}$} & \multirow{2}{*}{$\begin{array}{l}\text { Time } \\
\text { Time }\end{array}$} & \multirow{2}{*}{$\begin{array}{l}1700 \\
1500 \\
\end{array}$} & & & & \\
\hline Cask & lium $B$ & sfill Complete: & & & & & & & & \\
\hline \multicolumn{11}{|c|}{ Particulate Generation: } \\
\hline Date & Time & $\begin{array}{c}\text { Water Temp } \\
\text { ( F) }\end{array}$ & $\begin{array}{l}\text { A Time } \\
(\mathrm{hr})\end{array}$ & $\begin{array}{c}\text { Ave. Temp } \\
\left({ }^{\circ} \mathrm{F}\right)\end{array}$ & $\begin{array}{c}\text { Ave. Termp } \\
(\mathrm{K})\end{array}$ & $\begin{array}{c}\text { Rate } \\
\text { Constant } \\
\left(m g / h r-\mathrm{cm}^{2}\right)\end{array}$ & $\begin{array}{c}\text { Enhance } \\
\text { Factor }\end{array}$ & $\begin{array}{c}\text { Rate } \\
(\mathrm{kg} / \mathrm{hr})\end{array}$ & $\begin{array}{c}\text { Part. Gen. } \\
\text { (kg) }\end{array}$ & $\begin{array}{c}\text { Cumulative } \\
\text { Part. Gen. } \\
(\mathrm{kg})\end{array}$ \\
\hline $1 / 4 / \times X$ & 1700 & 51 & 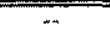 & 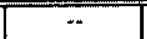 & -- & - & - & $\ldots$ & $-\infty$ & 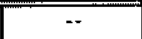 \\
\hline $1 / 5 / \times X$ & 0000 & 50 & 7 & 50.5 & 283.4 & 0.00098 & 22 & 0.0014 & 0.0101 & 0.0101 \\
\hline $1 / 6 / X X$ & 0001 & 51 & 24 & 50.5 & 283.4 & 0.00098 & 22 & 0.0014 & 0.0346 & 0.0447 \\
\hline $1 / \pi / \times X$ & 0000 & 51 & 24 & 51.0 & 283.7 & 0.00101 & 22 & 0.0015 & 0.0355 & 0.0802 \\
\hline $1 / 8 / X X$ & 0000 & 50 & 24 & 50.5 & 283.4 & 0.00098 & 22 & 0.0014 & 0.0346 & 0.1148 \\
\hline $1 / 9 / X X$ & 0000 & 51 & 24 & 50.5 & 283.4 & 0.00098 & 22 & 0.0074 & 0.0346 & 0.1494 \\
\hline $1 / 10 / \times X$ & 0000 & 52 & 24 & 51.5 & 284.0 & 0.00103 & 22 & 0.0015 & 0.0363 & 0.1857 \\
\hline $1 / 11 / X X$ & 0000 & 53 & 24 & 52.5 & 284.5 & 0.00108 & 22 & 0.0016 & 0.0381 & 0.2238 \\
\hline $1 / 12 / X X$ & 0000 & 54 & 24 & 53.5 & 285.1 & 0.00114 & 22 & 0.0017 & 0.0400 & 0.2638 \\
\hline $1 / 13 / \times X$ & 0000 & 55 & 24 & 54.5 & 285.7 & 0.00119 & 22 & 0.0017 & 0.0419 & 0.3057 \\
\hline $1 / 14 / x X$ & 0000 & 55 & 24 & 55.0 & 285.9 & 0.00122 & 22 & 0.0018 & 0.0429 & 0.3486 \\
\hline $1 / 15 / \times X$ & 0000 & 54 & 24 & 54.5 & 285.7 & $0.00 \$ 19$ & 22 & 0.0017 & 0.0419 & 0.3904 \\
\hline $1 / 16 / X X$ & 0000 & 55 & 24 & 54.5 & 285.7 & 0.00119 & 22 & 0.0017 & 0.0419 & 0.4323 \\
\hline $1 / 17 / X X$ & 0000 & 53 & 24 & 54.0 & 285.4 & 0.00116 & 22 & 0.0017 & 0.0409 & 0.4732 \\
\hline $1 / 18 / \times X$ & 0000 & 54 & 24 & 53.5 & 285.1 & 0.00114 & 22 & 0.0017 & 0.0400 & 0.5132 \\
\hline $1 / 19 / \mathrm{XX}$ & 0000 & 52 & 24 & 53.0 & 284.8 & 0.00111 & 22 & 0.0016 & 0.0390 & 0.5522 \\
\hline $1 / 20 / \times x$ & 0000 & 51 & 24 & 51.5 & 284.0 & 0.00103 & 22 & 0.0015 & 0.0363 & 0.5885 \\
\hline $1 / 21 / X X$ & 0000 & 51 & 24 & 51.0 & 283.7 & 0.00101 & 22 & 0.0015 & 0.0355 & 0.6240 \\
\hline $1 / 22 / x \times$ & 0000 & 52 & 24 & 51.5 & 284.0 & 0.00103 & 22 & 0.0015 & 0.0363 & 0.6603 \\
\hline $1 / 23 / x X$ & 0000 & 52 & 24 & 52.0 & 284.3 & 0.00106 & 22 & 0.0015 & 0.0372 & 0.6975 \\
\hline \multirow[t]{2}{*}{$1 / 24 / \times X$} & 0000 & 54 & 17.5 & 53.0 & 284.8 & 0.00111 & 22 & 0.0016 & 0.0285 & 0.7260 \\
\hline & & 54 & 6 & 53.0 & 284.8 & 0.00111 & 10 & 0.0007 & 0.0048 & 0.7308 \\
\hline $1 / 25 / X X$ & 0000 & 53 & 24 & 53.5 & 285.1 & 0.00114 & 10 & 0.0008 & 0.0182 & 0.7489 \\
\hline $1 / 26 / x X$ & 0000 & 54 & 24 & 53.5 & 285.1 & 0.00114 & 10 & 0.0008 & 0.0182 & 0.7671 \\
\hline $1 / 26 / X X$ & 1500 & 54 & 15 & 54.0 & 285.4 & 0.00116 & 10 & 0.0008 & 0.0116 & 0.7787 \\
\hline
\end{tabular}

Total Particulate from Fuel Basket \#3 Loaded into MCO

$0.779 \mathrm{~kg}$ 
HNF-SD-SNF-OCD-001, Rev. 5

Table B-8. Tracking Example - Particulate Generated During Fuel Basket 4 Queuing

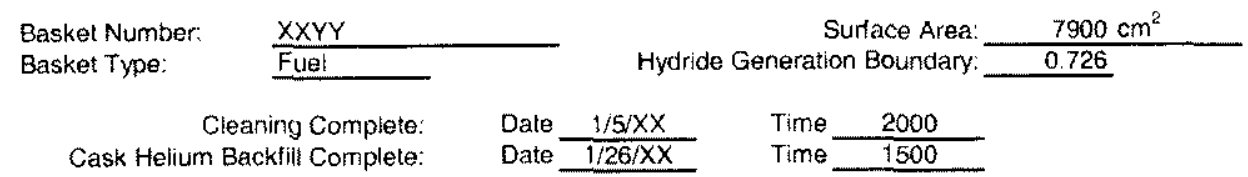

\begin{tabular}{|c|c|c|c|c|c|c|c|c|c|c|}
\hline \multicolumn{11}{|c|}{ Particulate Generation: } \\
\hline Date & Time & $\begin{array}{c}\text { Water Temp } \\
\text { (F) }\end{array}$ & $\begin{array}{c}\Delta \text { Time } \\
\text { (hr) }\end{array}$ & $\begin{array}{c}\text { Ave. Temp } \\
\left({ }^{\circ} \mathrm{F}\right)\end{array}$ & $\begin{array}{c}\text { Ave. Temp } \\
\text { (K) }\end{array}$ & $\begin{array}{c}\text { Rate } \\
\text { Constant } \\
\left.\text { (mg/hr-cm }{ }^{2}\right)\end{array}$ & $\begin{array}{c}\text { Enhance } \\
\text { Factor }\end{array}$ & $\begin{array}{c}\text { Fate } \\
(\mathrm{kg} / \mathrm{hr})\end{array}$ & $\begin{array}{c}\text { Part. Gen. } \\
(\mathrm{kg})\end{array}$ & $\begin{array}{c}\text { Cumulative } \\
\text { Part. Gen. } \\
(\mathrm{kg})\end{array}$ \\
\hline $1 / 5 \mathrm{XX}$ & 2000 & & $\ldots$ & $\overline{\ldots *}$ & -- & - & -- & $\bar{m}$ & -.. & $\omega *$ \\
\hline $1 / 6 / x \times$ & 0000 & 51 & 4 & 25.5 & 269.5 & 0.00028 & 22 & 0.0004 & 0.0016 & 0.0016 \\
\hline $1 / 7 / \mathrm{XX}$ & 0000 & 51 & 24 & 51.0 & 283.7 & 0.00101 & 22 & 0.0015 & 0.0355 & 0.0371 \\
\hline $1 / 8 / x \times$ & 0000 & 50 & 24 & 50.5 & 283.4 & 0.00098 & 22 & 0.0014 & 0.0346 & 0.0717 \\
\hline $1 / 9 / \times x$ & 0000 & 51 & 24 & 50.5 & 283.4 & 0.00098 & 22 & 0.0014 & 0.0346 & 0.1063 \\
\hline $1 / 10 / x \times$ & 0000 & 52 & 24 & 51.5 & 284.0 & 0.00103 & 22 & 0.0015 & 0.0363 & 0.1426 \\
\hline $1 / 11 / x \times$ & 0000 & 53 & 24 & 52.5 & 284.5 & 0.00108 & 22 & 0.0016 & 0.0381 & 0.1807 \\
\hline $1 / 12 / X X$ & 0000 & 54 & 24 & 53.5 & 285.1 & 0.00114 & 22 & 0.0017 & 0.0400 & 0.2207 \\
\hline $1 / 13 / X X$ & 0000 & 55 & 24 & 54.5 & 285.7 & 0.00119 & 22 & 0.0017 & 0.0419 & 0.2626 \\
\hline $1 / 14 / X X$ & 0000 & 55 & 24 & 55.0 & 285.9 & 0.00122 & 22 & 0.0018 & 0.0429 & 0.3055 \\
\hline $1 / 15 / X \times$ & 0000 & 54 & 24 & 54.5 & 285.7 & 0.00119 & 22 & 0.0017 & 0.0419 & 0.3474 \\
\hline $1 / 16 / x \times$ & 0000 & 55 & 24 & 54.5 & 285.7 & 0.00119 & 22 & 0.0017 & 0.0419 & 0.3893 \\
\hline $1 / 17 / \mathrm{XX}$ & 0000 & 53 & 24 & 54.0 & 285.4 & 0.00116 & 22 & 0.0017 & 0.0409 & 0.4302 \\
\hline $1 / 18 / X X$ & 0000 & 54 & 24 & 53.5 & 285.1 & 0.00114 & 22 & 0.0017 & 0.0400 & 0.4701 \\
\hline $1 / 19: \times x$ & 0000 & 52 & 24 & 53.0 & 284.8 & 0.00111 & 22 & 0.0016 & 0.0390 & 0.5091 \\
\hline $1 / 20 / X X$ & 0000 & 51 & 24 & 51.5 & 284.0 & 0.00103 & 22 & 0.0015 & 0.0363 & 0.5454 \\
\hline $1 / 21 / X X$ & 0000 & 51 & 24 & 51.0 & 283.7 & 0.00101 & 22 & 0.0015 & 0.0355 & 0.5809 \\
\hline $1 / 22 / X X$ & 0000 & 52 & 24 & 51.5 & 284.0 & 0.00103 & 22 & 0.0015 & 0.0363 & 0.6172 \\
\hline $1 / 23 / \times X$ & 0000 & 52 & 24 & 52.0 & 284.3 & 0.00106 & 22 & 0.0015 & 0.0372 & 0.6544 \\
\hline $1 / 24 / X X$ & 0000 & 54 & 24 & 53.0 & 284.8 & 0.00111 & 22 & 0.0016 & 0.0390 & 0.6934 \\
\hline $1 / 25 / X X$ & 0000 & 53 & 19.5 & 53.5 & 285.1 & 0.00114 & 22 & 0.0017 & 0.0325 & 0.7260 \\
\hline & & 53 & 4.5 & 53.5 & 285.1 & 0.00114 & 10 & 0.0008 & 0.0034 & 0.7293 \\
\hline $1 / 26 / X \times$ & 0000 & 54 & 24 & 53.5 & 285.1 & 0.00114 & 10 & 0.0008 & 0.0182 & 0.7475 \\
\hline $1 / 26 / x \times$ & 1500 & 54 & 15 & 54.0 & 285.4 & 0.00116 & 10 & 0.0008 & 0.0116 & 0.7591 \\
\hline
\end{tabular}

Total Particulate from Fuel Basket \#4 Loaded into MCO

$0.759 \mathrm{~kg}$

\section{Table B-9: Tracking Example - Queuing Generated Particulate Loaded in MCO}

Cumulative Particulate Contained within MCO

\begin{tabular}{|c|c|c|}
$\begin{array}{c}\text { Basket } \\
\text { Number }\end{array}$ & $\begin{array}{c}\text { Basket } \\
\text { Type }\end{array}$ & $\begin{array}{c}\text { Cumulative } \\
\text { Part. Gen. } \\
(\mathrm{kg})\end{array}$ \\
\hline \hline XXXX & Scrap & 4.3017 \\
XXXY & Fuel & 0.8165 \\
XXXZ & Fuel & 0.7972 \\
XXYX & Fuel & 0.7787 \\
XXYY & Fuel & 0.7591 \\
\hline Total & & 7.4533 \\
\hline
\end{tabular}

(Cumulative Particulate Generation Limit $\leq 11.9 \mathrm{~kg}$ ) 


\section{B.6 REFERENCES FOR APPENDIX B}

Pajunen, A. L., 1998, Uranium Hydride in Multi-Canister Overpacks, HNF-3372, Rev 0, COGEMA Engineering, Richland, Washington.

Reilly, M. A., 1998, Spent Nuclear Fuel Project Technical Databook, HNF-SD-SNF-TI-015, Rev. 6, DE\&S Hanford, Richland, Washington.

Sherrell, D. L., 1998, Post Fuel-Cleaning Corrosion of Uranium Within MCO Payloads, HNF-3048, Rev. 0, and ECN 648623, DE\&S Hanford, Richland, Washington.

Sherrell, D. L., 1999, Spent Nuclear Fuel Inventory in Bulk MCO Water at the Cold Vacuum Drying Facility, HNF-SD-W441-CN-001, Rev. 3A, DE\&S Hanford, Richland, Washington. 
HNF-SD-SNF-OCD-001, Rev. 5

APPENDIX C. TECHNICAL CHECK

C-1 
HNF-SD-SNF-OCD-001, Rev. 5

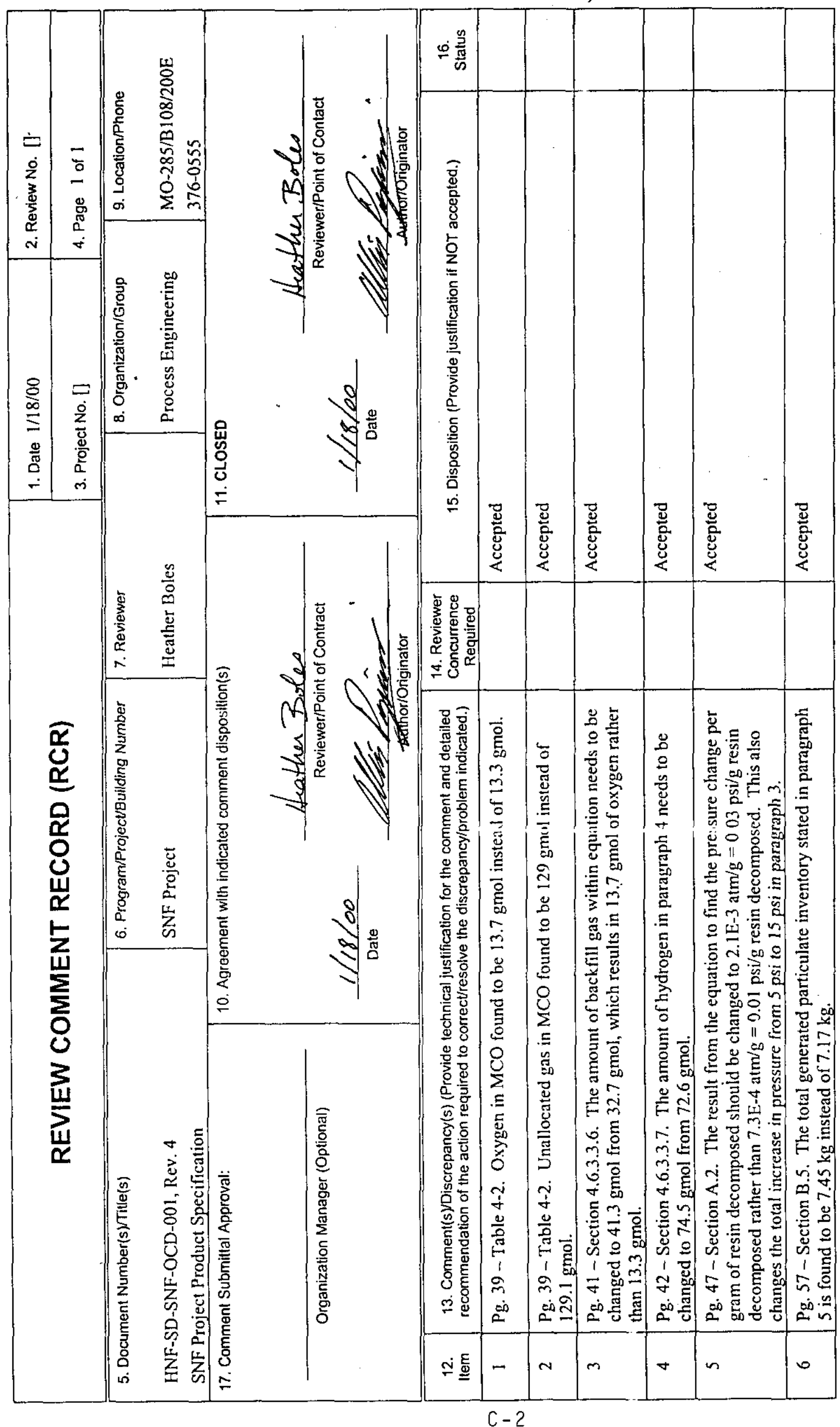


REVIEW CHECKLIST

Document Reviewed:

HNF-SD-SNF-OCD-001, Rev. 4 - Spent Nuclear Fuel project Product Specification

Scope of Review:

This review encompassed only calculations included within the document.

Yes No NA

$\bigcirc \bigcirc$ * Previous reviews complete and cover analysis, up to scope of this revjew, with no gaps.

O $\bigcirc$ Problem completely defined.

$\bigcirc \bigcirc$ Accident scenarios developed in a clear and logical manner.

O $\bigcirc$ Necessary assumptions explicitly stated and supported.

O $\bigcirc$ Computer codes and data files documented.

- $\bigcirc \bigcirc$ Data used in calculations explicitly stated in document.

(-) $\bigcirc$ Data checked for consistency with original source information as applicable.

(-) $\bigcirc$ Mathematical derivation checked including dimensional consistency of results.

$\bigcirc \bigcirc$ Models appropriate and used within range of validity or use outside range of established validity justified.

( $\bigcirc \bigcirc$ Hand calculations checked for errors. Spreadsheet results should be treated exactly the same as hand calculations.

$\bigcirc \bigcirc$ Software input correct and consistent with document reviewed.

$\bigcirc \bigcirc$ Software output consistent with input and with results reported in document reviewed.

$\bigcirc \bigcirc$ Limits/criteria/guidelines applied to analysis results are appropriate and referenced. Limits/criteria/guidelines checked against references.

$\bigcirc \bigcirc$ Safety margins consistent with good engineering practices.

$\bigcirc \bigcirc$ Conclusions consistent with analytical results and applicable limits.

$\bigcirc \bigcirc$ Results and conclusions address all points required in the problem statement.

$\bigcirc \bigcirc$ Format consistent with appropriate NRC Regulatory Guide or other standards.

(-) $\bigcirc$ * Review calculations, comments, and/or notes are attached.

(-) $\bigcirc$ Document approved.

Heather Boles Leather Boles

Reviewer (Printed Name and Signature)

$1 / 18 / 00$

Date

*Any calculations, comments, or notes generated as part of this review should be signed, dated and attached to this checklist. Such material should be labeled and recorded in such a manner as to be intelligible to a technically qualified third party. 
HNF-SD-SNF-OCD-001, Rev. 5

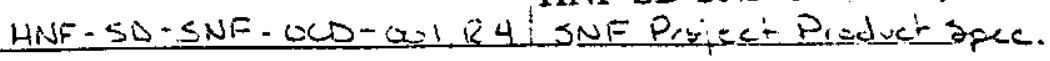

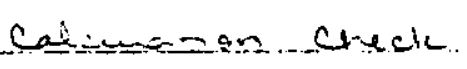

$1 / 2$

S=-tur 4.1.2.1 - Cuares Surap Bomidet Sictor Looding

AHB $1 / 18 / 2000$

$$
\begin{array}{r}
A=4 \pi^{2}=\pi d^{2} \text { where } d=1 / 4 \text { in } \times 2.54 \frac{\mathrm{sm}}{\mathrm{m}}=0.635 \mathrm{~cm} \\
A=\pi(0.635)^{2}=1.267 \mathrm{~cm}^{2} / \text { surap piecs }
\end{array}
$$

tutal sciap surfice aivar, 834 serap piecus

$$
1.20=\mathrm{cm}^{2} / \text { scrap picin } \times 834 \text { surap pewes }=1056.49 \mathrm{~cm}^{2} \mathrm{vs} \text {. }
$$

increase: $\frac{1056.49}{25.400}=0.0417 \times 100 \cdot 4.17 \%$ increasir

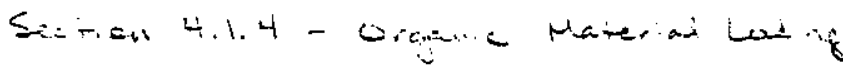

(3)

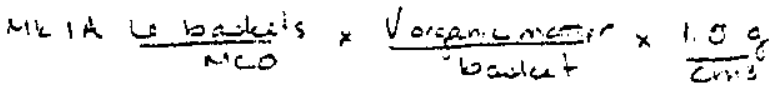

$$
\begin{aligned}
& \text { Vergan...nster }=3 \mathrm{in}^{2} \times 5 \mathrm{mils} \times \frac{\text { in }}{1000 \mathrm{mils}} \\
& 3 \ldots \times 0.00 \sin =0.05 \operatorname{in}^{3} \times \frac{m^{3}}{6.102 E_{4} \mathrm{in}^{3}} \times\left(\frac{100 \ldots}{k}\right)^{3} \\
& =0.2458 \mathrm{~cm}^{3}
\end{aligned}
$$

$$
6 \times 0.2458 \times 1.5=2.212 \mathrm{~g} / \mathrm{mcC}
$$

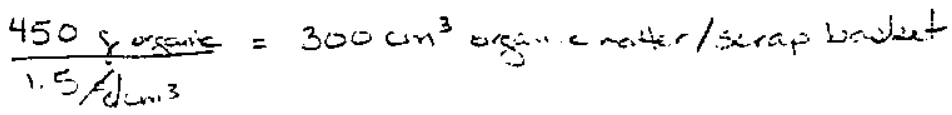

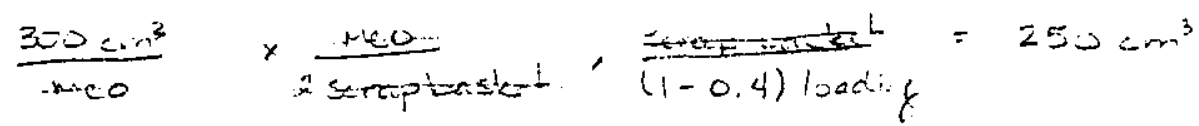

Son-iun 4.3.4- Caik Tenperative

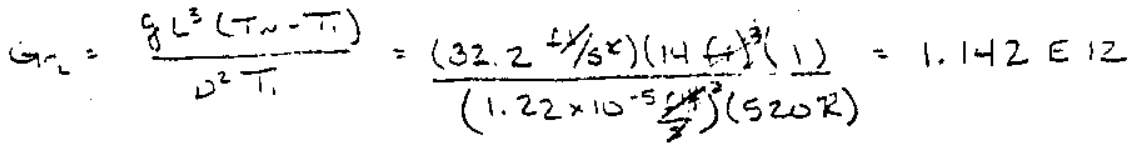

$$
\begin{aligned}
& \operatorname{Gr} P_{r}=(1.142 E 12)(8.07)=9.213 \Xi 12 \\
& h=\frac{k}{L}(0.021)\left(G_{r_{L}} P_{r}\right)^{2 / 5}=\frac{\left(0.34 \frac{B T}{4 r f t-F}\right)}{(14 \mathrm{ft})}(0.021)(9.213 E 12)^{2 / 5} \\
& =73.22 \frac{\mathrm{BTU}}{\mathrm{hr} \cdot \mathrm{f \textrm {t } ^ { 2 }} \cdot \cdot \mathrm{F}}
\end{aligned}
$$

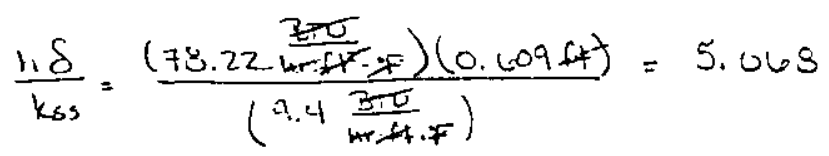

C -4 


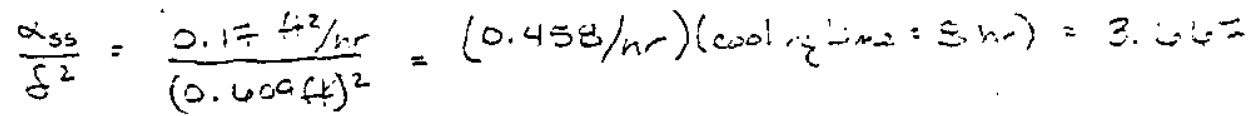

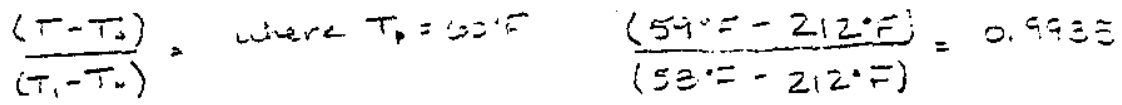

$$
\begin{aligned}
& \text { 正- } \\
& 3-3 \cdots+V=
\end{aligned}
$$

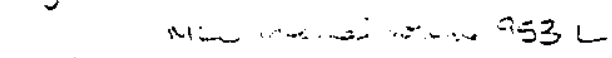

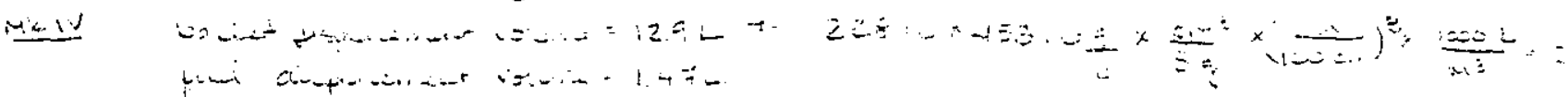

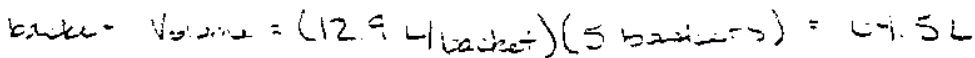

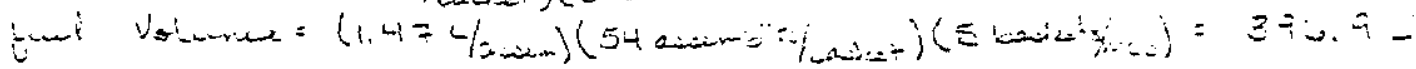
$V=953-[645+396.9 L]=491.6 \mathrm{~L} / \mathrm{KKO}$

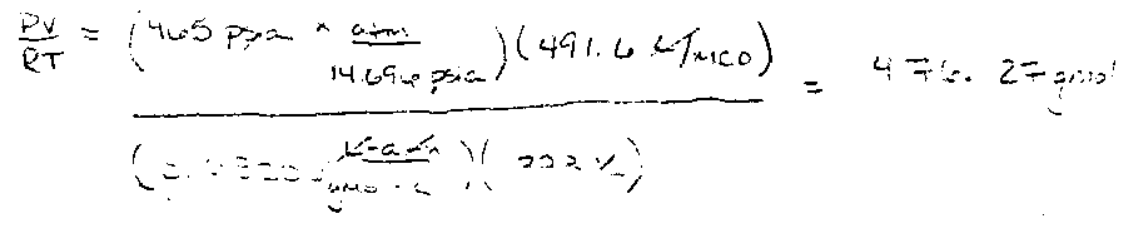

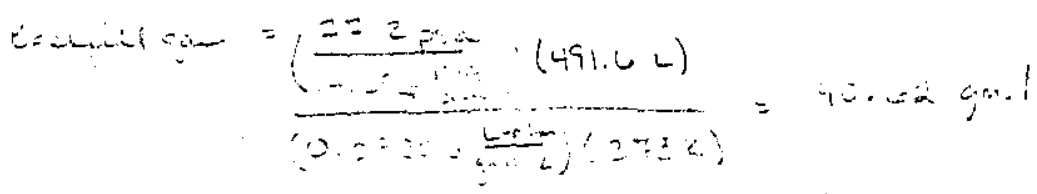

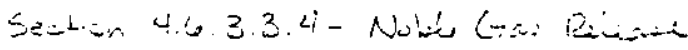

$C=45.45 \% \operatorname{cor}$

$X_{c}=$ L28. Lesin.

$\mathrm{H}_{2} \mathrm{O}=275 \mathrm{i}^{\ldots+\mathrm{i}}$

$$
\begin{aligned}
& u+2 H_{2} O \rightarrow \mathrm{NO}_{2}+\mathrm{H}_{2} \\
& x-275
\end{aligned}
$$

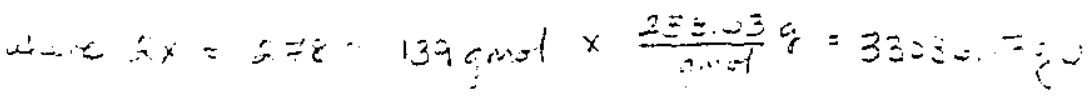

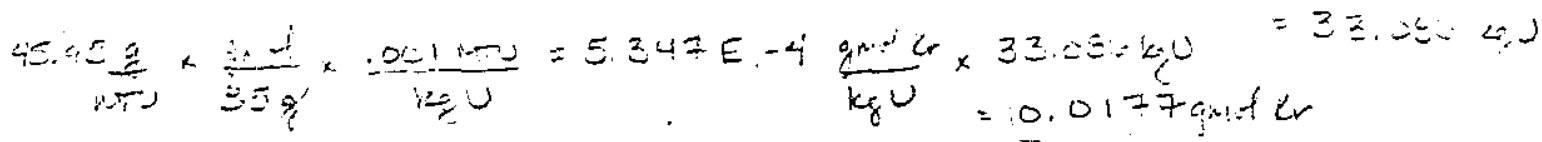

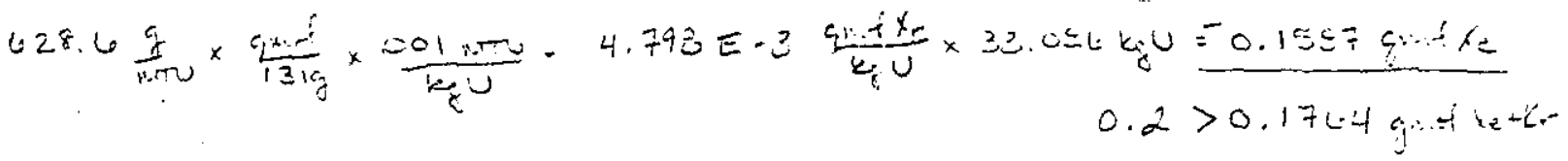




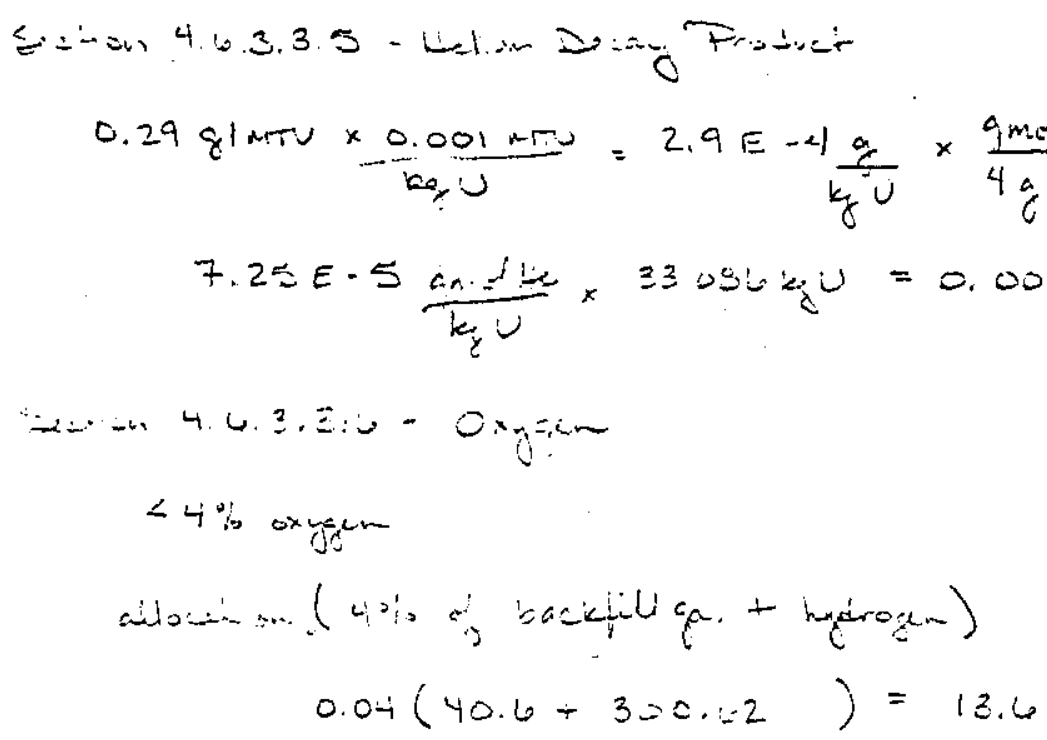




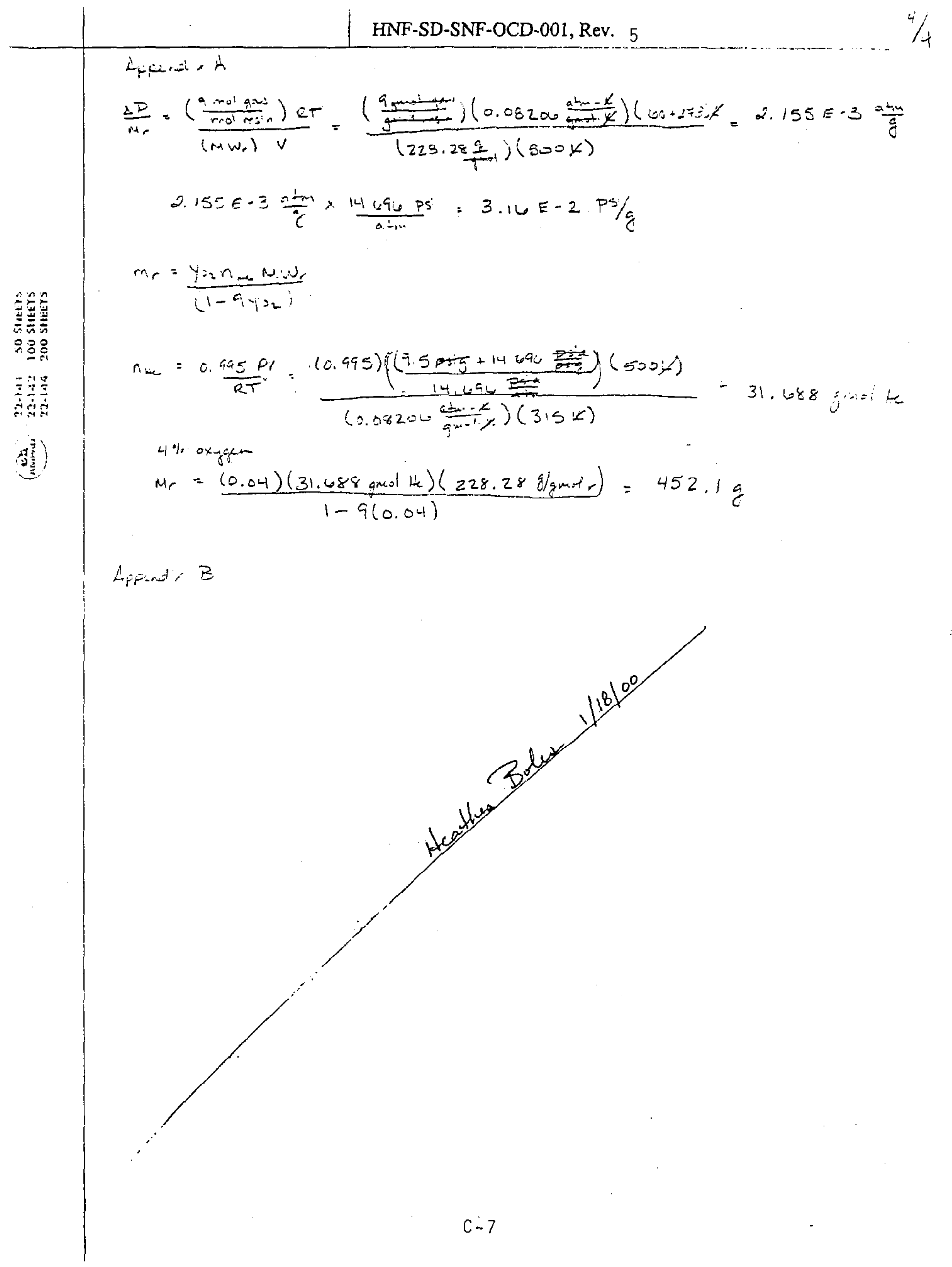


HNF-SD-SNF-OCD-001, Rev. 5

\section{APPENDIX D. MINIMUM CASK RESIDENCE TIME IN BASIN WATER}

\section{D.1 BACKGROUND/PURPOSE}

The shipping window for transport of an MCO/Cask, loaded with fuel, from the basins to the CVD Facility is based on thermal analyses. These analyses assume that the package is at an initial temperature at the start of the shipping window. Since a cask could arrive at the basin from the CSB after transport on a hot day or be stored outside for a significant time period, the potential exists for the cask and MCO to initially be warmer than the initial temperature assumed by the transport analyses.

A hot cask would be cooled by the basin water. The purpose of this appendix is to estimate the minimum time an $\mathrm{MCO} /$ cask would be required to reside in the basin water to satisfy the initial temperature criterion used by transport thermal analyses. Since the cask itself represents the dominant thermal mass of the loaded $\mathrm{MCO} /$ cask system, cooling of a hot empty cask immersed in the basin water is used as the basis for determining minimum residence times.

\section{D.2 SUMMARY}

This appendix summarizes the basis for determining the minimum residence time required for a hot cask in basin water such that the cask mass averaged temperature (assumed to enter the water at $150^{\circ} \mathrm{F}$ ) is less than $70^{\circ} \mathrm{F}$. A mass averaged temperature is used for comparison with the initial conditions required for transport assuming residual thermal gradients would essentially equalize in the cask wall upon removal from the basin water.

The hot cask is found to essentially equilibriate with the water temperature in approximately 8 hours, based on the time for the cask mass averaged temperature to be reduced to less than $70^{\circ} \mathrm{F}$ by water at $69^{\circ} \mathrm{F}$ (the cask wall temperature varies between $69^{\circ} \mathrm{F}$ and $70^{\circ} \mathrm{F}$ for this particular case). Shorter residence times are required to cool the cask below $70^{\circ} \mathrm{F}$ when immersed in colder basin water. Figure D-1 indicates the variation of the required cooling time with temperature. Based on Figure D-1, the cask will satisfy the transport initial temperature assumptions after immersion for 2 hours if the basin water is maintained below $53^{\circ} \mathrm{F}$. 
HNF-SD-SNF-OCD-001, Rev. 5

\section{Figure D-1. Variation of Cask Cooling Time with Basin Water Temperature}

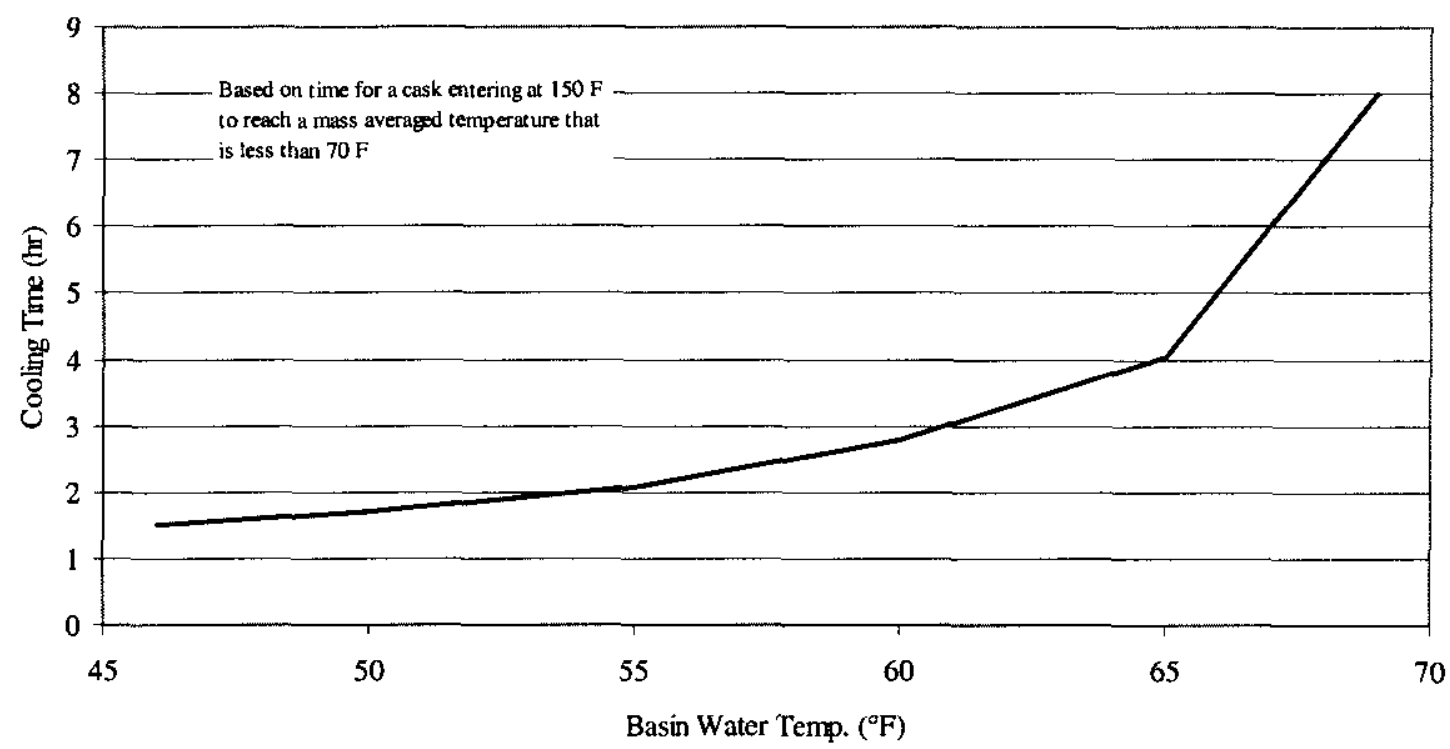

\section{D.3 Cask CoOling Time Basis}

A simplified model of cask cooling was used to estimate the residence times for a cask in basin water that satisfies the initial temperature criterion. The basic configuration modeled is shown in Figure D-2. Upon immersion in the basin water, the cask is assumed to be insulated from the basin water at the outer wall by the immersion pail structure. Basin water is assumed to cool the inner surface of the cask by natural convection. The presence of the empty MCO in the cask and the effects of loading fuel baskets are neglected.

The transient temperature profile of the cask is evaluated at three points in the cask by modeling the cask wall as a flat plate with one surface insulated and convective heat transfer from the other surface. Dimensionless plots for the temperature response of a thick plate with insulated rear face after sudden exposure to a uniform convective environment are presented in Rohsenow and Hartnett (1973). The temperature response plots allow evaluation of the cask wall temperature at the cooled surface, an interior cask wall point that is $40 \%$ of the distance between the cooled and insulated surface, and the insulated surface. These three temperatures are used to calculate a mass averaged cask temperature as the cask is cooled. 
Figure D-2. Assumed Cask Cooling Configuration

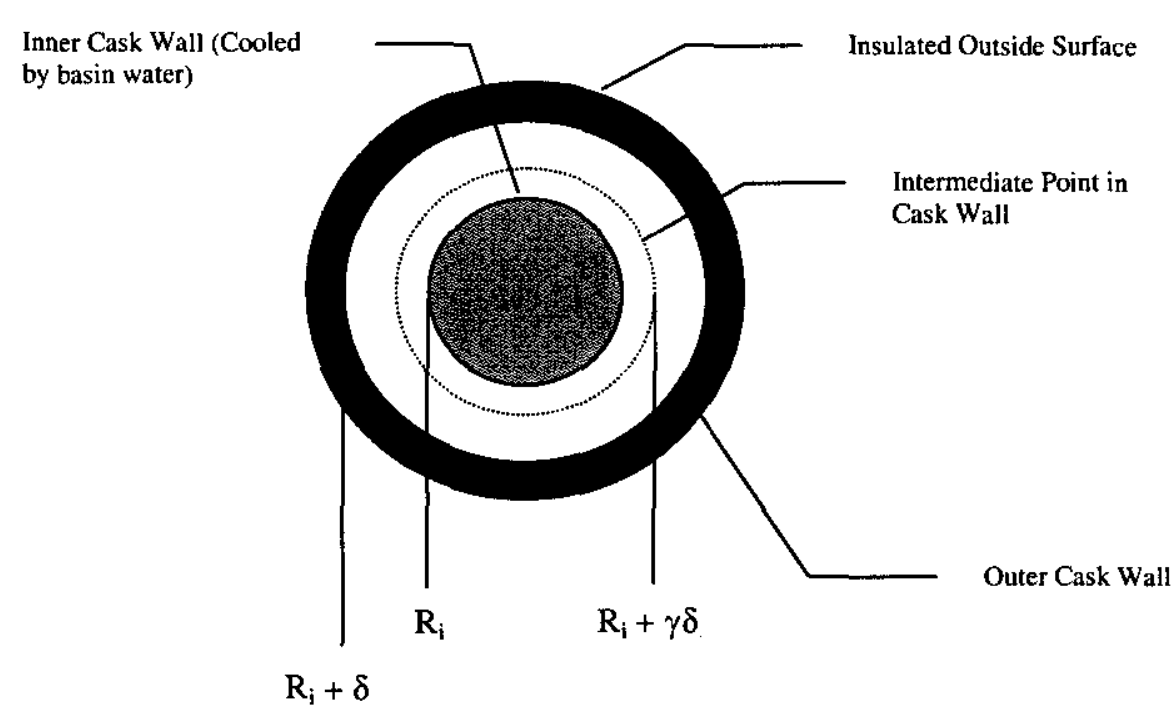

An example of the temperature response calculation is indicated by estimating the cask cooling time assuming the basin water temperature is $69^{\circ} \mathrm{F}$. The cask wall is modeled as a thick plane, insulated at one surface, with thickness equal to the cask wall thickness ( 7.31 inches).

Welty, et al. (1969) describes a correlation for convective heat transfer from a vertical plane. For material properties at $80^{\circ} \mathrm{F}$ (Welty, et al. 1969) and cask dimensions (Smith 2000),

$$
\begin{aligned}
& \operatorname{Pr}=\text { water Prandtl Number }=5.89 \\
& \mathrm{v}=\text { water kinematic viscosity }=0.929 \times 10^{-5} \mathrm{ft}^{2} / \mathrm{sec} \\
& \mathrm{k}=\text { water thermal conductivity }=0.35 \mathrm{BTU} / \mathrm{hr}-\mathrm{ft}-{ }^{\circ} \mathrm{F} \\
& \beta=\text { water thermal expansion coefficient }=1.3 \times 10^{-4},{ }^{\circ} \mathrm{F}^{-1} \\
& \mathrm{k}_{\mathrm{ss}}=\text { stainless steel thermal conductivity }=9.4 \mathrm{BTU} / \mathrm{hr}-\mathrm{ft}-{ }^{\circ} \mathrm{F} \\
& \alpha_{\mathrm{ss}}=\text { stainless steel thermal diffusivity }=0.17 \mathrm{ft}^{2} / \mathrm{hr} \\
& \mathrm{L}=\text { cask height }=14 \mathrm{ft} \\
& \delta=\text { cask wall thickness }=7.31 \text { inches }=0.609 \mathrm{ft}
\end{aligned}
$$

the convective heat transfer coefficient at the cask wall can be estimated based on the Grashof Number, Gr.

$$
G r_{L}=\frac{\beta g L^{3}\left(T_{w}-T_{l}\right)}{v^{2}}
$$

where: $\mathrm{g}=32.2 \mathrm{ft} / \mathrm{sec}^{2}$

$\mathrm{T}_{\mathrm{w}}=$ the cask wall temperature, ${ }^{\circ} \mathrm{F}$

$\mathrm{T}_{1}=$ the basin water temperature, ${ }^{\circ} \mathrm{F}$ 
For $\mathrm{Gr}_{\mathrm{L}} \mathrm{Pr}>10^{9}$, Welty, ,et al. (1969) recommends a heat transfer coefficient correlation equivalent to the following.

$$
h=\frac{k}{L}(0.021)\left(G r_{L} \operatorname{Pr}\right)^{3 / 5}
$$

where: $\mathrm{h}=$ the convective heat transfer coefficient, BTU/hr- $\mathrm{ft}^{2}-{ }^{\circ} \mathrm{F}$

For $\left(T_{w}-T_{l}\right)=1^{\circ} \mathrm{F}$,

$$
G r_{L} \operatorname{Pr}=\frac{\left(1.3 \times 10^{-4}\right)(32.2)\left(14^{3}\right)(1)}{\left(0.929 \times 10^{-5}\right)^{2}}(5.89)=7.8 \times 10^{11}>10^{9}
$$

which indicates the correlation applies when the cask temperature is at least $1^{\circ} \mathrm{F}$ greater than the water. Therefore, the convective heat transfer coefficient is at least

$$
h=\frac{(0.35)}{(14)}(0.021)\left(7.8 \times 10^{11}\right)^{2 / 5}=30 B T U / h r-f t^{2}-{ }^{\circ} \mathrm{F}
$$

when the cask temperature is at least $1^{\circ} \mathrm{F}$ greater than the water temperature.

Rohsenow and Hartnett (1973) present temperature response curves for a thick plate with insulated rear face after sudden exposure to a uniform convective environment (see Figure 22 in Section 3 of reference). Based on the response curves after 8 hours of cooling, or $\mathrm{h} \delta / \mathrm{k}_{\mathrm{ss}}=(30)(0.609) /(9.4)=2$ and $\alpha_{\mathrm{ss}}$ (cooling time) $/ \delta^{2}=(0.17)(8 \mathrm{hr}) /(0.609)^{2}=3.7$, the dimensionless temperature at the rear face (equivalent to the outer surface of the cask wall) is

$$
\frac{\left(T-T_{0}\right)}{\left(T_{l}-T_{0}\right)}=0.98
$$

where: $\mathrm{T}=$ the temperature at the rear face

$\mathrm{T}_{0}=$ the initial cask temperature

Based on the temperature response curve, if the initial cask temperature were to be an extreme value of $150^{\circ} \mathrm{F}$ immediately before immersion in the cask loading pit, with the basin water temperature at $69^{\circ} \mathrm{F}$, a point on the inside cask wall would reach $70^{\circ} \mathrm{F}$ after 8 hours. This cooling time results in the entire cask wall satisfying the temperature requirement of being less than $70^{\circ} \mathrm{F}$. Use of a mass averaged temperature from multiple points in the cask wall, assuming the temperature gradients effectively equalize at the conclusion of the cooling time period, provides a more refined estimate of the required cooling time. 
The mass averaged cask temperature is calculated by linear interpolation of the radial cask wall temperature gradient (shown as points $R_{i}, R_{i}+\gamma \delta$, and $R_{i}+\delta$ on Figure D-2). The mass averaged temperature for the cask, based on three known temperature points shown in Figure D-2, is

$$
T_{\text {ave }}=\frac{2 \pi}{A}\left[\frac{a_{2}}{3}\left(R_{i}+\delta\right)^{3}+\frac{\left(a_{1}-a_{2}\right)}{3}\left(R_{i}+\gamma \delta\right)^{3}-\frac{a_{1}}{3} R_{i}^{3}+\frac{b_{2}}{2}\left(R_{i}+\delta\right)^{2}+\frac{\left(b_{1}-b_{2}\right)}{2}\left(R_{i}+\gamma \delta\right)^{2}-\frac{b_{1}}{2} R_{i}^{2}\right]
$$

where:

$$
\begin{array}{ll}
a_{1}=\frac{\left(T_{2}-T_{1}\right)}{\gamma \delta} & a_{2}=\frac{\left(T_{2}-T_{3}\right)}{(\gamma-1) \delta} \\
b_{1}=T_{1}-\frac{R_{i}}{\gamma \delta}\left(T_{2}-T_{1}\right) & b_{2}=T_{3}-\frac{\left(R_{i}+\delta\right)}{(\gamma-1) \delta}\left(T_{2}-T_{3}\right)
\end{array}
$$

$\mathrm{T}_{1}=$ temperature at inner cask wall (cooled surface), ${ }^{\circ} \mathrm{F}$

$\mathrm{T}_{2}=$ temperature at intermediate point within cask wall, ${ }^{\circ} \mathrm{F}$

$\mathrm{T}_{3}=$ temperature at outer cask wall (insulated surface), ${ }^{\circ} \mathrm{F}$

$\mathrm{R}_{\mathrm{i}}=$ inner radius of cask $(2.1 \mathrm{ft})$

$\delta=\quad$ cask wall thickness $(0.609 \mathrm{ft})$

$\gamma=$ fraction of wall thickness to location of $T_{2}$, dimensionless

$\mathrm{A}=$ cross sectional area of cask $\left(9.2 \mathrm{ft}^{2}\right)$

Trial and error calculations are used to determine a cooling time where the mass averaged cask temperature is reduced to $70^{\circ} \mathrm{F}$ assuming a range of basin water temperatures. The trial and error procedure results are shown in Table D-1. The cask cooling times as a function of basin water

\begin{tabular}{|c|c|c|c|c|c|}
\hline \multirow{2}{*}{$\begin{array}{c}\text { Basin Water } \\
\text { Temperature, }{ }^{\circ} \mathrm{F}\end{array}$} & \multirow{2}{*}{$\begin{array}{l}\text { Cask Cooling } \\
\text { Time, hr }\end{array}$} & \multicolumn{3}{|c|}{ Cask Temperature Estimates, ${ }^{\circ} \mathrm{F}^{(1)}$} & \multirow{2}{*}{$\begin{array}{l}\text { Mass Averaged Cask } \\
\text { Temperature, }{ }^{\circ} \mathrm{F}^{(2)}\end{array}$} \\
\hline & & $T_{1}$ & $\mathrm{~T}_{2}$ & $\mathrm{~T}_{3}$ & \\
\hline 46 & 1.5 & 52.0 & 70.2 & 80.0 & 69.5 \\
\hline 50 & 1.7 & 55.0 & 69.7 & 78.0 & 69.6 \\
\hline 55 & 2.1 & 58.8 & 69.3 & 76.0 & 69.5 \\
\hline 60 & 2.8 & 63.0 & 69.3 & 74.5 & 69.8 \\
\hline 65 & 4.0 & 66.7 & 69.5 & 71.0 & 69.6 \\
\hline 69 & 8.0 & 69.4 & 69.0 & 70.0 & 70.0 \\
\hline
\end{tabular}
temperature from Table D-1 form the basis for Figure D-1.

\section{Table D-1. Cask Cooling Time Estimates}

Notes:

(1) From thermal response curves in Rohsenow and Hartnett (1973).

(2) From Equation (D-3). 


\section{D.4 REFERENCES FOR APPENDIX D}

Rohsenow, W. M., and J. P. Hartnett, 1973, Handbook of Heat Transfer, McGraw-Hill Book Company, New York, New York.

Smith, R. J., 2000, Safety Analysis Report for Packaging (On-Site) Multi-Canister Overpack Cask, HNF-SD-TP-SARP-017, Rev 2, Waste Management Federal Services, Inc., Richland, Washington.

Welty, J. R., C. E. Wicks, and R. E. Wilson, 1969, Fundamentals of Momentum, Heat and Mass Transfer, John Wiley \& Sons, New York, New York.

\section{D.5 Technical Check of AppendiX D}

This appendix calculation was performed by H. A. Boles and checked by A. L. Pajunen (checksheet attached). 
Document Reviewed:

HNF-SD-SNF-OCD-001, Rev 4-A, Appendix D

Scope of Review:

Reviewed hand calculations added as Appendix D

Yes No NA

$\square \square \quad$ \ * Previous reviews complete and cover analysis, up to scope of this review, with no gaps.

\ $\square \quad \square \quad$ Problem completely defined.

$\square \quad \square \quad \square \quad$ Accident scenarios developed in a clear and logical manner.

\ $\square \quad \square \quad$ Necessary assumptions explicitly stated and supported.

$\square \square \quad \square \quad$ Computer codes and data files documented.

$\bigotimes \quad \square \quad \square \quad$ Data used in calculations explicitly stated in document.

$\bigotimes \square \square$ Data checked for consistency with original source information as applicable.

$\bigotimes \quad \square \quad \square \quad$ Mathematical derivation checked including dimensional consistency of results.

$\bigotimes \quad \square \quad \square \quad$ Models appropriate and used within range of validity or use outside range of established validity justified.

$\bigotimes \quad \square \quad \square \quad$ Hand calculations checked for errors. Spreadsheet results should be treated exactly the same as hand calculations.

$\otimes \quad$ Software input correct and consistent with document reviewed.

$\square \square \square$

Software output consistent with input and with results reported in document reviewed.

$\square \square \square$

Limits/criteria/guidelines applied to analysis results are appropriate and referenced.

Limits/criteria/guidelines checked against references.

$\square \square \quad \square \quad$ Safety margins consistent with good engineering practices.

$\otimes \quad \square \quad \square$

$凶$

Conclusions consistent with analytical results and applicable limits.

Results and conclusions address all points required in the problem statement.

$\square \square \quad \square$

Format consistent with appropriate NRC Regulatory Guide or other standards.

$\square \square \otimes$

* Review calculations, comments, and/or notes are attached.

\ $\square \quad \square \quad$ Document approved.

A.L. Pajunen

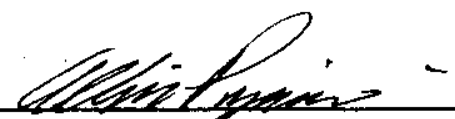

Reviewer (Printed Name an\&Signalure)

$4 / 17 / 00$

Date

*Any calculations, comments, or notes generated as part of this review should be signed, dated and attached to this checklist. Such material should be labeled and recorded in such a manner as to be intelligible to a technically qualified third party.

$$
\text { D-7 }
$$

